\title{
WestVirginiaUniversity
}

THE RESEARCH REPOSITORY @ WVU

Graduate Theses, Dissertations, and Problem Reports

2009

\section{Fiber reinforced polymer (FRP) bridge deck life-cycle cost analysis}

Sidharta Sahirman

West Virginia University

Follow this and additional works at: https://researchrepository.wvu.edu/etd

\section{Recommended Citation}

Sahirman, Sidharta, "Fiber reinforced polymer (FRP) bridge deck life-cycle cost analysis" (2009). Graduate Theses, Dissertations, and Problem Reports. 4525.

https://researchrepository.wvu.edu/etd/4525

This Dissertation is protected by copyright and/or related rights. It has been brought to you by the The Research Repository @ WVU with permission from the rights-holder(s). You are free to use this Dissertation in any way that is permitted by the copyright and related rights legislation that applies to your use. For other uses you must obtain permission from the rights-holder(s) directly, unless additional rights are indicated by a Creative Commons license in the record and/ or on the work itself. This Dissertation has been accepted for inclusion in WVU Graduate Theses, Dissertations, and Problem Reports collection by an authorized administrator of The Research Repository @ WVU.

For more information, please contact researchrepository@mail.wvu.edu. 


\title{
Fiber Reinforced Polymer (FRP) Bridge Deck \\ Life-cycle Cost Analysis
}

\author{
Sidharta Sahirman \\ Dissertation submitted to the \\ College of Engineering and Mineral Resources \\ at West Virginia University \\ in partial fulfillment of the requirements \\ for the degree of
Doctor of Philosophy
in \\ Industrial Engineering
}
Robert C. Creese, Ph.D., P.E., CCE, Chair Cheryl Brown, Ph.D.
Hota V. GangaRao, Ph.D., P.E.
Bhaskaran Gopalakrishnan, Ph.D. P.E.
Majid Jaraiedi, Ph.D.
Industrial and Management Systems Engineering Department Morgantown, West Virginia 2009

Keywords: FRP, Life-cycle costing, Service Life, Bridge Deck 


\section{ABSTRACT \\ Fiber Reinforced Polymer (FRP) Bridge Deck Life-cycle Cost Analysis}

Sidharta Sahirman

A model was developed to compare the life cycle cost (LCC) of fiber reinforced polymer (FRP) bridge decks with steel reinforced concrete (SRC) bridge decks. The objective was to analyze the viability of FRP for certain bridge deck projects.

Current LCC models of FRP bridge decks versus SRC bridge decks consider only manufacturing and erection costs in the cost calculations. They do not consider one of the most important advantages of FRP for construction, which is its light weight. The proposed model includes the cost savings in support structures when FRP is chosen as opposed to SRC, as well as the user costs occurring during bridge installation, maintenance, repair, and disposal processes. A computer program, FRP Bridge Deck LCC Analyzer, was developed for conducting the comparison analysis. The program incorporates the service life estimation of the FRP deck based on the Factor Method. An LCC comparison between FRP bridge deck and SRC bridge deck was developed for a Base Case.

Three case studies of bridges in West Virginia were performed using the program. Sensitivity of certain parameters including FRP manufacturing cost and average daily traffic (ADT) were studied. The results suggest that FRP bridge deck was economically viable to replace concrete bridge decks for Goat Farm, Katy Truss, and La Chein bridge deck projects. 


\section{ACKNOWLEDGMENTS}

I would like to express my gratitude to all who have helped me bring this work to completion. Throughout this doctoral program, I have met and built relationships with many, not only knowledgeable, but also generous and inspiring people. I cherish each and every contribution to my development as a scholar and a teacher.

Dr. Robert C. Creese, my advisor, has my utmost gratitude. His extensive knowledge and logical way of thinking have been of great value to me. His patience, understanding, encouragement, and personal guidance have enabled me to finish my research and present this dissertation. He has been my teacher in school, my friend in discussion of life, and part of my family with whom I have shared difficulties I've found in the many years I've spent in Morgantown, WV. He is simply my lifesaver, who has given me untiring help during difficult moments. Those moments are indelible in my mind.

I am deeply grateful to Dr. Hota GangaRao, Director of Construction Facilities Center, West Virginia University, for his detailed and constructive comments and for his important support throughout this work. His figure, who reminded me of my late father,

made me feel comfortable discussing some things beyond his vast knowledge and experience about FRP. His stimulating suggestions and encouragement helped me throughout my research. 
My warm thanks are due to Dr. Majid Jaraiedi, Dr. Bhaskaran Gopalakrishnan, and Dr. Cheryl Brown for their enthusiasm, valuable advice, and friendly help. Their kind support and guidance have been of great value in this study. I also wish to thank Dr. Brown for revising the English of my proposal manuscript.

I wish to thank The U.S. Department of Transportation, Federal Highway Administration, which sponsored this work under the Center of Excellence Project (Contract No. DTFH61 04-R-00032). The financial support is gratefully acknowledged.

My sincere thanks to the special people in the University of Jenderal Soedirman, Indonesia, especially Dr. Ahmad Iqbal, the Dean of the College, for the regular contact and advice; Professor Rubiyanto Misman, the former President of the University for the warm support; Dr. Purnomo Sukardi, my colleague who encouraged me to come to the US; and Dr Siswantoro, my greatest friend and colleague, for taking care of my official and unofficial business in Indonesia. Without their encouragement, understanding, and support, it would have been very difficult for me to finish this job.

Ultimately, of course, it all comes down to family, and here I have been blessed with good fortune beyond normal measure. My late father and mother, Sunardi and Sri Suparti, to whom I thank for their encouragement to study in the US and to fight to survive in this country regardless of what happened in my personal life. Though thousands of miles were between us, they always motivated me. Their loving memories make me a stronger person. Thank you Bapak, Ibu. You are always in my heart. 
My special gratitude is due to my closest family in the US: Gautama, Golda, and Morgan for their loving support. Morgan, I will always cherish the wonderful times we had driving between Miami and Morgantown in the very cold weather with you accompanying me while doing my as you call it, "homework" in West Virginia. You are my little boy, but yet your understanding is beyond comparison.

Last, but most importantly, I have had the unflagging devotion of a wonderful and beautiful wife, Bina Setyawati, who has been with me through it all, with patience, love, and even professional suggestions along the path of my study. When I faced difficult moments, when I was overcome with nightmares and I didn't know what to do, and when I felt like giving up, she has always been there for me and brought me back on track, wiped my tears, cheered me up, and backed me up with everything I need. There is no way to express how much she means to me. This PhD belongs to her. 


\section{TABLE OF CONTENTS}

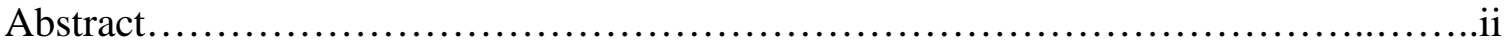

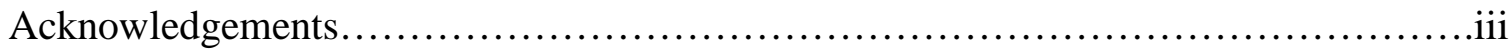

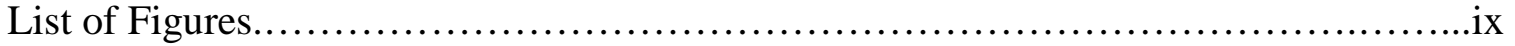

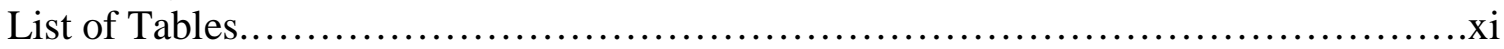

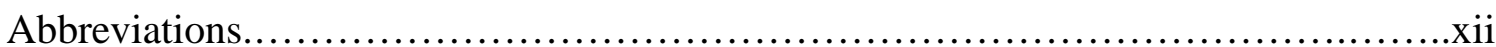

I. Introduction and Research Objectives..........................................

1.1 Introduction.................................................................

1.2 Need for Research............................................................. 4

1.2.1 Initial Cost Analysis.......................................................4

1.2.2 Life-cycle Cost Analysis..............................................4

1.3 Research Objectives and Organization........................................6

1.3.1 Research Objectives................................................6

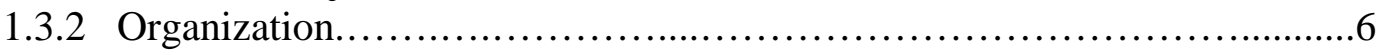

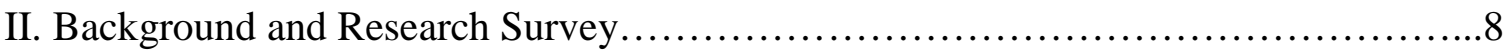

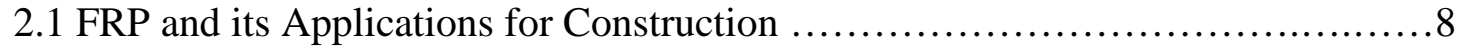

2.1.1 Basic Properties and Advantages/Disadvantages of FRP..................8

2.1.2 Applications of FRP for Construction....................................11

2.1.3 FRP Bridge Deck Manufacturing.............................................13

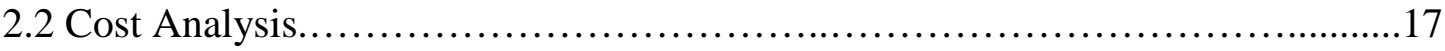

2.2.1 Initial Cost Analysis.......................................................

2.2.2 Life Cycle Cost Analysis..................................................19

2.3 The Economic Evaluation of Composites for Construction........................23

2.4 Deterioration of FRP...................................................... 24

2.4.1 Deterioration Phase............................................... 26

2.4.2 Factors Affecting FRP Service Life..................................28

2.4.2.1 Factors Associated with the Environment........................28

2.4.2.2 Factors Associated with Designs..............................30

2.4.3 Available Deterioration Models.......................................32

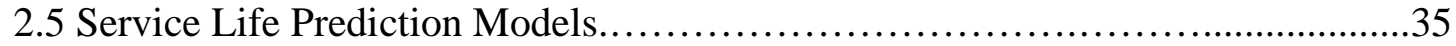

2.5.1 The Probabilistic Methods......................................... 37

2.5.2 The Factor Method....................................................38

2.5.3 Modified Factor Methods................................................40

2.6 Performance of FRP Bridge Deck in Service...................................45

2.7 FRP Bridge Deck Fabrication Costs and Related Variables......................48

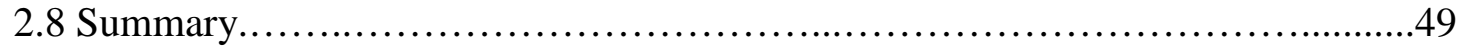

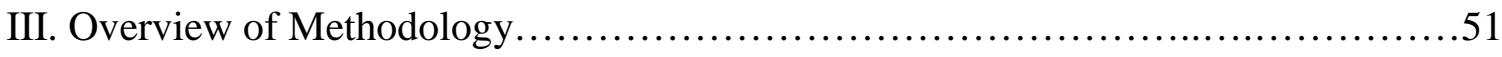

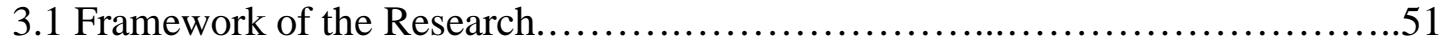

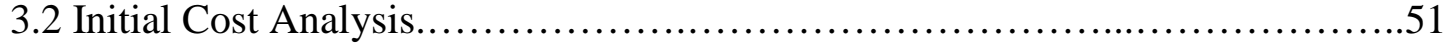

3.2.1 Agency Initial Costs.............................................. 51 
3.2.2 User Costs during Initial Construction...............................56

3.2.3 Cost Savings in Substructure Costs...................................57

3.2.4 Initial Cost Ratio Comparisons........................................60

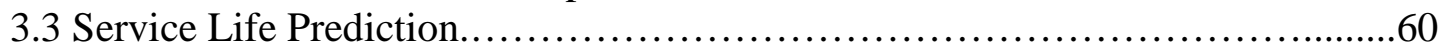

3.4 Life-cycle Cost Modeling.....................................................67

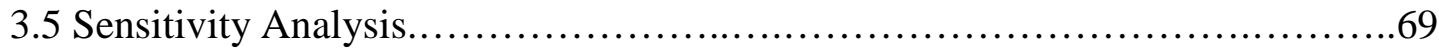

3.6 Base Case and Case Studies...............................................69

3.7 Summary.............................................................. 70

IV. FRP Bridge Deck Life-cycle Cost Model .....................................71

4.1 Life-cycle Cost Breakdown............................................. 71

4.1.1 Initial Costs...........................................................71

4.1.2 Maintenance, Inspection, and Repair Costs..................................71

4.1.3 Disposal Costs.......................................................... 72

4.2 Life Cycle Model Analyzer................................................ 72

4.2.1 Service Life Module..................................................... 75

4.2.2 Initial Cost Module....................................................... 77

4.2.3 Maintenance/Inspection/Repair Module...............................82

4.2.4 Deck Disposal Cost......................................................85

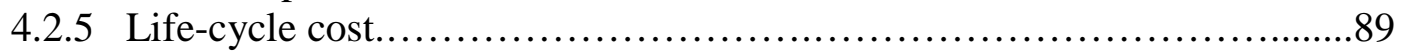

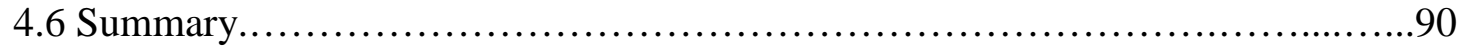

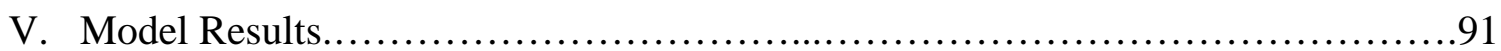

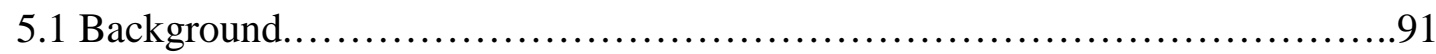

5.1 .1 The Bridge Example...........................................91

5.1 .2 Basic Scenario...................................................91

5.1.3 Life-cycle Cost Analysis.............................................94

5.1.3.1 Bridge Deck Service Life and Study Period.....................94

5.1.3.2 Level 1 Initial Costs...........................................94

5.1.3.3 Level 1 Maintenance, Inspection, and Repair Costs..............96

5.1.3.4 Level 1 Disposal Cost.......................................98

5.1.3.5 Agency Costs................................................100

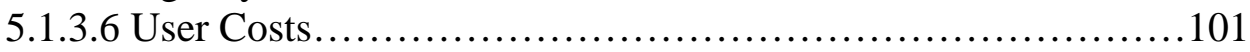

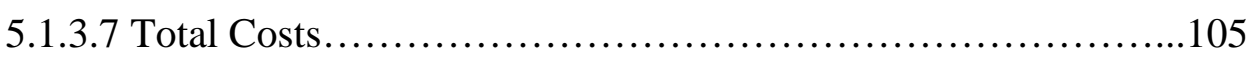

5.1.3.8 Savings Comparison of Decks and Sensitivity Analysis.........106

5.2 The Case Study Bridges.................................................. 107

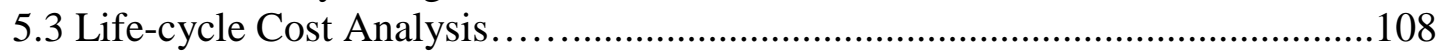

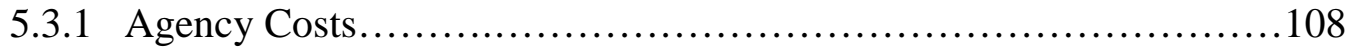

5.3 .2 User Costs........................................................112

5.3.3 Total Costs..................................................... 112

ว.4 Savings Comparison of Decks and Sensitivity Analysis......................112

5.4.1 Goat Farm Bridge............................................113

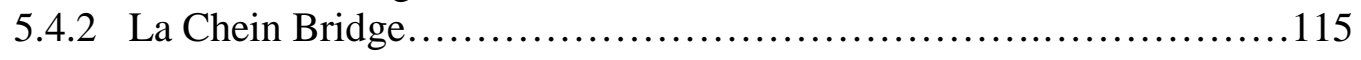

5.4.3 Katy Truss Bridge............................................117

5.5 Discussion ........................................................... 117

5.5.1 Effects of FRP Manufacturing Cost................................117 
5.5.2 Effects of Inspection/Anticipated Maintenance Schedules..............118

5.5.3 Effects of Average Daily Traffic (ADT) ...........................121

5.5.4 Effects of Discount Rate (DR) ...................................121

5.5.5 Effects of Other Parameters......................................123

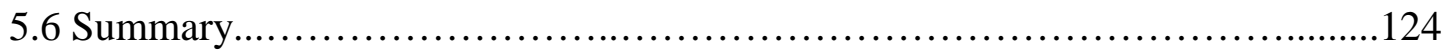

VI. Conclusions and Recommendations......................................... 125

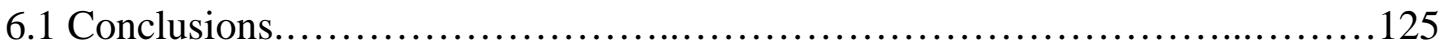

6.2 Recommendations for Future Research..................................126

Bibliography............................................................129

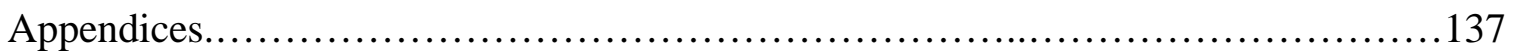




\section{LIST OF FIGURES}

Page

Figure 2.1a Detail of Kansas Composite Bridge Deck...............................15

Figure 2.1b Detail of Infrastructure Composites Sandwich Deck.......................15

Figure 2.1c Detail of Martin Marietta Composite Sandwich Bridge Deck...............16

Figure 2.1d Detail of Hardcore Composite Filled-core Sandwich Deck..................16

Figure 2.1e Detail of Creative Pultrusions Hollow-core Sandwich Deck.................17

Figure 2.1f Detail of Strongwell's Double-Wall Beam (DWB).......................17

Figure 2.1g Detail of Bedford Reinforced Plastics Inc. Prodeck8..........................17

Figure 2.2 Systematic Methodologies for Service Life Prediction of Building.

Components (ISO 15686 Part 2 [ISO 2001])............................36

Figure 2.3 Relationships between Different Types of Service Life

Prediction Methods................................................... 37

Figure 3.1 Flow Chart of Research Methodology.......................................51

Figure 3.2 FRP Bridge Deck Manufacturing Cost Estimates............................55

Figure 3.3 Bridge Deck Life Cycle Phases........................................67

Figure 4.1 Components of Life-cycle Cost for FRP Bridge Deck.....................72

Figure 4.2 Life-cycle Cost Breakdowns for FRP Bridge Deck Cost Components.......73

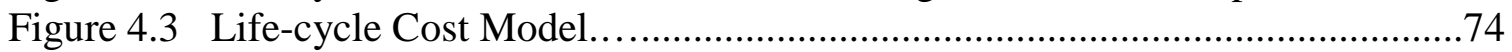

Figure 4.4 Screen Shot of the Input Screen......................................76

Figure 4.5 Default Maintenance/Inspection Schedule for SRC Bridge Decks.............84

Figure 4.6 Default Maintenance/Inspection Schedule for FRP Bridge Decks............84

Figure 5.1 Agency Cost Distribution of Reader Run FRP Bridge Deck.................103

Figure 5.2 Agency Cost Distribution of Reader Run SRC Bridge Deck................104

Figure 5.3 User Cost Distribution of Reader Run FRP Bridge Deck....................104

Figure 5.4 User Cost Distribution of Reader Run SRC Bridge Deck.......................104

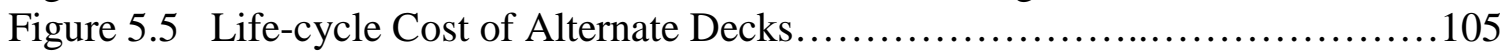

Figure 5.6 Effects of ADT....................................................107

Figure 5.7 Effects of Manufacturing Costs.........................................107

Figure 5.8 Agency Cost Distribution of Goat Farm FRP Bridge Deck

(Basic Scenario).....................................................109

Figure 5.9 Agency Cost Distribution of La Chein FRP Bridge Deck

(Basic Scenario)...............................................109

Figure 5.10 Agency Cost Distribution of Katy Truss FRP Bridge Deck

(Basic Scenario....................................................110

Figure 5.11 Agency Cost Distribution of Goat Farm FRP Bridge

(Basic Scenario; Cost Saving Considered).............................110

Figure 5.12 Agency Cost Distribution of La Chein FRP Bridge

(Basic Scenario; Cost Saving Considered)..............................110

Figure 5.13 Agency Cost Distribution of Katy Truss FRP Bridge Deck

(Basic Scenario; Cost Saving Considered)............................111

Figure 5.14 LCC Cost of Goat Farm Bridge as a Function of Deck Cost.................115

Figure 5.15 Effects of ADT on LCC Cost of Goat Farm Bridge.........................115

Figure 5.16 LCC Costs of La Chein Bridge............................................116

Figure 5.17 Effects of ADT on Percentage of User Cost of La Chein Bridge................116 
Figure 5.18 Effects of ADT on Percentage of User Cost of Katy Truss Bridge.........117

Figure 5.19 Effects of Discount Rate on Life-cycle Cost of Goat Farm Bridge.....,...121 


\section{LIST OF TABLES}

Page

Table 2.1 FRP Bridge Decks Installed by Six Major Manufacturers.....................14

Table 2.2 ESLC Calculation Example of a Window........................................44

Table 3.1 WV FRP Bridge Deck Costs Data..........................................53

Table 3.2 Factors Affecting FRP Deck Service Life and Their Importance Based on

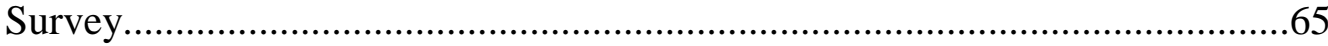

Table 3.3 Results of the 2nd Questionnaire.......................................66

Table 3.4 Multipliers for Each Factor...........................................66

Table 4.1 Life-cycle Cost Model Data Input Items..................................75

Table 4.2 WV Landfill Locations and Their Distance.................................87

Table 4.3 Landfill Tipping Fees for Model.........................................88

Table 5.1 Default Parameters (2005 Values).........................................92

Table 5.2a Inspection /Anticipated Repair Schedules................................93

Table 5.2bModified Inspection/Anticipated Maintenance Schedules......................93

Table 5.3 I_ife-cycle Cost Breakdown for Reader Run................................102

Table 5.4 FRP Deck Life-cycle Cost Tabulation..................................103

Table 5.5 Life-cycle Cost Breakdown under Basic Scenario............................114

Table 5.6 LCC Breakdown for Goat Farm and La Chein Bridge Decks.................120

Table 5.7 LCC Breakdown for La Chein Bridge Deck under Different ADTs.............122 


\section{ABBREVIATIONS}

$\begin{array}{ll}\text { AASHTO } & =\text { American Association of State Highway and Transportation Officials } \\ \text { ACCS } & =\text { Advanced Composite Construction System } \\ \text { ADT } & =\text { Average Daily Traffic } \\ \text { ARTBA } & =\text { American Road and Transportation Builders Association } \\ \text { ASSET } & =\text { Advanced Structural Systems for Tomorrow's Infrastructure } \\ \text { AUC } & =\text { Average Unit Cost } \\ \text { BRP } & =\text { Bedford Reinforced Plastics } \\ \text { CIM } & =\text { Condition Index Maintenance } \\ \text { CIR } & =\text { Condition Index Repair } \\ \text { CPI } & =\text { Consumer Price Index } \\ \text { DL } & =\text { Dead Load } \\ \text { DM } & =\text { Damage Mode } \\ \text { DOT } & =\text { Department of Transportation } \\ \text { EDM } & =\text { Engineering Design Method } \\ \text { EF } & =\text { External Factors } \\ \text { ESLC } & =\text { Estimated Service Life of the Component } \\ \text { FHWA } & =\text { Federal Highway Administration } \\ \text { FRP } & =\text { Fiber Reinforced Polymer } \\ \text { GFRC } & =\text { Glass Fiber Reinforced Concrete } \\ \text { GFRP } & =\text { Glass Fiber Reinforced Polymer } \\ \text { HC } & =\text { Hardcore } \\ \text { ICI } & =\text { Infrastructure Composite Inc. } \\ \text { ISO } & =\text { International Standard Organization } \\ \text { IRC } & =\text { Institute for Research in Construction (Canada) } \\ \text { LCCA } & =\text { Life-cycle Cost Analysis } \\ \text { LCC } & =\text { Life-cycle costing } \\ \text { LMP } & =\text { Lot Mid-Point } \\ \text { LRFD } & =\text { Load and Resistance Factor Design } \\ \text { MD } & =\text { Material Damage } \\ \text { MRR } & =\text { Maintenance, Repair, and Rehabilitation } \\ \text { MMC } & =\text { Martin Marietta Composites } \\ \text { NCDOT } & =\text { North Carolina Department of Transportation } \\ \text { NCHRP } & =\text { National Cooperative Highway Research Program } \\ \text { NTI } & =\text { New Technology Introduction } \\ \text { NYDOT } & =\text { New York Department of Transportation } \\ \text { RSLC } & =\text { Reference Service Life of Component } \\ \text { SCRIMP } & =\text { Seaman Composite Resin Infusion Molding Process } \\ \text { SRC } & =\text { Steel Reinforced Concrete } \\ \text { TD } & =\text { Temporal-Difference } \\ \text { TRB } & =\text { Transportation Research Bureau } \\ \text { UV } & =\text { Ultra Violet } \\ \text { VARTM } & =\text { Vacuum Assisted Resin Transfer Molding } \\ \text { WVDOT } & =\text { West Virginia Department of Transportation } \\ \text { Sq ft } & =\text { Square Feet } \\ & \end{array}$




\section{Chapter 1}

\section{Introduction and Research Objectives}

\section{$1.1 \quad$ Introduction}

The American Road and Transportation Builders Association (ARTBA) released a report in 1996 that there are 594,709 bridges throughout the United States (U.S.). Of those 152,945 (26\%) are described as being "structurally deficient or functionally obsolete,” according to data from the Federal Highway Administration (FHWA) in 2006 [102]. Structurally deficient bridges are bridges that are closed or restricted to light vehicles because of deteriorated structural components. Functionally obsolete bridges are those that cannot safely service the volume and/or type of traffic using them. Advance composites, such as fiber reinforced polymer (FRP), have the potential to provide better solutions to structurally deficient bridges [64].

An FRP composite is defined as a combination of a polymer matrix (either a thermoplastic or thermoset resin, such as polyester, isopolyester, vinyl ester, epoxy, or phenolic) and a reinforcing agent, such as glass, carbon, aramid, or other reinforcing material so that there is a sufficient aspect ratio (length to thickness) to provide a discernable reinforcing function in one or more directions. The fiber is the critical constituent in composites and occupies 30-70\% of the composite matrix volume.

FRP composites have a low weight, a high strength-to-weight ratio, high tensile strength, and a high fatigue resistance. They do not exhibit chloride corrosion problems, which have been a challenge for bridge engineers. It is believed that these properties will result in lower maintenance costs and a longer life for bridge decks. It has also been observed that FRP composites maintain their superior qualities under a wide range of 
temperatures. Other highly desirable qualities of composites are high resistance to elevated temperature, abrasion, corrosion, and chemical attack. Some of the advantages in the use of composite structures include the ease of manufacturing, fabrication, handling, and erection, which may result in shorter delivery time.

As a new technology application, FRP bridge decks are hampered by a lack of performance standards and design and construction experience, as well as by high initial costs. Standards have been established recently, but widespread deployment will not occur until there is more experience in their use, and FRP costs decrease sufficiently to support their selection. There is no sound conclusion about the competitiveness of FRP for bridge decks at this time. More research is needed to determine if the technology can become cost competitive for new bridge decks. FRP decks are highly competitive as replacements for concrete decks where load requirements increase on existing structures.

Ehlen and Marshall [29] suggested that despite the FRP weight advantage over traditional materials, economic and technical barriers hinder the introduction of these new technologies, whereas Tang and Podolny [91] had a more optimistic view. Tang and Podolny suggested that FRP composite technology could be part of the solution to the national bridge problem. Composites can be used for the construction of an entire bridge structure or as a decking material to be supported by concrete or steel girders, or to rehabilitate current bridges. However, up to year 2007, there had only been approximately 80 completed bridge deck projects using FRP composite materials nationwide, and most of these were built within the last ten years [34]. Federal funding for FRP bridge deck construction has decreased since then.

The use of FRP composites as a replacement for steel reinforced concrete (SRC) 
bridge decks have significant potential advantages with increased service life and lower maintenance costs, but the increased initial costs may make them unfeasible on a cost basis. Since FRP is a new technology material, this technology must be compared with conventional technology. In comparing some choices, minimum criteria must first be satisfied. When comparing the composite bridge decks with conventional bridge decks, FRP must meet the conventional technical requirements. Since it has been known that FRP bridge decks can meet the required technological criteria, then the major criterion is total cost as to which material can provide the lowest cost over the bridge deck life.

Assuming the claim of a lower maintenance cost is true, the initial costs of FRP decks must further be reduced to become cost competitive with SRC decks. For that reason, an analysis of initial costs of FRP decks is required. However, the comparison of infrastructural projects that have high investment costs and a long life expectancy requires using a life-cycle costing (LCC) methodology, because there are costs beyond the initial construction costs that should be considered. The Federal Highway Administration (FHWA) encourages states to use LCC when determining which roadway projects to fund.

Life-cycle Cost consists of initial costs, maintenance costs, and disposal costs. Each consists of direct costs (agency costs) as well as indirect costs (user costs and third party costs). To be able to predict maintenance costs, one should first determine the service life of the infrastructure and its deterioration rate, but those pieces of information are not available for FRP bridge decks. Most designs of bridge structures are for SRC decks and then modifications are made for the use of FRP decks. Since FRP decks are approximately 80 percent lighter than SRC decks, the dead load is lower and the 
supporting structures can be reduced. The estimated savings for reduced support structures for FRP decks must be considered in the life-cycle cost analysis. Also, the faster erection of FRP decks must be considered.

\subsection{Need for Research}

\subsubsection{Initial Cost Analysis}

FRP bridge deck initial costs include manufacturing costs, installation costs, and user costs that take place during deck installation. Available initial cost analyses of FRP bridge decks versus SRC bridge decks only considered manufacturing and erection costs. They did not consider one of the most important advantages of FRP for construction, its light weight.

The initial cost analysis should not only include the manufacturing cost of the bridge deck, but also the cost savings in support structures when FRP is chosen as opposed to SRC, as well as the user costs incurred during the bridge installation process. It is believed that the proposed initial cost analysis provides a better comparison between the two choices.

\subsubsection{Life-Cycle Cost Analysis}

Life-cycle Cost analysis (LCC) is the comprehensive way to compare-long term projects, such as bridge projects. Regardless of the importance of this analysis, there has been little research conducted for FRP bridge decks. Five important studies performed are those by Lopez-Anido [53], Ehlen [28], Nathan and Onyekmeluwe [61], Roychoudury and Creese [76], and Nishizaki et al. [63]. The fundamental differences 
between the proposed LCC models and the previous research are as follows:

1. In the available models, the service life of an FRP bridge deck is either fixed or is estimated by the user. It is understandable that one makes assumptions about values according to what one believes, because the FRP bridge deck service life is currently unknown. However, since service life plays an important role in LCC estimation, it is important to get the best possible estimate for FRP bridge deck service life. For that reason, a separate module to estimate the service life for the bridge under consideration is included in the model. Lack of data, however, makes it difficult to use a sophisticated service life prediction method. Hence, the estimation model is based on the factor method. Experts' opinions were applied to determine the importance of each related factor. For this purpose, the first questionnaire was prepared and distributed. Based on these results, a second questionnaire was prepared. Samples of the two questionnaires are given in Appendix 1 and Appendix 2.

2. An initial cost module emphasizes the substructure cost reductions from using FRP as bridge deck material. This provides a better comparison between the two bridge deck systems.

3. Sensitivity of maintenance/anticipated repair schedules is included. Ehlen [28] used a preset maintenance/repair schedule based on a concrete deck maintenance/repair schedule to obtain maintenance/repair costs. In this research, FRP deck maintenance/anticipated repair schedules based on expert judgment were analyzed, and the sensitivity of the different maintenance schedules are discussed. 


\subsection{Research Objectives and Organization}

\subsubsection{Research Objectives}

The main objective of the dissertation is to study the economic viability of FRP bridge decks compared to traditional material, i.e., steel reinforced concrete (SRC). By utilizing initial cost and life-cycle costing analysis, this study seeks to quantify the costs associated with FRP systems as well as ones for SRC systems. Excel-based software was programmed to facilitate the study. The primary objectives of this dissertation were to:

(1) Evaluate the economic feasibility of fiber-reinforced polymer (FRP) bridge decks based on initial cost analysis, including cost savings from reduced substructure costs and reduced construction time.

(2) Estimate FRP bridge deck service life using the factor method.

(3) Construct a life-cycle cost model for FRP bridge decks. Study the life-cycle cost (LCC) of FRP bridge decks to determine the effect of reduced structural costs on total LCC and to determine the economic life required for FRP to be equivalent to SRC. Three West Virginia bridges were used as case studies.

\subsubsection{Organization}

The scope of this research is to analyze FRP bridge deck project life-cycle costs in which the individual costs are accrued from an LCC model. The main focus was to study the viability of an FRP bridge deck compared to SRC bridge deck project.

The dissertation is organized into six chapters. Chapter 1 discusses the background of the study and research objective. Chapter 2 provides a systematic 
literature review of the topics related to the research, which includes information about FRP manufacturing and its use in construction industries, and the life-cycle management process for bridges. Chapter 3 provides an overview of the life-cycle costing approach used in this study and describes how both agency and social costs were incorporated into the analysis. Furthermore, a discussion of service life estimation, estimation of FRP manufacturing costs, as well as the concept of substructure cost reductions implemented in this research are included. Chapter 4 presents the research methodology used in this study along with explanation of how detailed calculations were performed. Since the lifecycle cost model used for this study is comprised of several smaller modules, this chapter demonstrates how each module in the model functions. Chapter 5 reports the results of the life-cycle cost model as well as a sensitivity analysis report for the case studies. The sensitivity analysis indicates which variables have the greatest impact on the final results of the model. Chapter 6 offers conclusions, recommendations, and suggestions for future research. 


\section{Chapter 2}

\section{Background and Research Survey}

\subsection{FRP and Its Applications for Construction}

\subsubsection{Basic Properties and Advantages/Disadvantages of FRP}

Fiber-reinforced polymer (FRP) composites are defined as a polymer matrix, either thermoset or thermoplastic, that is reinforced with fibers or other reinforcing material with a sufficient aspect ratio (length to thickness) to provide a discernible reinforcing function in one or more directions. FRP composites are anisotropic, i.e., the properties differ depending on the direction of the fibers [64]. Mechanical properties of composites depend on many variables, such as fiber types, orientations, and architecture. The fiber is the important constituent in composites, which occupies 30-70 percent of the matrix volume in the composites and is the primary contribution to the mechanical properties of the composite [90].

FRP decks have a very low self-weight but a high strength-to-weight ratio, high tensile strength, and high fatigue resistance. They do not exhibit the traditional corrosion problems of SRC structures that have been a continuing challenge for bridge engineers. This results in lower maintenance costs for FRP bridges. It has also been observed that FRP structures maintain their superior qualities under a wide range of temperatures [80]. Other desirable qualities of composites are a higher resistance to elevated temperature, abrasion, corrosion, and chemical attack. Some of the advantages in the use of composite structures include the ease of manufacturing, fabrication, handling, and erection, which result in short project delivery time [90]. A list of the typical advantages of FRP are: (1) strength; (2) directional strength; (3) high resistance to corrosion and chemicals; (4) high 
resistance to elevated temperature; (5) low thermal conductivity; (6) high dielectric strength (insulator); (7) high resistance to abrasion; (8) dimensional stability; (9) nonmagnetic; (10) toughness; (11) fatigue; (12) light weight; (13) ease in fabrication, manufacturing, handling, and erection; (14) year-round construction (weather resistance); (15) short project delivery time; (16) high performance; (17) long-term durability; and (18) an excellent strength-to-weight ratio [90].

One concern with FRP composites is their long-term durability because there is not sufficient historical performance data in bridge applications of FRP materials. There are concerns for the long-term integrity of bonded joints, components under cyclic fatigue loading, improper curing of the resins and moisture absorption, and ultraviolet light exposure of composites that may affect the strength and stiffness of the structural system. Certain resin systems have been found ineffective in the presence of moisture. In the case of a glass fiber composite, moisture absorption may affect the resin and allow the alkali to degrade the fibers [91].

The disadvantages of FRP include the following: (1) high initial cost, (2) creep and shrinkage, (3) potential for environmental degradation (alkali attack, UV radiation exposure, moisture absorption, etc.), (4) inconsistency of material properties, (5) global and local buckling, (6) increased aerodynamic instability with light weight, (7) need for highly trained specialists, (8) lack of standards and design guidelines, and (9) limited joining and connection technology (adhesive joints, fasteners) [90]. For the construction industry, FRP products can provide the following benefits: (1) increased service life of the structure, (2) reduced maintenance costs due to resistance to deicing salts and other corrosive agents, (3) reduced field installation time due to engineered system packaging 
and the light weight of the materials, (4) reduced traffic delays due to faster construction, (5) increased reliability due to pre-engineered systems and resistance to corrosion, and (6) allows a greater vehicular load on the same understructure due to weight reduction of the FRP deck structure [64].

The advantages of FRP for bridge deck applications based on Reeve [70] are:

(1) Light Weight. FRP bridge decks weigh about 10 to 20 percent of a structurally equivalent SRC deck, and they significantly reduce the dead load. In new construction, this can translate into savings throughout the structure as the size of structural members and the foundation are reduced accordingly.

(2) Corrosion Resistance. FRP's are not susceptible to chloride corrosion, offering a promising alternative to SRC bridge decks.

(3) Quick Installation Time. Prefabricated FRP deck panels can be installed quickly compared to the labor-intensive process of constructing a cast-in-place deck.

(4) High Strength. Static tests of FRP decks greatly exceed the strengths of traditional SRC decks.

(5) Lower Life-Cycle Costs. Reeve believed that total savings in deck replacement and maintenance costs over the service life of an FRP bridge deck are much greater than the initial cost of the entire structure. Unfortunately, long-range durability claims are often viewed with skepticism by the construction industry. Furthermore, few public agencies select materials based on projected life-cycle costs. He suggested that FRP deck prices must become more competitive, since price is one of the major barriers to FRP deck market development. Earlier, Ehlen and Marshall [29] have suggested that economic and technical barriers have hindered the introduction of new FRP technologies. 
Reeve [70] concluded that FRP decks must be reduced to, at most, 1.25 times the installed cost of the reinforced concrete decks (typically in the range of \$25 to \$35 per square foot) to be a viable alternative. Hence, the installed cost of an FRP deck should be less than \$45 per square foot, which was not obtained to date. Furthermore, he also recommended concentration on a single segment of the bridge market, i.e., low profile decks, which have fewer design issues, to be able to provide a more cost competitive FRP bridge deck.

Currently, the lowest estimated price for FRP decks is approximately \$65 per square foot [52], and it is estimated to be $\$ 60$ per square foot [11]. A typical Hardcore 8 inch composite bridge deck costs $\$ 75$ per square foot for manufacturing and transportation, a typical Martin Marietta 8 inch deck costs $\$ 88$ per square foot. The actual installed costs range from $\$ 75$ to $\$ 93$ per square foot [45].

However, Lopez-Anido [54] believed that other cost advantages of FRP bridge decks may partially, or completely, compensate for this high initial cost, especially when there is a need for light weight, strong corrosion resistance, and/or rapid installation. Additionally, O’Connor and Hooks suggested that the weight savings of FRP over SRC can allow the conversion of dead load to live load carrying capacity. On new construction, the weight savings should lower foundation requirements (i.e., fewer or smaller piles).

\subsubsection{Applications of FRP for Construction}

FRP composite technology has been incorporated into the industrial world for about 70 years. Only recently has it been gaining popularity and getting accepted as a bridge material. Nevertheless, most bridge contractors throughout the world continue to 
use traditional materials such as steel and concrete, thereby taking advantage of wellproven materials with appropriate design codes. Those authorities who have decided to employ FRP materials in their bridge construction projects have primarily used them to reduce the dead weight of existing concrete bridges and thus increase or maintain the current live-load capability. More recently FRP reinforcing bars are also applied in SRC structures. Fiber Reinforced Polymers (FRPs) are increasingly being used as reinforcement in new concrete structures and as strengthening materials for the rehabilitation of existing concrete structures [100].

The next step in FRP applications for construction was the development of bridge decks composed entirely of FRP materials. The first FRP highway bridge was built in 1982 in Miyun, China [35]. In 1986, the world's first highway bridge using composite reinforcing tendons was built in Germany. The first all-composites pedestrian bridge was installed in 1992 in Aberfeldy, Scotland.

The mechanical properties of FRP materials explain why they appear to be very convenient for use in bridge decks. The most obvious characteristics are the low dead load combined with high strength and resistance to de-icing salts and water. As a result of these advantages, different FRP bridge deck systems have already been developed [42]. Additionally, Gurtler [42] stated that while several pedestrian bridges have already been constructed entirely of composite materials, most road bridges still need main steel girders or concrete beams to be cost-effective. The deck elements are usually bonded together and then fastened to primary steel girders or concrete beams with either of two types of connections: mechanical fasteners, such as shear studs or bolts, or adhesive bonding. 
The Federal Highway Administration (FHWA) has used FRP to build pedestrian bridges and highway bridges, as well as for bridge strengthening and bridge repairs. For more than 20 years FHWA has funded innovative bridge research. As a result, there are more vehicular bridge projects using FRP composite materials in the U.S. than in any other country. The first FRP reinforced concrete bridge deck was built in 1996 at McKinleyville, West Virginia, followed by the first all-composite vehicular bridge deck in Russell, Kansas, [91] on December 4, 1996. The all-complete decks used a wet lay-up manufacturing method (manufacturer: KSCI), a technology transfer from the defense industry. The FRP deck panels were shop-fabricated with composite honeycomb cells sandwiched between two face sheets. It took the Russell County work crew one day to install the bridge superstructure.

As of 2009, FHWA listed 13 completed FRP deck projects in West Virginia. Those are: (1) Market St. Bridge, Ohio County, (2) Laurel Lick Bridge, Lewis County, (3) Wickwire Run Bridge, Taylor County, (4) Hanover Bridge, Pendleton County, (5) Boy Scout Camp Bridge, Raleigh County, (6) Katy Truss Bridge, Marion County, (7) La Chein Bridge, Monroe County, (8) Montrose Bridge, Randolph County, (9) West Buckeye Bridge, Monongalia County, (10) Howell's Mill Bridge, Cabel County, (11) Goat Farm Bridge, Jackson County, (12) CR1 over Mud River (Howell’s Mill Bridge), Cabel County, and (13) Kite Creek Bridge, Monroe County.

\subsubsection{FRP Bridge Deck Manufacturing}

By 2005, there were 83 FRP bridge decks installed in the U.S. [62]. Among them, 79 were manufactured by six companies: (1) Creative Pultrusions, Inc., (2) Hardcore Composites, Inc., (3) Infrastructure Composites, Inc. (4) Kansas Composite Industries, 
Inc., (5) Martin Marietta Composites, Inc., and (6) Strongwell, Inc. Bedford Reinforced Plastics partnered with West Virginia University to produce FRP decks in 2004. It supplied FRP decks for one project in West Virginia. There are two major types of FRP decks currently in use: sandwich structures and adhesively bonded pultruded shapes [52]. FRP sandwich structures cost about $\$ 570$-\$1,184 per square meter (\$53-\$111 per square $\mathrm{ft}$ ) and weight $0.75-1.1 \mathrm{kN}$ per square meter; FRP adhesively bonded pultrusions cost \$700-\$1,076 per square meter $(\$ 65-\$ 100$ per square $\mathrm{ft}$ ) and weight $0.88-1.1 \mathrm{kN}$ per square meter [101]. Zhou and Lesko added that pultruded FRP deck systems are the most promising. Table 2.1 provides a summary of the number of decks installed by the six major manufacturers from 1996 through 2004 [62].

Table 2.1 FRP Bridge Decks Installed by the Six Major Manufacturers [62].

\begin{tabular}{|l|c|c|c|c|c|c|c|c|c|c|}
\hline \multirow{2}{*}{ Manufaccurer } & \multicolumn{9}{|c|}{ Number of Decks Installed in Each Year } \\
\cline { 2 - 15 } & 1996 \& Prior & 1997 & 1998 & 1999 & 2000 & 2001 & 2002 & 2003 & 2004 & TOTAL \\
\hline \hline Kansas Composite Industries, Inc. & 1 & & & 2 & 5 & 3 & & 1 & & 12 \\
\hline Infrastructure Composites, Inc. & & & & 1 & & & & & & 1 \\
\hline Martin Marietta Composites, Inc. & 1 & 2 & & 1 & 2 & 8 & 4 & 6 & 3 & 27 \\
\hline Hardcour Composites, Inc. & & 2 & 3 & 4 & 7 & 9 & 1 & & & 26 \\
\hline Creative Pultrusions, Inc. & & 3 & 2 & 2 & 1 & & 1 & & & 9 \\
\hline Strongwell, Inc. & 1 & 2 & & & & & & 1 & & 4 \\
\hline Others & & & & & & & 2 & 2 & & 4 \\
\hline TOTAL & 3 & 9 & 5 & 10 & 15 & 20 & 8 & 10 & 3 & 83 \\
\hline
\end{tabular}

There are three different manufacturing processes used by the above manufacturers: (1) pultrusion processes, (2) vacuum assisted resin transfer molding (VARTM), and (3) hand laminating. Strongwell, Bedford Reinforced Plastics, Creative 
Pultrusions, and Martin Marietta employ the pultrusion process; hand lamination is used by Kansas Composite Industries as well as by Infrastructure Composites bridge deck systems; VARTM is used by Hardcore Composites. Each manufacturer has a unique design for FRP bridge decks. The following figures (Figures 2.1 a through f) depict the detail of FRP bridge decks designed by the above manufacturers.

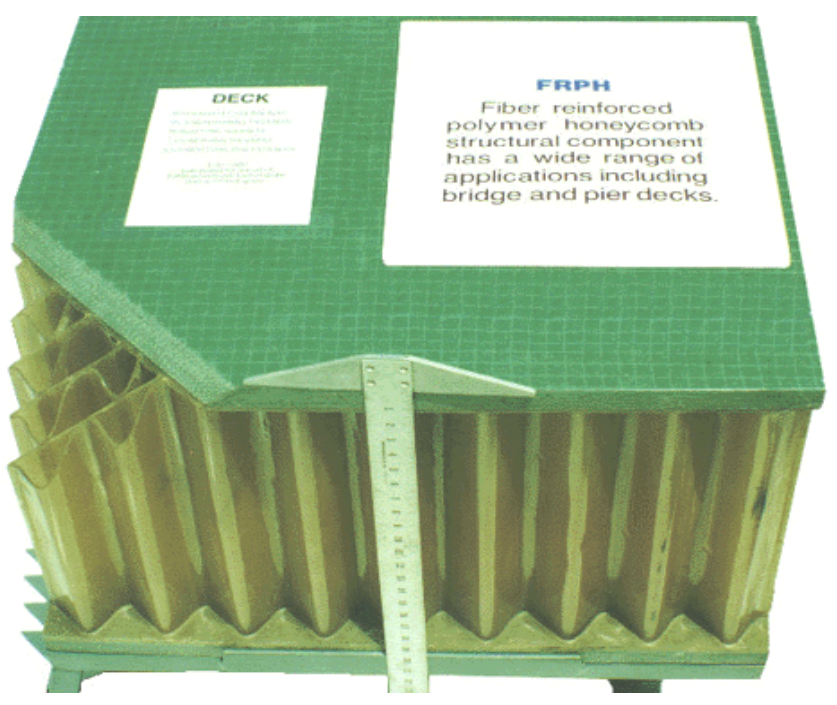

Figure 2.1a Detail of Kansas Composite Bridge Deck [62]

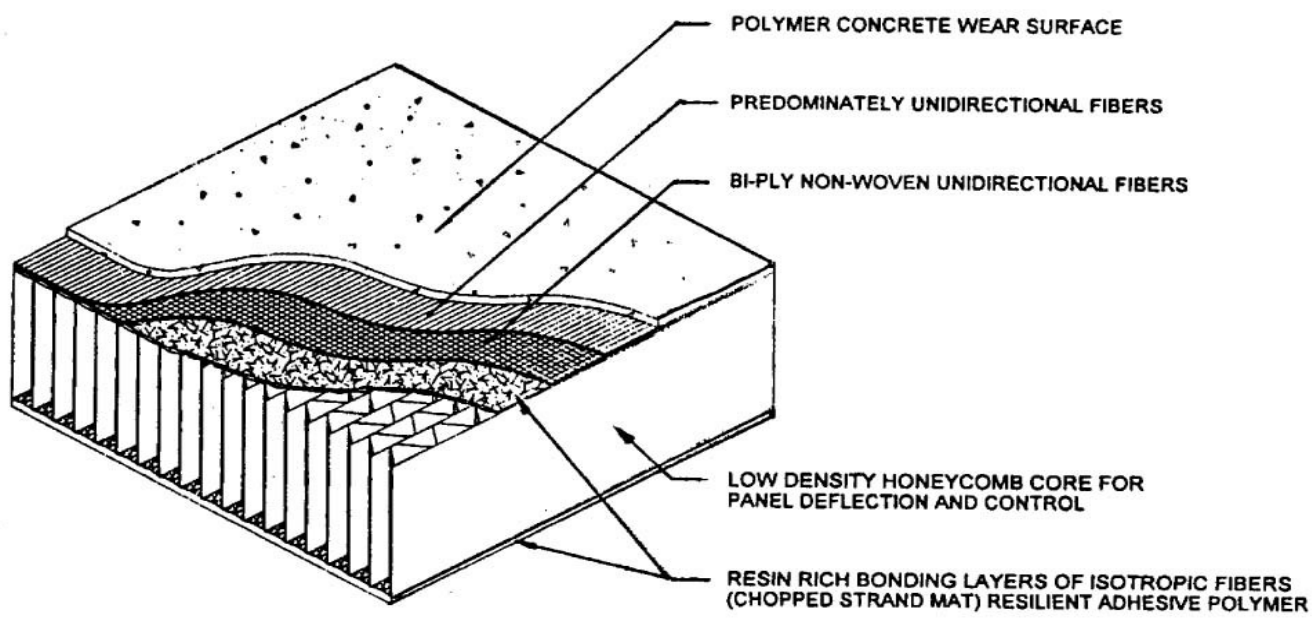

- Basic ICI Deck panel Configuration

Figure 2.1b Detail of Infrastructure Composites Sandwich Deck [62] 


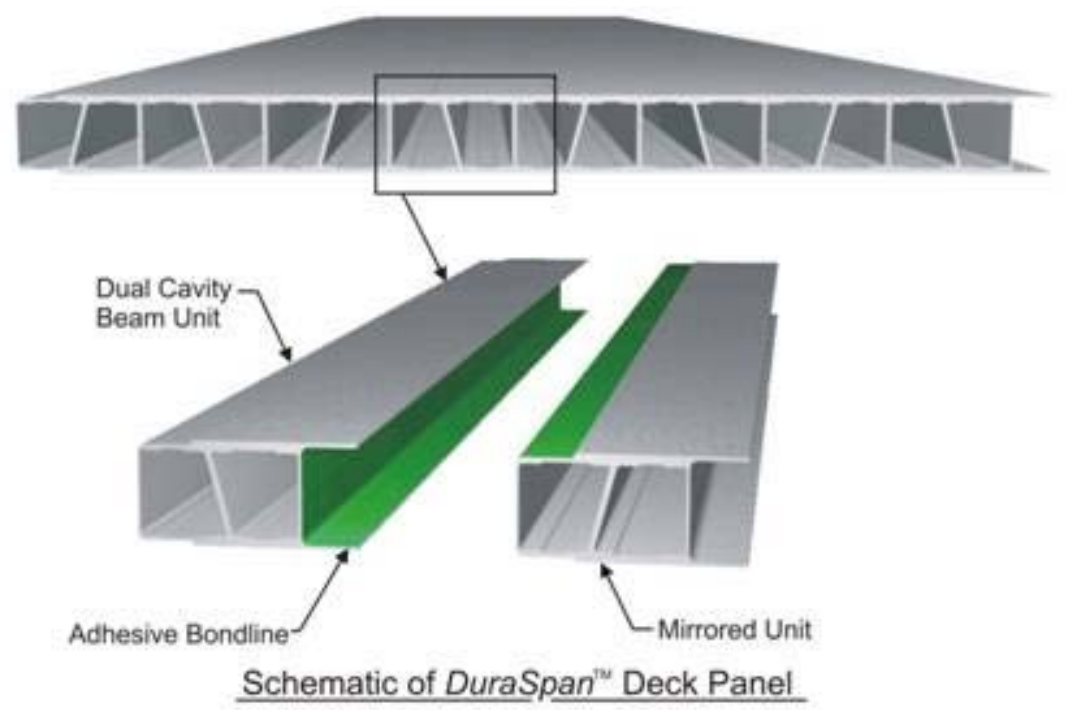

Figure 2.1c Detail of Martin Marietta Composite Sandwich Bridge Deck [62]

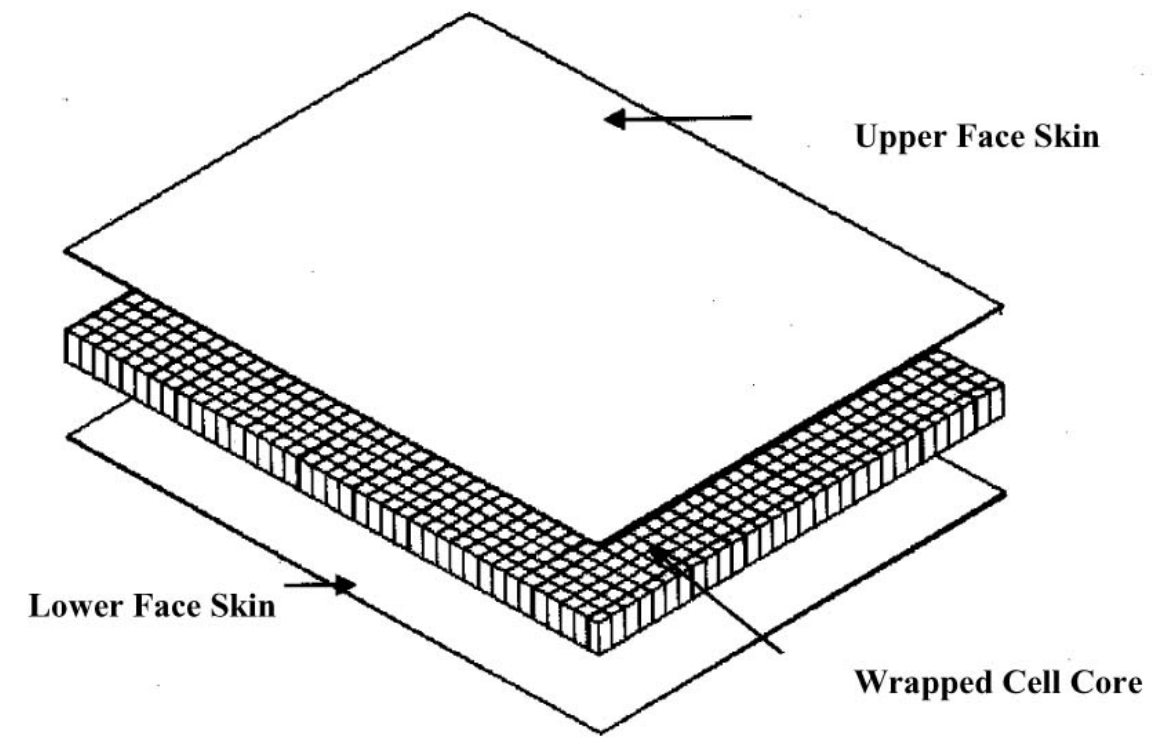

Figure 2.1d Detail of Hardcore Composite Filled-core Sandwich Deck [62] 


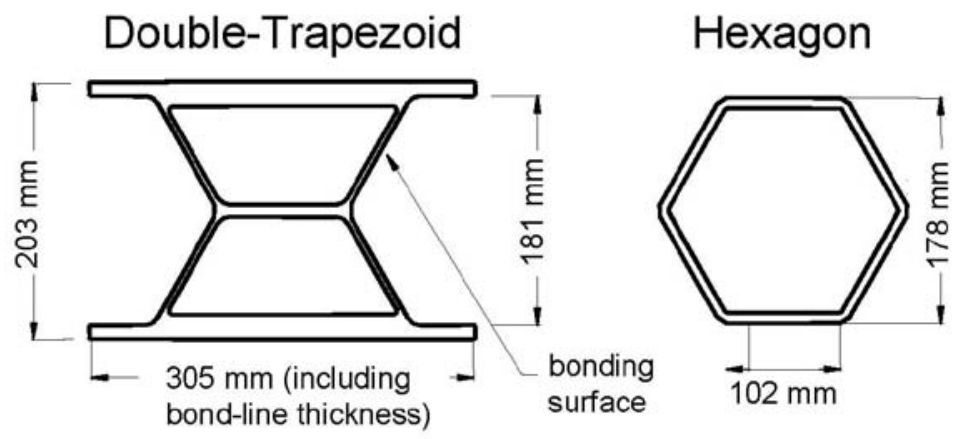

Figure 2.1e Detail of Creative Pultrusions Hollow-core Sandwich Deck [62]

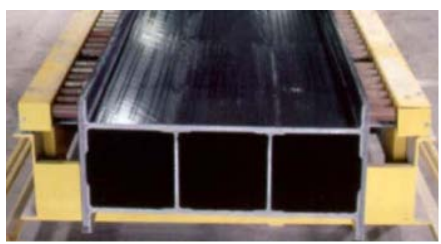

Figure 2.1f Detail of Strongwell's double-wall beam (DWB) [62]

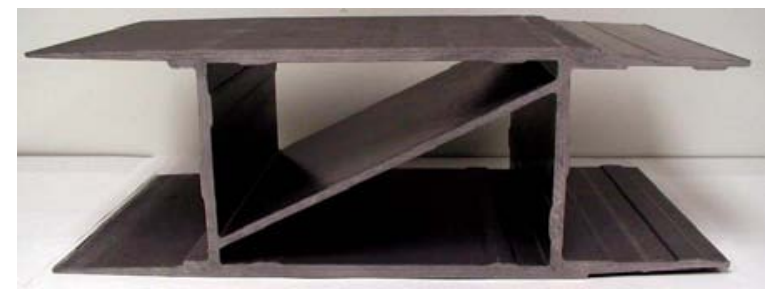

Figure 2.1g Detail of Bedford Reinforced Plastics Inc. Prodeck8 [11].

\subsection{Cost Analysis}

The two approaches commonly used for cost analysis are initial costs analysis and life-cycle cost (LCC) analysis. Life-cycle cost includes the initial costs; maintenance, inspection, and repair costs; and the disposal costs. Therefore, initial costs are a subset of the total life-cycle cost. When initial costs are the major cost component, life-cycle 
costing results will be similar to considering only initial costs. However, when inspection, maintenance, and disposal costs become dominant, life-cycle costing must be utilized. Maintenance costs depend on the frequency and amount of maintenance performed during the life-cycle. Inspection includes the cost of the quality assurance procedures, testing, and record maintenance. Repair is similar to maintenance costs, but is done for major items such as deck and/or overlay replacement and typically is not performed on a regular basis. While life-cycle costing is probably the best process to study the competitiveness of FRP for large structure projects, sometimes it is not possible to obtain all the necessary data.

\subsubsection{Initial Cost Analysis}

For FRP bridge decks, the initial costs include material costs, component manufacturing, fabrication, assembly, shipment, installation and testing costs. Knowing the initial costs from the recent past, future initial costs can be estimated by utilizing improvement (learning) curve theory.

Three types of improvement curve models were developed based on their definition of the dependent variable: the average time basis, the marginal time basis, and the individual unit-time basis. The model with the highest coefficient of determination $\left(\mathrm{R}^{2}\right)$ for its logarithmic linear regression was utilized. The two most important models are the Wright model and the Crawford model [55]. 


\subsubsection{Life-Cycle Cost Analysis}

Life-cycle costing (LCC) is defined as "the total cost of the system or product under study over its complete life cycle or the duration of the period of study, whichever is the shorter" [64]. LCC is a form of value engineering in which the costs of alternatives can be determined and compared. The study period of LCC is defined as the length of time over which an investment is evaluated. It depends on the time horizon of the investor or the expected life of the system. Three key times of the study period are (1) the base date (beginning of study period), (2) the service date (beginning of operational period), and (3) the end date (end of study period) [39].

The six main steps in an LCC analysis are to: (1) identify feasible project alternatives, (2) establish common assumptions, (3) identify relevant project costs, (4) convert all dollar amounts to present value, (5) compute and compare LCCs of alternatives, and (6) interpret results [39]. Assumptions should be clearly defined. The most common assumptions are the definitions of life, costs, initial costs, discounting and inflation, taxation, and benefits.

LCC is commonly promoted on a cost-only basis, but it is suggested that all expenditures that generate a value must be measured for a meaningful study. The choice of discount rate may be determined by either sensitivity analysis or by the calculation of a "break-even" discount rate [73]. It is argued that the application of LCC at an early design stage will greatly enhance system design and operation [64].

One of the disadvantages of LCC is inherent uncertainty. Thus, handling of uncertainty must be emphasized [31]. Infrastructural projects, such as bridges, which have high investment costs and long life expectancies, should use life-cycle costing. 
LCC is necessary when a project has high investment costs and high cumulative maintenance and removal costs over the life of the project [21].

Ehlen and Marshall [29] provide a general method for evaluating the life-cycle cost effectiveness of new-technology materials, such as FRP, in relation to conventional materials. They recommended nine steps for calculating the life-cycle cost of a newtechnology material vis-à-vis a conventional material. Those steps are to: (1) define the project objective and minimum performance requirements; (2) identify the alternatives for achieving the objectives; (3) establish the basic assumptions for the analysis; (4) identify, estimate, and determine the timing of all relevant costs; (5) compute the LCC for each alternative; (6) perform sensitivity analysis by recomputing the LCC for each alternative using different assumptions; (7) compare the alternative's LCCs for each set of assumptions; (8) consider the other project effects; and (9) select the best alternative. In each alternative the user should use the same fixed discount rate and the same study period. Implicit in any LCC analysis is the assumption that every proposed alternative will satisfy the minimum performance requirements of the project. These requirements include structural, safety, reliability, environmental and specific building code requirements. If an alternative satisfies performance requirements and has additional positive features that are not explicitly accounted for in the LCC analysis, then consider an alternative economic measure such as net benefits. Step 6 of Ehlen and Marshall's method is a fundamental part of assessing new construction materials. The costs and technical performance of new materials are intrinsically uncertain; the method must address this uncertainty.

Further, it is suggested to use the LCC classification scheme when evaluating 
new-technology materials, mainly to make sure that all costs associated with the project are taken into account for each alternative [29]. The three levels of costs proposed include: level 1 cost by LCC category (typically used are construction, operation/maintenance/repair, and disposal); level 2 costs by the entity that bears the cost (agency costs, user costs, and third-party costs); and level 3 costs by elemental breakdown (elemental costs, non-elemental costs, new-technology introduction costs).

Nystrom et al. [64], based on their LCC analysis of short-span FRP bridges (small bridges with a span less than 10 meters, which represent more than half of the bridge applications nationally and are critical to rural highways and city streets), suggested that total FRP designs for short-span bridges are not financially viable. Unless there are particular intangible benefits to justify the premium, or new low-cost materials are developed that will significantly lower the material costs, this technology will not be cost-competitive for the standard small bridge [64]. The expectation that FRP bridges will have lower maintenance and repair costs was not factored into the analysis, assuming the impact would be small. For example, even though FRP may be durable and easy to repair, it might also be more difficult to inspect. Sophisticated, nondestructive evaluation/testing devices and fiber optic sensors, which are costly, may be needed to monitor the in-service condition of and the presence of moisture in the bridge deck [91]. Nystrom et al. [64] concluded that the application of FRP technology will be limited to other niche markets, such as decks and bridge repair. A life-cycle cost analysis by Ehlen [28] of three fiber-reinforced-polymer bridge decks (SCRIMP FRP deck, wood-core FRP deck, and pultruded-plank FRP deck) indicated that the wood-core FRP deck was cost effective for a particular class of bridges and traffic levels if new technology 
introduction (NTI) costs are divided among three similar projects.

Balendran et al. [10], based on some case studies of FRP strengthening applications, concluded that the use of FRP material for strengthening concrete structures was rapidly gaining acceptance due to its enhanced properties and cost effectiveness. Nathan and Onyemelukwe [61] studied bridge deck replacement alternatives for the Sunrise Boulevard movable bridge in Ft. Lauderdale, Florida. LCC analysis was done on an existing steel grid deck and a proposed FRP deck. Cost data for the steel deck as well as the FRP deck were obtained from the Florida Department of Transportation and Strongwell Inc., respectively. As the basis for their calculations, they used 40 years for the life of the steel deck and 50 years for the life of the FRP deck, along with a discount rate of 2 percent. Considering the uncertainty of FRP costs and service life, sensitivity analysis was done for both factors. The results showed that rehabilitation or replacement for steel costs more than the FRP deck alternative. While the benefit to cost ratio for the steel deck was slightly higher, the difference between both decks (steel 1.8 and FRP 1.7) was only 5percent. The analysis suggested that, in the long term, the FRP deck is cost effective.

LCC analyses have shown that FRP bridge decks used on conventional multibeam overpass bridges can reduce the life-cycle cost of a bridge anywhere from 10 to 30 percent over a 75-year design life. The major component of the cost savings is a reduction in user costs associated with the increased speed of construction and fewer traffic impacts due to a reduction in maintenance and rehabilitation requirements. 


\subsection{The Economic Evaluation of Composites for Construction}

An interesting framework for life-cycle cost assessment of composites in construction was suggested by Hastak et al. [43]. They proposed a model that utilized the historical life-cycle performance data for conventional materials, knowledge about material properties, and deterioration characteristics for new and conventional materials to effectively assess the life-cycle cost and behavior of composite materials in construction. There are two basic assumptions stated for this proposed model. First, the life-cycle performance is based on the severity of damage modes (DM). Damage modes may include corrosion, fatigue, and spalling due to freeze-thaw. Factors affecting damage modes include maintenance practices, average daily traffic (ADT), temperature, moisture, weathering, salt, and humidity. The second assumption is that while the factors may or may not be independent, their individual influence on a damage mode is independent. The model integrates deterioration characteristics of structural components under different environmental and loading conditions to establish performance envelopes. Monte Carlo simulation models were generated to evaluate various maintenance, repair, and rehabilitation strategies possible over the life-cycle. The life-cycle cost associated with each scenario was computed at different discount rates to obtain the optimal lifecycle cost for various material options. The framework proposed provided a methodology at the macro level that would require micro-level development at various steps within the methodology to arrive at the final results.

Hastak et al. [44] developed a life-cycle benefit-cost model for composite materials used in construction. Their model has three main components: (1) life-cycle benefit assessment, (2) life-cycle cost assessment, and (3) benefit-cost assessment. Their 
model provides a method for comparing various alternative materials using value-based preferences of the decision makers and non-monetary evaluation of benefits. It was assumed that life-cycle cost data for each material option are available from another model.

\section{$2.4 \quad$ Deterioration of FRP}

Among the FRP types available, Glass Fiber Reinforced Polymer (GFRP) is the lowest cost and consequently has the highest potential of being cost effective. Therefore, many researchers decided to focus on studying the deterioration mechanism of this type of FRP. Consequently, information on the mechanism of GFRP deterioration is more complete compared to other types of FRP.

Different researchers have suggested several different mechanisms for degradation of GFRP in concrete. One important degradation mechanism suggested is the cutting of the Si-O bonds by reaction with $\mathrm{H}_{2} \mathrm{O}$ molecules and $\mathrm{OH}$ ions in water and alkaline solution, respectively. Regarding the polymer matrix, base hydrolysis of ester bonds has been emphasized as the main degradation mechanism.

Several research projects with the aim of evaluating the durability of GFRP in alkaline environments have been presented in recent years. However, the approaches adopted in these projects are generally qualitative, and no serious attempt was made to predict service life in a real application. A few researchers suggested methods to make quantitative assessments of the service life of GFRP in alkaline environments.

Saadatmanesh and Tannous [79] used Fick's law to predict the reduction in strength of various FRP tendons. In general, this law was considered to adequately 
predict the loss in strength of the tendons studied. This approach assumed that the ingress of alkali ions in the GRFP material could be measured. A bar that lost tensile strength in a layer penetrated by alkali ions may also lose its bond strength. Therefore, bond strength may well control the service life rather than the tensile strength.

Another suggested approach was to utilize the time-temperature relationship established for glass fiber-reinforced concrete by Vijay and GangaRao [94]. This relationship was used to transform time under accelerated exposure of GFRP bars (in alkali solution or embedded in concrete) into time in real applications. Based on the series of experiments and the time transformation suggested, they concluded that the service life of the FRP bars with durable resin is at least 60 years with 20 percent sustained stress on the bar. The benefit of using this approach is that reliable timetemperature relationships for glass fiber reinforced concrete (GFRC) are available for relatively long exposure times. However, it is not obvious that time-temperature relationships that apply to degradation of GFRC are also valid for GFRP.

Based on this drawback, Dejke [24] suggested a new model for time-shift factors based on the Arrhenius equation in his study of degradation mechanisms of GFRP in concrete and possible degradation modes. He studied the degradation mechanism in the material after environmental exposure (water, alkali, concrete), which included different failure modes, matrix and interface degradation, fiber degradation, and transport mechanisms (alkali and water) in either an accelerated or non-accelerated test. It should be noted that in this test, the bars were not subjected to any mechanical stress nor involved any cycling. Hence, any effects caused by such cycling in exposure conditions were not covered in that investigation. 
Regardless of the different approaches that the last two researchers used, their conclusions were similar with regard to tensile strength value of FRP under consideration. Vijay and GangaRao [94] noted a tensile strength reduction of 55 percent in 30 months due to accelerated aging under alkaline conditioning and freeze-thaw variations (approximately equivalent to a lower bound service life of 59 years in real life weathering with 20 percent sustained stress). Concrete covered bars would have a service life of 90-120 years. Dejke [24] predicted that the tensile strength drops to 50 percent of the original strength after 55 years in concrete (humidity 100 percent) at $10^{\circ}$ C. The strength, however, would not drop dramatically in years 55-100. Furthermore, it was reported that there was no significant deterioration in the modulus of elasticity. Apparently the environment has a much lower influence on the stiffness of the reinforcement than on the tensile strength.

Unfortunately, these research studies were limited in their scope, and did not provide in-depth insights into the post-damage strength and behavior of FRP decks, or into the effect of damage on the useful life of these components. Clearly, in the civil infrastructure and for FRP decks in particular, research is lacking in the areas of damage estimation, damage accumulation, and remaining service life prediction [62].

\subsubsection{Deterioration Phase}

The deterioration phase of FRP is not fully understood as the different mechanical properties of FRP deteriorate at different rates and to a different extent. Therefore, it is vital to study the environmental effect on all mechanical properties important for the performance of FRP reinforcement in concrete to determine the overall durability and the 
deterioration phase of certain FRP applications. Testing only one property, i.e., tensile strength, may give misleading information about overall environmental resistance.

The four basic indices that define the physical characteristics of FRP composites are (1) axial (longitudinal tensile strength), (2) bending strength (flexural strength), (3) shear strength (inter-laminar shear strength) and (4) modulus [41] must be examined in a timely manner. Environmental factors that control the rate of degradation should be noted to be able to determine the time of each phase under different conditions.

Besides environmental conditions, FRP material components deteriorate due to service loads and type of FRP itself. Short-term behavior of FRP composites was found to vary significantly depending on the types of fibers and resins, fiber volume fraction, fiber orientation, manufacturing process, and production quality control process. Sensitivity to deteriorating mechanisms can be substantially different for FRP structures manufactured with different processes.

Additionally, Hong et al. [46] suggested seven external factors (EFs) and seven damage modes (DMs) for FRP bridge deck panels. The seven EFs include (1) temperature, (2) moisture, (3) chemicals, (4) loading cycle, (5) freeze and thaw, (6) ultraviolet light, and (7) fire attack. The seven DMs consist of (1) moisture (water) effect, (2) alkali environment, (3) thermal effect, (4) creep/relaxation effect, (5) fatigue effects, (6) ultraviolet exposure, and (7) fire effects. Furthermore, they considered that resin and fiber were the main constituent materials of the bridge deck, which would be effected by the EFs and DMs resulting in material damages (MDs). 


\subsubsection{Factors Affecting FRP Service Life}

\subsubsection{Factors Associated with the Environment}

There are basically three environmental factors that control the rate of degradation: temperature, moisture content, and stress level [24]. A more complete list of factors included: moisture (water, humid air, liquid), temperature (freeze-thaw cycling, elevated temperature, fire), weather conditions (physical, chemical, UV rays), physical weathering conditions (static load, fatigue, creep), and chemical weathering conditions (exposure to alkaline, acid, aqueous). Among those, moisture content and its absorption phenomena were of critical interest [41].

Dokun et al. [26] suggested that the unavailability of a nondestructive methodology that can quantitatively track changes in material properties (within a control volume) as a function of accumulated damage is one impediment to the development of a quantitative understanding of deterioration in thick FRP components. One of the difficulties in defining reliable monitoring techniques for these components is caused by the significant variation in material properties [95]. Because of this variation, material property variations within the same specimen (or from specimen to specimen) can be greater than the changes caused by material degradation.

Preliminary tests on the durability of FRP samples conducted at the Institute for Research in Construction (IRC) in Canada indicated that glass-fiber FRPs may have a short life span in the alkaline environment of concrete. A carbon-fiber FRP, known for its high resistance to chemical degradation, showed modest but noticeable degradation. A one-year duration study to provide more information about the causes and mechanisms of FRP deterioration was done by IRC in 2006. The report indicated the problems found: 
physical damage in the form of cracking and etching of the surface, the exposure of some fibers, and the onset of chemical degradation.

The absorption of water into thermosetting polymers and their composites can greatly influence the mechanical properties of the resin and its composites. Temperature affects the rate of moisture absorption as the diffusion coefficient increases with temperature. As indicated by Vijay and GangaRao [94], there is a strong temperature dependence of moisture absorption in GFRP bars under different conditioning schemes. Moisture absorption was found to increase with temperature, and alkaline conditioning resulted in maximum moisture absorption.

Bijen [13] suggested that the long history of FRP for marine equipment has shown that FRP structures can be successfully engineered to have long service lives in contact with moisture and aqueous solutions. However, FRP structures, as well as all other organic polymers, are not waterproof; moisture diffuses into them causing changes in properties. Properties of these composites change over time, and degradation accelerates under harsh conditions. Environmental conditions that affect FRP deterioration include freeze-thaw conditions, temperature, humidity, and the presence of an alkali environment [50]. Sridharan [89] determined that a significant amount of material degradation occurs when FRP components are aged in water at a temperature below the glass transition temperature $\left(117^{\circ} \mathrm{C}\right.$ for this material). It was shown that the drop in longitudinal tensile modulus in a specimen was not due to changes in the matrix but was caused by a combination of the degradation of the glass fibers and failure of the fiber matrix interface. 


\subsubsection{Factors Associated with Designs}

An FRP bridge deck may fail in the top surface, bottom surface, or in the core. It is believed that design plays an important role in these problems. Some of the FRP bridge deck design factors to be considered and the related possible problems of an improper design are deflection, strain, connections, overlay, and thermal difference problems [42, 62]:

\section{(1) Deflection}

The main purpose for deflection limitations is to prevent local or global deformations under a wheel load that may cause delamination or cracking of the overlay. Deflection was not a problem in SRC decks. For FRP, deflection criteria has recently settled into the L/300 to L/500 range, which is consistent with the provisions in the current AASHTO LRFD Code provisions for orthotropic steel and timber decks. Regular load testing is necessary to study the actual deflections of the deck from time to time. In many cases, deflection criteria control the design.

\section{(2) Strain}

As a general rule of thumb for structural FRP applications, design strains are typically kept below 20 percent of ultimate capacity. However, bridge deck applications are typically stiffness-driven (deflection driven), resulting in strains well below that level. As a result of such low levels of strain, fatigue and creep are not an issue when properly designed and fabricated. Field strains of the deck or stringers should be measured regularly to evaluate the performance of the bridge, particularly to study the fatigue behavior of deck-to-girder connections and deck deformations. 


\section{(3) Deck-to-Girder Connections}

FRP bridge decks have been installed on steel, concrete, and FRP girders. Connection options include all-adhesive, mechanical fasteners, and conventional shear studs. Composite bending action between the deck and support girders is possible but the ability to provide this will depend on each specific deck type and manufacturer. Effectiveness and composite action of deck-to-girder connection can be measured by studying the strain in the middle of the floor-beam. If there is no composite action, neutral axis of the floor-beam should be unchanged from the previous position. Gurtler (2004) [42] concluded that mechanical fasteners are adequate for traditional materials but not well-suited for FRP materials for various reasons.

\section{(4) Deck-to-Deck Connections}

Connection options are either all-adhesive or mechanical fasteners. Relative rotation of the adjacent FRP panels, as a result of improper connection, may cause reflective cracking at field joints. Effectiveness of deck-to-deck connections can be measured by studying the strain on both sides of the longitudinal joint. The test would indicate the quality of the joint, i.e., whether the load is completely carried across the joint or not. Repeated testing every few years would be required to determine the degradation of the joint effectiveness due to in-service loads and environmental conditions.

\section{(5) Overlay}

FRP bridge deck systems require an overlay to provide adequate skid resistance as well as abrasion protection. The overlay choices include the following: conventional asphalt, polymer-modified asphalt, polymer concrete, and micro-silica modified concrete 
[7]. In general, reflective cracking occurs at field joints due to relative rotation of the adjacent FRP panels. Thermal mismatch between the FRP deck and overlay will cause reflective cracking. Hong and Hastak [45] reported that asphalt seemed to work best for hardcore (HC) bridge decks. Polymer concrete and latex-modified concrete have also been successfully applied and are typically recommended for the HC deck system.

These are only some of the factors that might affect the deterioration of FRP bridge decks. An indepth analysis of all factors, how those factors might be correlated, and which design criteria should be examined to minimize the effects of those factors needs to be done. The analysis requires determining not only the required maintenance or repair time, but also the approximate area of the deck which needs to be repaired. Rather than using the maintenance cost as a function per square foot of bridge area, it is more suitable to use only the area of the deteriorating part of the bridge.

\subsubsection{Available Deterioration Models}

A validated deterioration rate model for FRP bridge decks does not exist. AbedAl Rahim and Johnston [2] have proposed a method for calculating the average change in condition rating in one year for a group of concrete bridges using historical condition data. They have developed deterioration curves for three major bridge elements (deck, superstructure, and substructure) based on material types. Abu-Tair et al. [3] showed that the modeling of deterioration rates could be performed using the factor method based on historic inspection data.

It is known that in the model-based approach for maintenance and repair decisionmaking, policy evaluation and policy selection are performed based on a deterioration 
model, a cost function, and a salvage value function to predict the effect of the actions prescribed by a policy on the sum of discounted costs incurred over a planning horizon. If it is not possible to build a deterioration model because of lack of data, another approach, temporal-difference, can be applied to determine maintenance and repair decisions. The temporal-difference (TD) learning method does not require a model of deterioration to come up with decisions. TD methods only assume that facilities are managed under a periodic review policy. To be able to use such a method for a bridge deck, the bridge deck condition is discretized into a number of states and a number of maintenance and repair actions along with the correspondent costs. The costs of performing the actions required are needed.

According to Ehlen and Marshall [29], the failure modes of the FRP material are understood to a degree. This information can be used to develop repair procedures and associated costs. Details of FRP failure modes or how one could estimate the associated costs were not provided. In the most recent research, Alagunsundaramoorthy et al. [4] studied structural behavior of FRP composite bridge deck panels. Among their findings, they stated that the mode of failure of pultruded FRP bridge decks is debondingpunching. They observed debonding of joints at the ends of sections of panels and punching at the loading points after failure. Overall, the single and pultruded FRP deck panels satisfied the deflection, shear, and flexure criteria as specified by the Ohio Department of Transportation.

Roychoudhury and Creese [21] suggested how to determine the year(s) in which an FRP bridge should get maintenance or repair. They proposed using two condition indices: condition index maintenance (CIM) and condition index repair (CIR) to make 
such decisions. The kind of repair strategy to be used (overlay or replacing the deck) was based on the combined condition indices of maintenance and repair and the age of the bridge deck. Since FRP bridge data was not available, SRC bridge data were used to develop the equations required for cost calculations. FRP data would be required to calibrate the model.

The Florida Department of Transportation modeled bridge deterioration using a Markovian model [87]. They use a system of 136 elements from their bridges. During an inspection, each element, i.e., bridge deck, was characterized in terms of a distinct set of possible "states." Next, a Markovian deterioration model was expressed as a matrix of transition probabilities. Because this deterioration model assumed no corrective action was taken, there was no probability of improvement in condition, i.e., probabilities of transition from higher states to lower states were zero. When an action was taken, the effect upon the condition was expressed in a do-something matrix. Repair, which may cause a transition to a better condition state, is an example of this situation. Each possible condition state may have zero or one or more feasible actions. Each feasible action results in a distribution of condition states immediately following the action. In both matrices, each row should sum up to 100 percent. To be able to predict the service life of a bridge element, one must have a long-term prediction of this element expressed probabilistically, i.e., matrix probability of each condition state each year for a certain number of years. This allows calculating an estimate of the condition for any future point in time using matrix multiplication.

Other existing deterioration models include the following:

1. The deterioration model for concrete highway bridges [38]. The condition rate of a 
bridge is estimated based on two variables: bridge age and average daily traffic $(\mathrm{ADT})$.

2. The deterioration model for bridge elements. The deterioration rates of bridge elements are predicted based on historical data from bridge inventories [2]. Two classes of environment (marine and non-marine), four types of materials (pre-stressed concrete, reinforced concrete, steel, and timber), and two classes of roadways (interstate and local roads) were considered.

3. For bridges in general. Sanders and Zhang [84] proposed bridge deterioration models as a function of $\mathrm{ADT}$, bridge age, time of rehabilitation, environmental factors, type of structure, and bridge components.

\subsection{Service Life Prediction Models}

The International Standard Organization provides the principles of the generic service life prediction method, as given in Figure 2.2. In general, service life prediction can be based on two different principal approaches: a deterministic approach and a probabilistic approach. Figure 2.2 gives the basis for development of service life prediction methods of various complexities and with different requirements for applicability and needs for input information. Three levels of service life prediction methods can be described as shown in Figure 2.3.

Similarly, Moser and Edvardsen [59] stated that there are two main methods for service life prediction: the probabilistic method and the factor method. Between those lies engineering methods. 


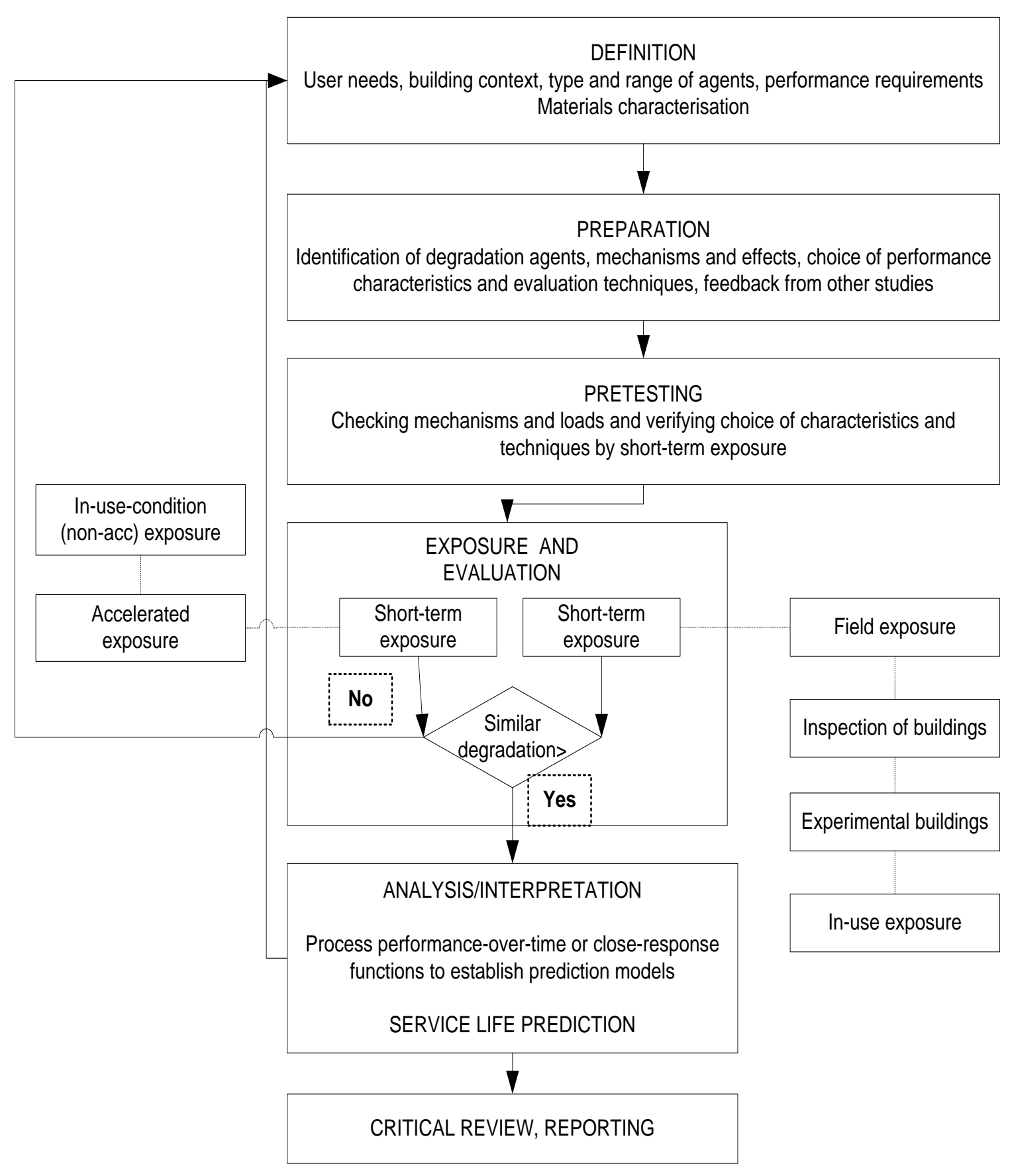

Figure 2.2 Systematic Methodology for Service Life Prediction of Building Components ISO 15686 Part 2 [93] 


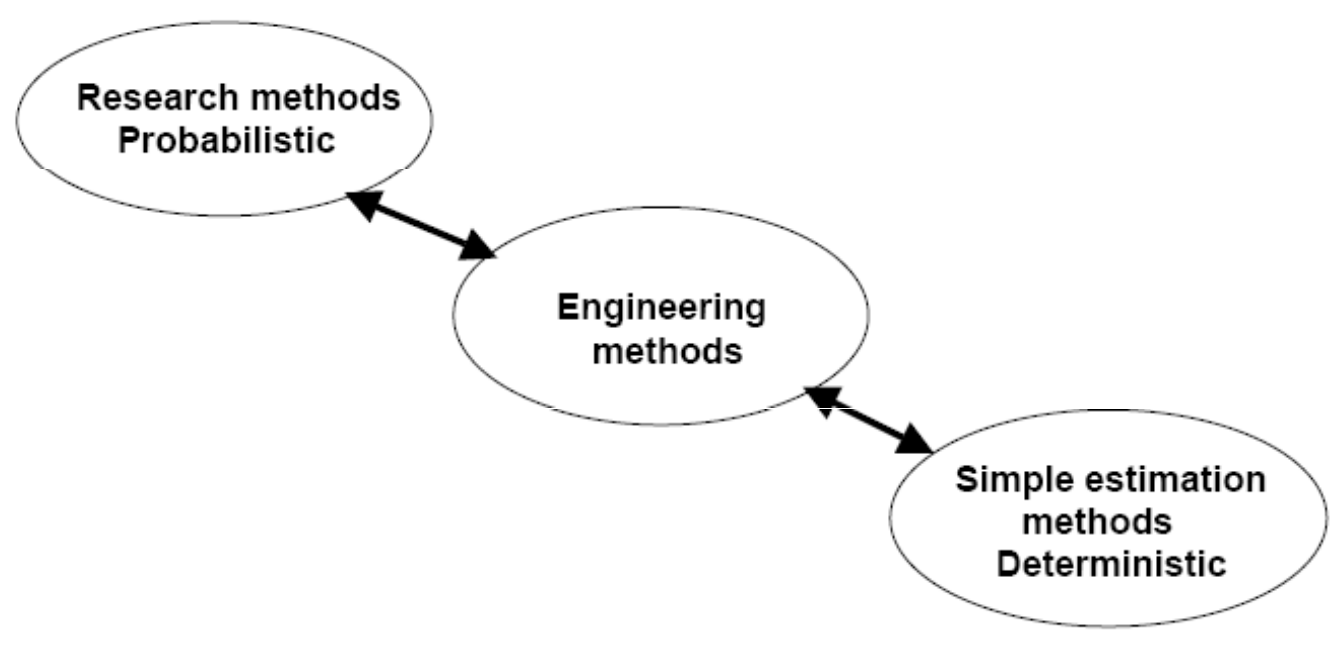

Figure 2.3 Relationships between Different Types of Service Life Prediction Methods [47]

\subsubsection{The Probabilistic Methods}

These methods are applied for large infrastructure projects in which teams of specialists are set up to investigate service life under the exact conditions. The disadvantage is that the model is too elaborate to be used on standard applications such as ordinary road bridges. An example of such an application is in the paper: "Probabilistic, Performance-based Service Life Design of Concrete Structures” by Lindvall [51]. He modeled the service life of a concrete structure as a combination of time-dependent deterioration processes, which are mainly governed by environmental influence. He discussed how the environment influences the degradation by changing material properties and the load-carrying capacity over time. Two examples of service life predictions for concrete structures are also shown - structures exposed to chloride penetration and structures exposed to carbonation. These predictions were made using a probabilistic approach (both mean values and scatters). 


\subsubsection{The Factor Method}

The factor method was developed as a tool to support service life prediction when there is a lack of adequate or reliable data or when more detailed experimental prediction is not possible. This method is based on a reference service life and modifying factors that relate to the specific condition of the element. The factor method, according to ISO/CD 15686, identifies the main factors of influence with regard to service life, and from there calculates a plain figure for the service life of the building or building component. Knowing the main factors of influence and the overall behavior of a component facilitates understanding of the relevant issues, even though they do not reflect reality very closely.

This method allows an estimate of the service life to be made for a particular component or assembly under specific conditions. It is based on a reference service life (normally the expected service life in a well-defined set of in-use conditions that apply to that type of component or assembly) and a series of modifying factors that relate to the specific conditions of the case.

Basically, the factor method applies seven factors, which include quality, exposure, and condition of the component considered, to the basic value of service life. Those factors have been designed to cover the main aspects affecting service life. The modifying factors include: (A) quality of components, (B) design level, (C) work execution level, (D) indoor environment, (E) outdoor environment, (F) in-use conditions, and (G) maintenance level. Any one (or any combination) of these variables can affect the service life. The factor method can therefore be expressed as a formula: 
$\mathrm{L}=\mathrm{L}_{\mathrm{ref}} * \mathrm{~A} * \mathrm{~B} * \mathrm{C} * \mathrm{D} * \mathrm{E} * \mathrm{~F} * \mathrm{G}$

Where

$\mathrm{L}=$ Estimated service life

$\mathrm{L}_{\mathrm{ref}}=$ Reference service life

A = Multiplication factor for quality of components

B = Multiplication factor for design level

$\mathrm{C}=$ Multiplication factor work execution level

$\mathrm{D}=$ Multiplication factor for indoor environment

$\mathrm{E}=$ Multiplication factor for outdoor environment

$\mathrm{F}=$ Multiplication factor for in-use conditions

$G=$ Multiplication factor for maintenance level

Generally, A, B, and C are agent factors related to inherent quality characteristics. The decision maker must define the relevant conditions and specify the factors. It should be noted that there is no pre-defined set of factors. The user of the method must consider the particular circumstances of the project and decide the most appropriate factors for those circumstances [14]. Hence, the seven factors are determined based on the user's judgment. There are neither predetermined factors nor an exact methodology to follow. The value of each factor ranges from 0 to 2, and values above 1 increase the service life, whereas values below 1 decrease the service life. $L_{\text {ref }}$ (reference service life) is the expected service life under most common conditions and can be determined by producer's data, testing laboratory data, previous experience with similar structures and materials under similar conditions, agreement among relevant bodies or commissions in cooperation with national institutions, or data in the existing standards and other technical 
literature [92].

The advantages of the factor method lie in its simplicity and ability to be conducted with minimal data. The main drawback is a single figure result for service life that does not take into account the variability of the processes involved. It should be understood that this method only gives an estimate of service life based on available information. The shortcomings of this method include: (1) plain multiplication of factors, which in reality might have different weights; (2) the result is just a single figure which does not reflect the variance of reality; (3) the data still needs to be accumulated; and (4) the lack of a direct relationship with data gathered (e.g. on the environment, climate, installation quality, in use conditions, etc.) to service life ([3], [47]). Despite these drawbacks, this method is still used in life-cycle costing simply because no other suitable approach is available.

The use of the ISO factor method for prediction of service life of building materials and components has been very limited. Most of the published cases are described in research papers or reports where examples of the use of the applications are provided. Widespread practical application of the method has been limited due to the lack of knowledge of the method among practitioners (architects, consultants, or building owners and managers) or due to the need for useful values of the various factors used in the method [47].

\subsubsection{Modified Factor Methods}

Modified factor methods include proposed methods to modify or improve the factor method approach, such as taking a stochastic approach to the factor method [1]. 
The engineering design method (EDM) is defined as any simple mathematical function using distributions for the individual factors in the function [59]. Moser and Edvardsen [59] provided three examples showing three variations of the EDM. The three examples are as follows. Example 1 (estimating service life for four windows facing different direction) was used to demonstrate the basic procedure of expansion of the factorial method. It used all seven factors of the factor method under the assumption that the information for defining the respective distribution was readily available. In this example each factor had a certain type of distribution (normal or lognormal). The results were distributions of predicted service lives. Example 2 (estimating service life of fiber cement slates used as wall cladding) demonstrated a modification of the factorial method. In this example, the input data was fairly scarce, far from complete, and not directly suited for application in a service life calculation. The authors showed how the interpretation of available limited data could lead to a service life prediction. Example 3 dealt with simplification of the probabilistic method. The example (estimating service life of reinforced concrete structures in two different climate conditions) demonstrated how a service life prediction can be obtained using a plain formula by introducing densities for the factors involved. It is clear that the key to this method is that the distributions of any factors in the relation are known. The general principles of the engineering design methods outlined by Moser [57] were:

1. Establish an equation describing the service life of the building or component, taking into account all identified relevant parameters. For standard cases, the equation of the factorial method as set up in ISO 15686-1 can be used. In other cases, modified or tailor-made equations must be set up. 
2. Gather data on the parameters of the above equation from experience, expert opinion, etc. Then, set up a probability density distribution for the individual parameters identified.

3. Perform the service life calculation.

4. Review the plausibility of the results using expert opinion, and when deemed necessary, modify the input data accordingly, i.e., go into greater detail in setting up the parameters for the variables dominating the service life.

An improvement of the factor method by introduction of statistical evaluation of the individual factors has been studied by Aarseth and Hovde [1]. A "step-by-step" principle has been applied, and this was developed within the project planning area. It was developed in Denmark in the 1970's but has since been further developed in Norway. It is a tool for improving the quality of the basis for decisions in project planning under uncertainty. As with estimating service life, a basic problem in project planning at an early stage is the lack of relevant information. The stochastic approach to the factor method is proposed to overcome the lack of information about uncertainty in the factor method. In this approach, the factors, which are handled as stochastic variables, are treated as elements, which finally are summed. All conditions that are assumed to influence the service life are identified and quantified in a systematic way. Every assumed interaction between factors is removed and the effect of the interactions is evaluated by introducing a new factor, a general conditions factor. The estimates are expressed in years, instead of in numbers close to 1 . A value for each of the individual factors of the factor method is given by use of a triple estimate, a minimum value, a maximum value, and the expected value. In order to give a reasonably good statistical 
representation of the triple estimates, an Erlang density function is used. In the following example, the Erlang density function with $k=10$ was applied to give reasonably good statistical representation of the triple estimates. The expected value $f$ and the standard deviation $s$ are calculated from the following equations: $f=\left(l+2.95^{*} m+h\right) / 4.95$ and $s=(h-$ 1)/4.6, where $l$ is the minimum estimate, $m$ is the expected estimate, and $h$ is the maximum estimate. The authors have applied this modified factor method for estimation of the service life of a wooden window, which was used as an example in ISO 15686 Part 1. By using the simple factor method as shown in the ISO Standard, the estimated service life of the window was 62.2 years, i.e., 60 years. By using the step-by-step principle and a statistically modified factor method, the estimated service life is calculated to $50 \pm 6$ years.

Table 2.2 provides the example of estimated service life of the component (ESLC) calculation. RSLC is the reference service life of the component (the value is 50 years for this example). Using this method the value of $l, m$, or $h$ could be negative, because they represent the difference (in number of years) of each factor relative to the RSLC.

Moser (1999) [58] also carried out an evaluation and improvement of the factor method by using statistical methods. Instead of a joint statistical treatment of all the factors as shown by Aarseth and Hovde [1] in the "step-by-step” principle, Moser applied an individual statistical treatment of each factor. This was done by using different statistical distributions for each factor (deterministic, normal, lognormal) and by giving individual figures for the minimum, most probable, and maximum value of each factor. Moser gave an example of estimating the service life of windows on all four sides of a 
Table 2.2 ESLC Calculation Example of a Window [1]

\begin{tabular}{|c|c|c|c|c|c|c|}
\hline Elements & I & $\mathbf{m}$ & $\mathrm{h}$ (in yrs) & $f$ & $\mathbf{s}$ & part of $s$ \\
\hline $\bar{A}$ & 0 & $\overline{5}$ & 10 & $\overline{5}$ & 2.17 & $\begin{array}{ll}14.3 \% \\
\end{array}$ \\
\hline$B$ & 0 & 5 & 10 & 5 & 2.17 & $14.3 \%$ \\
\hline$C$ & 0 & 5 & 10 & 5 & 2.17 & $14.3 \%$ \\
\hline D1 & -5 & 0 & 5 & 0 & 2.17 & $14.3 \%$ \\
\hline D2 & 0 & 5 & 10 & 5 & 2.17 & $14.3 \%$ \\
\hline$E$ & -5 & 0 & 5 & 0 & 2.17 & $14.3 \%$ \\
\hline $\mathrm{F}$ & 0 & 5 & 10 & 5 & 2.17 & $14.3 \%$ \\
\hline$G$ & 0 & 0 & 0 & 0 & 0.00 & $0.0 \%$ \\
\hline Sum & -10 & 25 & 60 & 25 & 15.22 & $100 \%$ \\
\hline RSLC + sum & 15 & 50 & 85 & \multirow{2}{*}{\multicolumn{3}{|c|}{$\begin{array}{l}\mathrm{RSLC}+\operatorname{sum} f=50 \\
\mathrm{ESLC}=50+6\end{array}$}} \\
\hline ESLC & & 50 & & & & \\
\hline
\end{tabular}

building. Rudbeck [78] presents a discussion of the factor method for service life prediction and concludes that before the most correct method can be determined, assisted by field data, one can only look at the possible advantages and disadvantages that the methods present.

From this viewpoint, the methods based on the ISO proposal with a probabilistic approach, described by Aarseth and Hovde [1] and Moser [58], seem to be the most usable. The requirement for input to develop the needed functions in the two methods is the same, but they report the input (i.e., the functions) in different ways. The method suggested by Aarseth and Hovde [1] reports the data in a very aggregated form (a low, a medium, and a high estimate for each parameter); whereas the method described by Moser [58] enables the use of all available data. From a statistical point of view, the latter method seems to be the most reliable. 


\subsection{Performance of FRP Bridge Deck in Service}

There are many benefits to using FRP composites to construct either pedestrian or highway bridges. FRP bridge decks are anisotropic, meaning the mechanical properties of the laminates vary with the volume and orientation of the fiber reinforcement (similar to the reinforcing steel in concrete). FRP has the following advantages for bridge decks: light weight, high strength and stiffness to weight ratios, and chloride corrosion resistance. However, the testing and in-service performance will largely determine the long-range viability of those bridges. Other barriers must be overcome, such as the high initial cost of materials, lack of design codes and inspection methods and lack of proven in-service durability data.

In-service performance of FRP bridge decks should be based on critical components of FRP decks and critical accumulated damage thresholds in those components must be determined. In order to provide standardized in-service performance reports, the National Cooperative Highway Research Program (NCHRP) is conducting research to develop recommended field procedures, evaluation guidelines, and reporting standards for periodic inspection of in-service FRP bridge decks. The first task of the project is the assessment of performance data, research findings, and other information to determine the failure modes and serviceability problems of FRP bridge decks.

Critical details, damage types, and the accumulated damage thresholds for each type of FRP bridge deck will be catalogued from technical literature and from unpublished experience of engineers, owners, fabricators, and others. Once complete historical data of in-service FRP bridge decks are available, one could create simulations 
that specify an economically efficient set of actions and their timing during the bridge's life-cycle to achieve longer service life with the lowest life-cycle cost.

Complete historical data of in-service FRP bridge decks are not available. Among the most important data found are the commonly observed problems or areas of concern noted by bridge owners or practitioners, which include:

1. Joints between FRP deck panels: Heavy leakage was generally observed, which typically resulted in corrosion of the steel stringers underneath the FRP deck joints.

2. Wearing surface: Delamination and debonding of wearing surfaces was noted on several bridges, typically when thin epoxy overlays were used as the wearing surface.

3. Haunch supports: There was a concern that FRP decks may not sit solidly, creating a gap between the bottom surface of the deck and the top surface of the haunch, causing impacts between them due to the passage of vehicles.

4. Curbs and parapets: The effect on the deck of impact-related damage to the curbs is an issue of concern, when curbs or parapets are connected to the deck.

5. Approach joints: critical areas, often requiring innovative details to bridge the transition from the approach to the deck.

6. Deck to stringer/beam connectors: Current design practice neglects any composite action between FRP deck and stringers. The problem arises when steel clips are used to connect the FRP deck to steel stringers.

7. Delamination of deck components: may result in an exponential reduction in the stiffness of the deck sections.

8. Moisture ingress: Consequent freeze-thaw could result in mechanical damage to the FRP deck, leading to delamination or cracking of FRP deck components, which allow 
moisture and water to seep into the porous core of the deck cross section.

Requests for inspection/maintenance records for FRP bridge decks in West Virginia were submitted to WVDOT in August 2007 and to each of the responsible bridge engineers in October 2007. Interviews with some of the bridge engineers were conducted in their offices or through emails in April 2008. As a result, the inspection/maintenance records have been obtained for the following bridges:

1. Boy Scout Camp Bridge, Raleigh County (HC deck on steel)

2. CR 1 over Mud River (Howell's Mill Bridge), Cabell Co.. (MMC deck on steel)

3. Goat Farm Bridge, Jackson Co. (BRP deck on steel)

4. Hanover Bridge, Pendleton Co. (KSCI deck on steel)

5. Howell's Mill Bridge, Cabel Co. (MMC deck on steel)

6. Katy Truss Bridge, Marion Co. (CP deck on steel)

7. Kite Creek Bridge, Monroe Co. (BRP deck on steel)

8. La Chein Bridge, Monroe Co. (BRP deck on steel)

9. Laurel Lick Bridge, Lewis Co. (CP superstructure and deck)

10. Market St. Bridge, Wheeling, Ohio Co. (CP deck on steel)

11. Montrose Bridge, Randolph Co. (HC deck on steel)

12. West Buckeye Bridge, Monongalia Co. (KSCI superstructure)

13. Wickwire Run Bridge, Taylor Co. (CP deck on steel)

Based on the above inspection reports, which are summarized in Appendix 4, it is suggested the most common problem is wearing surface. The common problems encountered for FRP bridge deck projects in WV are similar to the ones observed nationwide. Hong and Hastak [45] stated that since FRP bridge deck panels have been 
used on highway bridge structures for just the last few years, only a small number of state DOT's currently using them have experienced any maintenance issues. Maintenance and operability issues for four out of five state DOTs (Kansas, New York, Ohio, Oregon, and Pennsylvania) are related to durability of wearing surface. Furthermore, they suggested that the best-wearing surface is a function of the FRP deck manufacturing method used. Asphalt seemed to work best for HC bridge decks; however, polymer concrete and latexmodified concrete have also been successfully applied and are typically recommended for the HC deck system [45].

For West Virginia FRP bridges, it is observed that the performance of bridge decks produced using different production methods vary. While all other bridge decks are in good or fair condition, a hand lay-up bridge deck installed in Pendleton County in 2001 is in poor condition. Currently, the inspection/maintenance schedules applied for FRP bridge decks are following the same guidelines as for SRC decks.

\subsection{FRP Bridge Deck Fabrication Costs and Related Variables}

FRP bridge decks used for bridge applications are produced by the various manufacturers, including Bedford Reinforced Plastics. Gurtler [42] suggested that the most common FRP bridge deck systems in use are (1) SuperDeck ${ }^{\circledR}$ (Creative Pultrusions Inc.), (2) ASSET (Advanced Structural Systems for Tomorrow's Infrastructure), (3) Kansas, (4) Hardcore, (5) DuraSpan (Martin Marietta Composites), and (6) ACCS (Advanced Composite Construction System). ASSET and ACCS are produced and applied outside the U.S. ACCS was demonstrated in England by Maunsell, while the ASSET bridge concept was developed by a European Consortium of seven partners 
partly funded by the European Commission. These bridge decks can be subdivided into two groups: pultruded profiles and sandwich panels. The most common pultruded bridge deck in the U.S.A is the DuraSpan system from Martin Marietta Composites. More than 25 of DuraSpan systems are already in service. All completed projects have steel or concrete main girders. The Kansas deck and the Hardcore deck are by far the most frequently used sandwich panels in bridge construction.

Bridge decks currently used are the ones produced by pultrusion processor, handlamination, or vacuum assisted resin transfer molding (VARTM). It is believed that the process differences influence the fabrication costs. The major variables that determine the fabrication cost of an FRP bridge deck include the following:

1. Technology used: Pultrusion, VARTM, and hand-lamination are the primary technologies used. The production process parameters that influence the fabrication cost are specified.

2. Material (type of fiber)

3. Resin (main enforcement)

4. Weight (lb/ft)

5. Number of Panels

6. Size of Panels

\section{$2.8 \quad$ Summary}

This chapter examined the background for this dissertation. It began with introducing FRP advantages and its applications for construction and continued with emphasizing the importance of life cycle cost (LCC) analysis as a cost analysis for a long 
term project. It then followed with explaining different ways to predict service life, an important input for LCC analysis. It was concluded with a survey of other research related to life-cycle costing for FRP bridge decks. 


\section{Chapter 3}

\section{Overview of Methodology}

\subsection{Framework of the Research}

A graphical depiction of the research methodology used for this study is given in Figure 3.1.

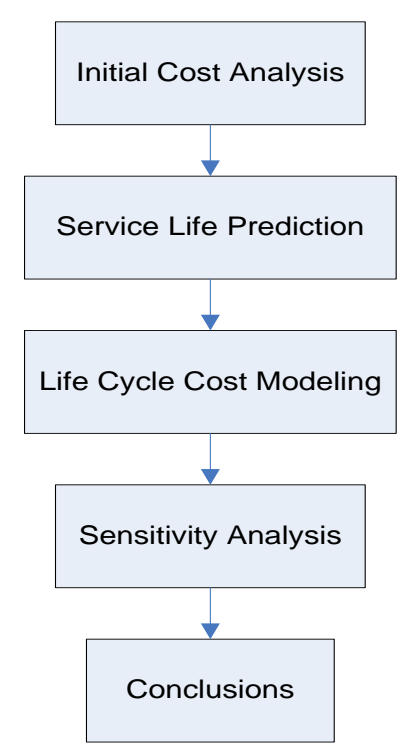

Figure 3.1 Flow Chart of Research Methodology

\subsection{Initial Cost Analysis}

Initial cost factors consist of agency initial costs and user costs during initial construction.

\subsubsection{Agency Initial Costs}

The agency initial cost for an FRP bridge deck consists of the manufacturing cost of the bridge deck, the transportation cost, the installation costs, as well as cost savings resulting from the weight reduction of the FRP bridge deck as opposed to an SRC bridge deck. The formula for bridge deck manufacturing costs as a function of the year the 
bridge deck was installed and total area footage of the bridge deck was determined using learning curve analysis. The Wright model was selected for implementation. The MidLot approach was not considered because the possible improvement doesn't commensurate the complexity of the process [80].

The concept of the learning curve was introduced to the aircraft industry in 1936 when T. P. Wright published an article in the February 1936 Journal of the Aeronautical Science. Wright described a basic theory for obtaining cost estimates based on repetitive production of airplane assemblies. Since then, learning curves (also known as progress functions) have been applied to all types of work from simple tasks to complex jobs like manufacturing a Space Shuttle.

Improvement (or learning) curve analysis is traditionally applied to discrete points. However, for this study it was applied on a cumulative basis to bridge decks. The model developed here studied the relationship between cumulative square feet of FRP bridge decks and average cost per sq ft. The approach was applied to data collected for WV pultruded FRP bridges. Hence, the equation is only valid for pultruded FRP bridges only.

Equation 3.1 describes the basis for the average cumulative curve. In this equation, $\mathrm{C}$ represents the average cost of different quantities $(\mathrm{N})$ of units.

$\mathrm{C}=\mathrm{a} * \mathrm{~N}^{\mathrm{b}}$

Where:

$\mathrm{a}=\operatorname{cost}$ for $1^{\text {st }}$ unit

$\mathrm{b}=$ exponent of learning curve

$\mathrm{C}=$ average cumulative cost of $\mathrm{X}\left(\$ / \mathrm{ft}^{2}\right)$ and 
$\mathrm{N}=$ cumulative square feet produced.

The equation was obtained by applying the Wright Improvement Model [21] for the WV bridge data (as given in Table 3.1) using an ordinary least squares model.

$\log (\mathrm{C})=\log (\mathrm{a})+\mathrm{b}^{*} \log (\mathrm{N})$

\section{2}

Table 3.1 WV FRP Bridge Deck Costs Data

\begin{tabular}{|c|c|c|c|c|c|c|c|c|c|}
\hline Bridge \# & Year & Cost/ft sq & Ft Sq & Cum ft sq & Total cost & $\begin{array}{c}\text { Cum tot } \\
\text { cost }\end{array}$ & $\begin{array}{c}\text { Average unit } \\
\text { cost }\end{array}$ & $\begin{array}{c}\text { log cum } \\
\text { ft sq }\end{array}$ & $\begin{array}{c}\text { log avg } \\
\text { unit (C) }\end{array}$ \\
\hline $\mathbf{( 1 )}$ & $\mathbf{( 2 )}$ & $\mathbf{( 3 )}$ & $\mathbf{( 4 )}$ & $\mathbf{( 5 )}$ & $\mathbf{( 6 ) = ( 3 ) \times ( 4 )}$ & $(\mathbf{7})$ & $\mathbf{( 8 ) = ( 7 ) / ( 5 )}$ & $\mathbf{( 9 )}=\log (\mathbf{5})$ & $(\mathbf{1 0})=\log (\mathbf{8})$ \\
\hline \hline & 1997 & $\$ 147.00$ & 320 & 320 & $\$ 47,040$ & $\$ 47,040$ & $\$ 147.00$ & 2.51 & 2.17 \\
2 & 1997 & $\$ 140.00$ & 651 & 971 & $\$ 91,140$ & $\$ 138,180$ & $\$ 142.31$ & 2.99 & 2.15 \\
3 & 2000 & $\$ 69.90$ & 1245 & 2,216 & $\$ 87,026$ & $\$ 225,206$ & $\$ 101.63$ & 3.35 & 2.01 \\
4 & 2002 & $\$ 55.70$ & 1100 & 3,316 & $\$ 61,270$ & $\$ 286,476$ & $\$ 86.39$ & 3.52 & 1.94 \\
5 & 2002 & $\$ 57.47$ & 780 & 4,096 & $\$ 44,827$ & $\$ 331,302$ & $\$ 80.88$ & 3.61 & 1.91 \\
6 & 2003 & $\$ 54.00$ & 1000 & 5,096 & $\$ 54,000$ & $\$ 385,302$ & $\$ 75.61$ & 3.71 & 1.88 \\
\hline
\end{tabular}

The ANOVA for the linear regression was as follow:

\begin{tabular}{lcccc}
\multicolumn{7}{l}{ ANOVA } & $d f$ & SS & MS & $F$ \\
\hline Regression & 1 & 0.07 & 0.07 & 38.29 \\
Residual & 4 & 0.01 & 0.00 & \\
Total & 5 & 0.08 & & \\
\hline \multicolumn{5}{c}{} \\
\hline Coefficients & Standard Error & t Stat & $P$-value \\
\hline Intercept & 2.86 & 0.14 & 20.54 & 0.0000332 \\
X Variable 1 & -0.26 & 0.04 & -6.19 & 0.0034670 \\
\hline
\end{tabular}

The ANOVA suggested that $a=10^{2.86}=732$ and $b=-0.26$. Hence, the average cumulative cost equation obtained for the WV bridge data set was

$\mathrm{C}\left(\$ / \mathrm{ft}^{2}\right)=732 * \mathrm{~N}^{-0.26}$ 
The equation to calculate total cumulative cost to produce $\mathrm{N}$ units was given as Equation 3.4 .

$\mathrm{Ct}=\mathrm{N}^{*}\left(\mathrm{a} * \mathrm{~N}^{\mathrm{b}}\right)=\mathrm{a} * \mathrm{~N}^{\mathrm{b}+1}$

Where

$\mathrm{Ct}=$ total cumulative cost to produce $\mathrm{N}$ units

The equation for unit cost basis, $\mathrm{Cu}$, was:

$\mathrm{Cu}\left(\$ / \mathrm{ft}^{2}\right)=\mathrm{dCt} / \mathrm{dN}=\mathrm{d}\left(\mathrm{a} * \mathrm{~N}^{\mathrm{b}+1}\right) / \mathrm{dN}=(\mathrm{b}+1) * \mathrm{a}^{*} \mathrm{~N}^{\mathrm{b}}$

$\mathrm{Cu}\left(\$ / \mathrm{ft}^{2}\right)=\mathrm{a}^{*}(\mathrm{~b}+1) * \mathrm{~N}^{\mathrm{b}}$.

Since $a=732$ and $b=-0.26$, the final equation was:

$\mathrm{Cu}\left(\$ / \mathrm{ft}^{2}\right)=540.95 * \mathrm{~N}^{-0.26}$

Where:

$\mathrm{C}=$ average cost $\left(\$ / \mathrm{ft}^{2}\right)$

$\mathrm{Cu}=$ unit cost $\left(\$ / \mathrm{ft}^{2}\right)$

$\mathrm{N}=$ the cumulative square feet of FRP bridge deck.

Overall, the model indicates that FRP bridge decks in WV will reach $\$ 45 / \mathrm{sq} \mathrm{ft}$ by 2013. This assumption is based on a continuing improvement rate of 16.5 percent over the 15 year period. Figure 3.2 shows the estimates of unit costs year to year based on this model. Furthermore, based on Equation 3-6 and the assumption that each year one FRP bridge deck with an average area of $1000 \mathrm{sq} \mathrm{ft}$ was produced, it was calculated that the unit cost of an FRP bridge deck built in 2005 would be $=$ $540.95 *((2005-1997) * 1000)^{-0.26}=52.28$ 


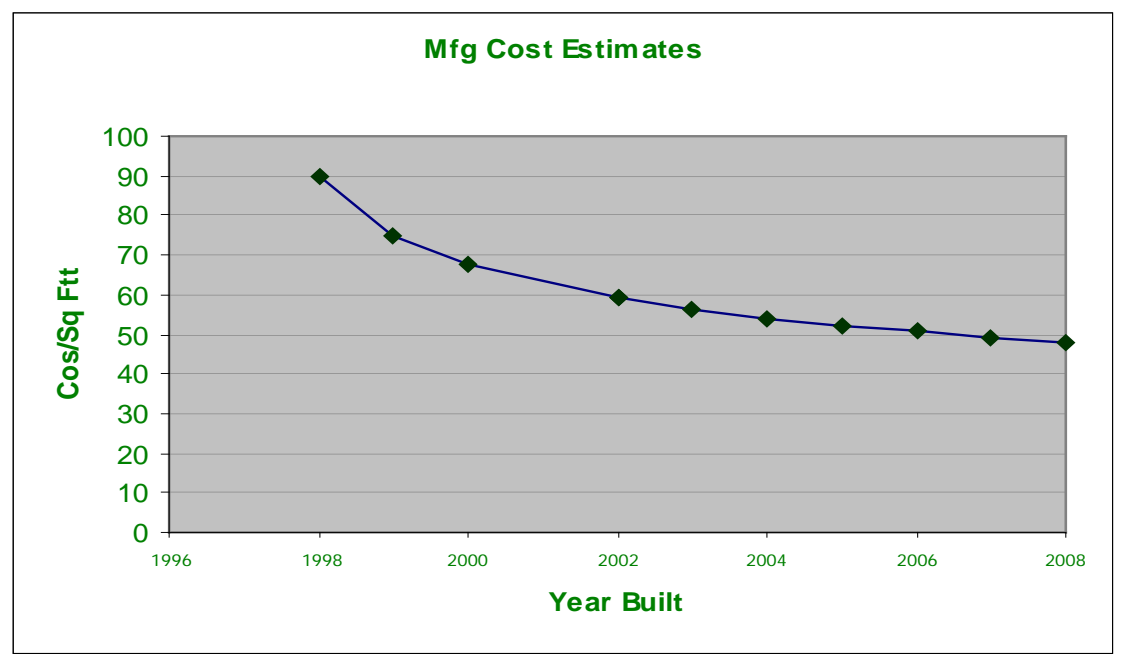

Figure 3.2 FRP Bridge Deck Manufacturing Cost Estimates

The most recent data of pultruded 8-inch FRP bridge decks with a total weight of $15.70 \mathrm{lb} / \mathrm{ft}^{2}$ obtained from Bedford Plastics for 2005 are as follows:

\begin{tabular}{|c|}
\hline Size of Bri \\
\hline Total Cost \\
\hline
\end{tabular}

Comparison of the two values suggested that the learning curve has terminated in 2005. Equation 3.6 shouldn’t be used to estimate manufacturing cost beyond year 2005. For that reason, the default value, i.e. the 2005 Bedford cost data, was applied for FRP deck projects from year 2005 forward. The above values are close to the lower limit of other FRP bridge deck manufacturing costs. As reported by Liu [52], the lower cost for current FRP decks is approximately \$65/sq ft. O’Connor [68] suggested that the cost of typical FRP decks is about $\$ 65$ - \$80/sq ft.

The transportation cost considered in this research was the total cost required to transport an FRP bridge deck from manufacturing site to project site. It was formulated as follow: 
Transportation costs $=2 * \mathrm{MD} * \mathrm{FE} * \mathrm{FC}+\mathrm{TO} *(2 * \mathrm{MD} / 40+6)$

MD = Distance between bridge deck manufacturer and project site (miles)

$\mathrm{FE}=$ Fuel efficiency of the truck (gallon/mile)

FC = Fuel cost $(\$ /$ gallon $)$

$\mathrm{TO}=$ hourly truck operating cost $(\$ / \mathrm{hr})$

Construction costs include labor costs for construction activity, which is estimated based on historical FRP bridge deck installation costs. It is basically a function of the total square foot of deck, which correlates to the number of man-days required to erect the bridge deck.

Installation costs $=$ Installation cost $/ \mathrm{sq} \mathrm{ft} *$ total square feet of bridge deck

\subsubsection{User Costs during Initial Construction}

Bridge deck installation leads to lost time for the drivers of the vehicles, higher vehicle operation costs, and increased accident rates. These costs, referred to as user costs, can be sizable depending on the total installation time as well as expected delay time. The expected delay time is a function of average daily traffic and length of the affected road work. These time figures are multiplied by the value of a user's time to obtain time costs for drivers and multiplied by vehicle operation cost per unit time to obtain increased vehicle operation cost. User costs, which take place during initial construction, include the following: (1) driver delay costs, (2) vehicle operating costs, and (3) accident costs. Third party costs are costs incurred by entities that neither are the agency nor the user. Examples of these costs are: (1) lost sales for a business establishment whose customer access is hindered by the construction project and (2) 
pollution cost due to the construction process. Third party costs are only significant for urban areas. Third party cost is not covered in this research.

The formulas used to calculate those costs are as follows [28]:

Driver delay costs $\quad=(\mathrm{RL} / \mathrm{CS}-\mathrm{RL} / \mathrm{NS}) * \mathrm{ADT} * \mathrm{~N} * \mathrm{HC}$

Vehicle operating costs $=(\mathrm{RL} / \mathrm{CS}-\mathrm{RL} / \mathrm{NS}) * \mathrm{ADT} * \mathrm{~N} * \mathrm{VC}$

Accident costs

$$
=\mathrm{RL} * \mathrm{ADT} * \mathrm{~N} *(\mathrm{CA}-\mathrm{NA}) * \mathrm{AC}
$$

Where:

$\mathrm{RL} \quad=$ length of affected roadway over which cars drive (miles)

$\mathrm{CS} \quad=$ traffic speed during bridge work activity (mph)

NS = normal traffic speed $(\mathrm{mph})$

ADT = average daily traffic

$\mathrm{N} \quad=$ number of days of road work

$\mathrm{HC}=$ hourly time value of drivers $(\$ / \mathrm{hr})$

$\mathrm{VC} \quad=$ hourly vehicle operating cost $(\$ / \mathrm{hr})$

CA = during construction, accident rate per million-vehicle-miles

NA = normal accident rates per million-vehicle-miles

$\mathrm{AC} \quad=$ cost per accident $(\$)$

\subsubsection{Cost Savings in Substructure Costs}

There are two different ways to calculate the cost savings in substructure when FRP is used for bridge decks. The difference is based on the nature of the two possible applications of FRP bridge decks: (1) building a totally new bridge or (2) bridge rehabilitation. 
For building a new bridge, one should include the cost savings in substructure costs since an FRP bridge deck is much lighter than an SRC bridge deck. The dead load resulting from an FRP bridge deck is also lower. Hence, to get the same total load capacity of the bridge, FRP bridge decks require less material or less expensive material for bridge supports.

For bridge rehabilitation projects, as demonstrated by Robert [72], who utilized an FRP bridge deck for rehabilitation of an historic bridge in Maryland, an FRP bridge deck enables an increase in the live load capacity without requiring major rehabilitation. Additionally, it is important to mention that the fast installation of the lightweight deck not only reduces the cost of direct labor associated with the installation itself, but also enables the installation to be finished faster. Fast installation was a very important factor in this case, since the bridge was on a school bus route, which could not be closed when school was in session. Hence, cost savings apart from the installation costs that should be included are: (1) the difference in rehabilitation of main structures if one is utilizing an FRP bridge deck versus an SRC bridge deck, and (2) the difference in third party costs due to differences in installation time.

The research focuses on the first possible scenario, building a new bridge. The cost savings in a new bridge should include savings due to reduced installation time and due to savings in reduced substructure costs. There are two sources of substructure cost savings when an FRP bridge deck is used:

1. Reduction of steel for bridge girders/beams/rollers required to support the bridge deck. Each pound saved in steel reduces the cost by $\$ 1.50$ for plate girders, $\$ 1.70$ for box girders, and $\$ 1.45$ for rollers [36]. 
2. Reduction of concrete required for abutments. Each cubic yard saved in substructure concrete reduces the cost by $\$ 900$ to $\$ 1,100$ [36]. The reduction in concrete for substructure was not determined in this study.

An equation is proposed that relates the size of the bridge, design, and other inputs to the amount of savings in steel and concrete when FRP bridge deck is used. The cost savings considered in this research was for the reduction of steel only in the stringers. For exterior stringers, it was assumed that the deck was simply supported on the exterior and on the adjacent interior stringer. The procedures are as follows:

1. Calculate maximum dead load moment, maximum live load moment, and total moment for exterior stringers.

2. Calculate shear due to dead load, shear due to live load, and total shear for exterior stringers.

3. Calculate bending moment due to dead load, bending moment due to live load, total moment for interior stringers.

4. Calculate shear due to dead load, shear due to live load, and total shear for interior stringers.

5. Check proposed stringer properties against the required stringer section, especially two conditions: stringer depth should be greater than the minimum depth to span ratio and section modulus should be greater than the required stringer section.

6. Check the deflection due to static load and check for stresses at various points in the cross section to determine if the stringer stresses fall under the specified allowable stresses. If not, the stringer designs may need to be modified.

7. The cost savings was obtained assuming only steel girder dimensions are changed and 
the abutment used is the same as the one for a reinforced concrete bridge. .

\subsubsection{Initial Cost Ratio Comparisons}

Beside the direct comparison between the two initial costs, these values are also used to learn the possible correlation between initial cost ratio and viability of FRP as a bridge deck alternative. For that, initial cost ratio is calculated for each bridge deck project. The initial cost ratio is defined as the ratio between (FRP initial costs substructure cost savings) and SRC initial costs.

\subsection{Service Life Prediction}

The actual service life of an FRP bridge deck is unknown and must be estimated. The ideal service life model might be obtained if actual FRP applications were monitored over a long period of time, but such data is not available. Under these circumstances, FRP bridge deck service life in this research was estimated using the factor method by employing the Delphi method. FRP experts served as the panel for this study.

The factor method was developed as a tool to support service life predictions when there is a lack of adequate or reliable data or when more detailed experimental predictions are not possible. The factor method is a way of bringing together consideration of each of the variables that are likely to affect service life. The factor method does not provide assurance of a service life; it merely gives an empirical estimate based on what information is available. It is different from a fully developed prediction of service life, which would ideally provide the reference service life for a factored estimate. That method allows an estimate of a reference service life (normally the expected service 
life in a well-defined set of in-use conditions that apply to that type of component or assembly) and a series of modifying factors that relate to the specific conditions of the case. That method is not a degradation model, but a method to transfer knowledge about service life from a known reference condition to a project specific condition.

The reference life is the time lapsed until a deteriorated stage is reached when the whole component has degraded under any one specified condition; under the circumstances of "normal” design, construction, use, maintenance, and climate exposure. The standard service life must be predicted on the basis of experience. The reference life was used to calculate the estimated service life of a component (ESLC) on the basis of adjusting the reference service life (RSLC) through the use of various in-use conditions or factors that relate to differences in the quality of the materials, workmanship, environment, and other factors that are known to alter these conditions.

To be able to implement factor methods, one estimate the reference service life (RSL) and determines (1) the important factors, (2) the reasonable span of the values of the different factors, and (3) the relative importance of the factors.

In this research, the Delphi method was utilized to carry out the three requirements mentioned above. The Delphi method allows experts to deal systematically with a complex problem or task. It comprises a series of questionnaires sent to a preselected group of experts. The outcome of a Delphi sequence is the experts' opinion. The panel viewpoint is summarized statistically rather than in terms of a majority vote. The minimum number of participants to ensure a good group performance is somewhat dependent on the study design. Experiments by Brockhoff [15] suggest that under ideal circumstances, groups as small as four can perform well. The results are as valid as the 
opinions of the experts who made up the panel. Fowles [37] describes the following ten steps for the Delphi method:

1. Formation of a team to undertake and monitor a Delphi on a given subject.

2. Selection of one or more panels to participate in the exercise. Customarily, the panelists are experts in the area to be investigated.

3. Development of the first round Delphi questionnaire.

4. Testing the questionnaire for proper wording.

5. Transmission of the first questionnaires to the panelists.

6. Analysis of the first round responses to determine the important factors.

7. Preparation of the second round questionnaire (service life predictions based on certain combinations of important factors to identify the proper multiplier for each factor).

8. Transmission of the second round questionnaire to the panelists.

9. Analysis of the second round responses (Steps 7-9 are reiterated as long as desired or necessary to achieve stability in the results).

10. Present the conclusions of the exercise.

For this research, the above steps were implemented. The objective of the first questionnaire is to determine all important factors related to FRP bridge deck service life that should be included in the estimations.

Factors that could potentially influence the performance of FRP bridge decks, the various maintenance and repair actions required, and the costs associated with these actions have been studied from historical data. Factors can be grouped under three major categories: factors associated with the inherent quality of the bridge deck, load 
conditions, and environmental conditions. The important factors, especially the ones associated with environmental conditions, may be different for each region. Hence, for this case study, only those factors corresponding to possible conditions that can be found in West Virginia are included in the analysis.

Knowing that service performance and long term durability of FRP decks is sensitive to factors such as manufacturing and fabrication standards, light and UV radiation, heat, moisture, and impact, these factors are considered for FRP bridge deck service life estimation. Three of the most current in-service performance evaluations of FRP have concluded that the long-term health of a deck is a factor of both the constituent material and the physical and environmental conditions [62]. The possible factors are summarized as follows.

\section{A. Factors Associated with the Inherent Quality of a Bridge Deck:}

1. Type of fibers used

2. Manufacturing process

3. Bridge deck design

4. Type and thickness of wearing surface applied

\section{B. Factors Associated with Environmental Conditions:}

5. Alkali content

6. Average humidity of the region

7. Light and UV exposure

8. Number of freeze-thaw cycles

C. Factors Associated with Operation/Maintenance:

9. Average daily traffic 
10. Frequency of scheduled maintenance

The first questionnaire is in Appendix 1. The experts who participated in this research are:

1. Dr. Hota GangaRao (Academia/WVU)

2. Ms. Vimala Shekar (Academia/WVU)

3. Dr. Sreenivas Alampalli (Practitioner/NYDOT)

4. Dr. Roberto Lopez-Anido (Academia/University of Maine)

5. Dr. Jerome O 'Connor (Practitioner/FHWA)

6. Dr. Arthur P. Yannoti (Practitioner/NYDOT)

7. Dr. T. Hong (Academia/Seoul University, Korea)

8. Dr. Aboutaha (Academia/Syracuse University)

9. Dr. A. Zureick (Academia/Georgia Tech Institute)

10 Mr. Mansour Mohseni (Practitioner/CODOT)

11. Mr. Jack Justice (Practitioner/FHWA)

12. Mr. Benjamin Tang (Practitioner/FHWA)

13. Mr. Scott Reeve (Manufacturer)

14. Mr. Doug Glemel (Manufacturer)

The results of the first questionnaire are presented in Table 3.2. The experts, who comprised academia, practitioners, and manufacturer representatives, suggested that type of fiber and resin, as well as manufacturing process used, have significant influence on the quality of a bridge deck and ultimately influence the service life. Their suggestions are supported by WV FRP bridge deck inspection reports: Pultruded bridge deck seems to perform better than other types. From the five environmental factors that may affect 
an FRP bridge deck's service life; they agreed that the two most important factors were wearing surface application and freeze-thaw cycles. Freeze-thaw severity has direct correlation with climate regions. Aside from those factors, they suggested that average daily traffic is an important factor in estimating FRP deck service life, which is also included in the original list of possible influence factors.

Based on these findings, the service life prediction was modified, and the second questionnaire was revised accordingly and distributed to gather expert opinions about (1) their estimates of FRP bridge deck service life under a certain set of conditions involving the above factors (RLSC), (2) estimates of service life, given certain conditions, to determine a span of the values for the different factors and the relative importance of the factors. The second questionnaire is given in Appendix 2.

Table 3.2 Factors affecting FRP deck service life and their importance based on survey

\begin{tabular}{|l|ccc|ccc|ccc|}
\hline FACTOR/ EXPERT \# & MIN & MAX & AVG & MIN & MAX & AVG & MIN & MAX & AVG \\
\hline \hline Type of fiber and resin & 4 & 5 & $\mathbf{4 . 8 3}$ & 4 & 5 & $\mathbf{4 . 4 0}$ & 4 & 4 & $\mathbf{4}$ \\
Manufacturing process & 4 & 5 & $\mathbf{4 . 3 3}$ & 4 & 5 & $\mathbf{4 . 6 0}$ & 5 & 5 & $\mathbf{5}$ \\
Design & 3 & 5 & $\mathbf{4 . 3 3}$ & 4 & 5 & $\mathbf{4 . 2 0}$ & 3 & 4 & $\mathbf{3 . 5}$ \\
Wearing Surface & 2 & 5 & $\mathbf{3 . 6 7}$ & 3 & 5 & $\mathbf{4 . 4 0}$ & 5 & 5 & $\mathbf{5}$ \\
\hline Humidity & 2 & 5 & 3.17 & 2 & 4 & 2.60 & 2 & 2 & 2 \\
Light and UV exposure & 2 & 4 & 3.17 & 2 & 4 & 2.60 & 2 & 4 & 3 \\
Alkali content & 1 & 4 & 2.67 & 1 & 4 & 2.20 & 1 & 1 & 1 \\
Freeze-thaw cycles & 2 & 5 & $\mathbf{3 . 1 7}$ & 3 & 5 & $\mathbf{3 . 6 0}$ & 2 & 4 & $\mathbf{3}$ \\
\hline EXPERT TYPE & \multicolumn{3}{c}{ Academian } & \multicolumn{3}{c}{ Practitioner } & \multicolumn{3}{c}{ Manufacturer }
\end{tabular}

FRP reference service life is 70 years, based on the second questionnaire. The value is somewhat similar to the average of expectation values among FRP experts. The estimates of service life of FRP bridge decks are 75 years (O’Connor, 2005 [68]; MMC Inc.), 60 years [64], and 75 years [48] based on an INDOT survey (which was sent to 
bridge engineers of each state DOT). The average service life of an SRC bridge deck is 25 to 50 years.

1. Among the three factors, i.e., freeze thaw cycles, wearing surface, and average daily traffic (ADT), the two experts that responded to the second questionnaire suggested that wearing surface is the most important factor to FRP service life, followed by freeze-thaw cycles and ADT. Some other experts responded to the survey with comments only, mainly because they felt that they did not have enough experience with FRP bridge deck projects to be able to answer the questions. The two experts did share similar estimations of FRP service life under different conditions as depicted in Table 3.3. Based on the answers, the multipliers for each factor were determined. The values are given in Table 3.4.

Table 3.3 Results of the Second Questionnaire

\begin{tabular}{|c|c|c|c|c|c|c|c|c|}
\hline $\begin{array}{l}\text { Freeze Thaw } \\
\text { Cycle }\end{array}$ & \multicolumn{2}{|l|}{ MILD } & \multicolumn{2}{|c|}{ MODERATE } & \multicolumn{2}{|l|}{ |MILD } & \multicolumn{2}{|l|}{ MILD } \\
\hline ADT & \multicolumn{2}{|c|}{$5,000-10,000$} & \multicolumn{2}{|c|}{$5,000-10,000$} & \multicolumn{2}{|c|}{$5,000-10,000$} & \multicolumn{2}{|c|}{$20,000-30,000$} \\
\hline Wearing Surface & \multicolumn{2}{|c|}{ POLYMER CONCRETE } & \multicolumn{2}{|c|}{ POLYMER CONCRETE } & \multicolumn{2}{|c|}{ CONVENTIONAL ASPHALT } & \multicolumn{2}{|c|}{ CONVENTIONAL ASPHALT } \\
\hline & $\overline{1}$ & 2 & 1 & 2 & $\overline{1}$ & $\overline{2}$ & $\overline{1}$ & 2 \\
\hline MIN & 60 & 62 & 50 & 54 & 50 & 50 & 50 & 45 \\
\hline EXP & 70 & 70 & 60 & 60 & 50 & 52 & 50 & 50 \\
\hline MAX & 80 & 74 & 70 & 64 & 60 & 60 & 60 & 56 \\
\hline
\end{tabular}

Table 3.4 Multipliers for Each Factor

\begin{tabular}{|c|c|c|c|}
\hline & Low & Medium & High \\
\hline ADT & 1 & 0.99 & 0.98 \\
\hline & $\begin{array}{c}\text { Polymer } \\
\text { Concrete }\end{array}$ & Asphalt & Other \\
\hline Wearing surface & 1 & 0.73 & 0.8 \\
\hline \multicolumn{4}{|c|}{} \\
\hline Freeze thaw cycle & 1 & 0.86 & 0.82 \\
\hline
\end{tabular}




\subsection{Life-cycle Cost Modeling}

Life cycle cost involves looking at the cost of a system in each phase of its life cycle. Figure 3.3 depicts the life cycle phases of the bridge deck for this study.

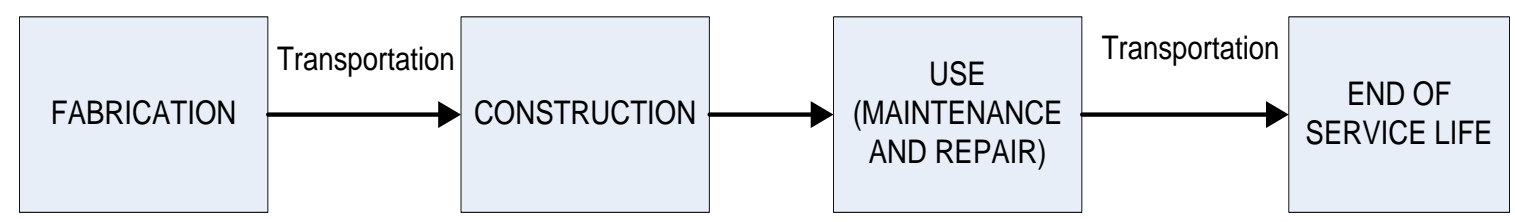

Figure 3.3 Bridge Deck Life Cycle Phases

The four main bridge deck construction activities used in this study are as follows:

1. Deck installation

2. Deck inspection and repair

3. Deck overlay replacement

4. Deck replacement

The key difference between the two systems is that the FRP deck is expected to extend the life of the bridge deck from 30 years to $x$ years, the estimated FRP service life. For the following explanation, $\mathrm{x}$ is assumed to be 60 years.

Once the main phases of life-cycle cost are identified, further cost breakdown needs to be determined to enable model implementation. In this study, costs are tallied for each of the life-cycle stages, converted into present-day dollars, and compared between the two systems. Life-cycle costs were separated into agency and user costs. Agency costs focus on those expenses directly incurred by government agencies. These 
include direct costs related to material production, construction, and end of life. Information about the bridge deck and construction process that served as the model parameters are collected from WVDOT and its bridge engineers, as well as from FRP bridge deck manufacturers, and from DMJM Harris, Inc. for the SRC bridge deck. This includes data on the composition of SRC and FRP bridge decks, quantity of material needed, labor, material and equipment cost data, and construction activity schedules. User costs include construction-related traffic crashes, extra vehicle operating costs, and user delay costs.

Once these figures are determined, an appropriate discount rate is applied to compute the present-day dollar equivalents of all costs incurred.

PV of $\mathrm{LCC}=\Sigma\left(\mathrm{C}_{\mathrm{t}} /(1+\mathrm{i})^{\mathrm{t}}\right)$

where $\mathrm{i}=$ the real discount rate for converting time $\mathrm{t}$ costs

Present values are determined for each stage of the life cycle and for each construction activity within each system. The U.S. federal government recommends using a three to five percent discount rate for long-term construction projects. The projects in this study assumed a three percent discount rate.

The following assumptions were used for the analysis:

(1) Expected service life of an SRC bridge deck is 30 years (WVDOT standard).

(2) Expected service life of an FRP bridge deck is 60 years (based on service life prediction), so the LCC study period is set at 60 years.

(3) Standard inspection for an SRC bridge deck: every two years (WVDOT standards).

(4) Supplemental inspection for SRC bridge decks: every 6 years (WVDOT standards).

(5) Anticipated Repairs: every three years starting on the 20th year (WVDOT). 


\subsection{Sensitivity Analysis}

A sensitivity analysis is conducted based on one or more other important parameter values that may change over time. Chandler (2004) [19] suggested that ADT assumptions had a major effect on life-cycle costs. Examining ADT is important because the most important failure mode is delamination, which is affected significantly by ADT. Expected service life and repair schedules were analyzed since they involve so much uncertainty. Hence, these three parameters were investigated for sensitivity analysis.

\subsection{Base Case and Case Studies}

Typically, a bridge deck is made using steel-reinforced concrete. Large slabs of concrete meet at the joint just above the support piers, where a steel expansion joint is placed. In the case of an FRP bridge deck, it was assumed that the deck was manufactured using the pultrusion process. Hence, the specifications, as well as the cost information, are based on the most recent data obtained from a pultrusion company.

Reader Run Bridge on WV Route 20 over Reader Run was used as the base case scenario. The bridge is 55 feet in length and 43 feet in width. Abutments are made of full, high-reinforced concrete. The designs, along with the cost information for this bridge, were obtained from DMJM Harris Inc., Morgantown, WV. The bridge deck was replaced in 2005. For that reason, all cost information is translated to reflect 2005 values. Reader Run Bridge maintained a traffic flow of 2,900 cars per day in each direction in 2002 and was predicted to have a traffic flow of 3,800 cars per day in each direction in 2023. In this analysis, it was assumed that the rate remains constant throughout the useful life of the bridge deck, i.e., 3,800 cars per day. ADT changes year 
after year are beyond the scope of this research. However, the effect of ADT on the lifecycle cost is examined in the sensitivity analysis. The proportion of cars, trucks, and other vehicles comprising the traffic flow is based on national average data.

The three case study bridges were Goat Farm Bridge, La Chein Bridge, and Katy Truss Bridge. Goat Farm Bridge is on County Route 21, in Jackson County, WV. It is 39 feet in length and 15 feet in width and had an ADT of 20. The FRP bridge deck was constructed in 2003. La Chein Bridge is on County Road 12 in Monroe County, WV. The 32.5 foot long and 24.3 foot wide La Chein Bridge was constructed in 2001 with ADT of 100 vehicles per day. The Katy Truss Bridge is located in Marion County, WV. This bridge had an ADT of 700, was 91.3 feet in length and 14.3 feet in width, and was constructed in 2000.

The analysis includes initial construction costs for the steel-reinforced concrete bridge, initial cost analysis for FRP bridge decks, and the weight reduction of the substructure. The bridge decks for both systems were replaced at the start of the analysis and will degrade over the study period.

\subsection{Summary}

This chapter examined the scope of the dissertation by explaining the flow chart of research methodology and describing how each step was performed. It described how service life estimation and FRP manufacturing estimation formulas were derived. It also defined the case studies, as well as the base case scenarios, that were used throughout the rest of the dissertation for the comparison and evaluation of FRP deck life-cycle cost versus SRC deck life-cycle cost. 


\section{Chapter 4}

\section{FRP Bridge Deck Life-cycle Cost Model}

\subsection{Life-cycle Cost Breakdown}

After an extensive literature review of life-cycle cost analysis, it was concluded that the life-cycle cost of FRP bridge decks should include initial costs, maintenance, inspection and repair costs, and disposal costs.

\subsubsection{Initial Costs}

Initial costs include manufacturing cost (as a function of raw material specifications, design, and manufacturing process parameters, labor cost, and overhead costs), transportation cost, installation cost (includes surface preparation, installation, curing, and finishing costs), safety costs (costs to assure safety during the installment process) and user costs. The user costs to drivers during construction are the sum of driver delay costs, vehicle operating costs, and costs due to the increased incidence of car accidents.

\subsubsection{Maintenance, Inspection, and Repair Costs}

Maintenance costs include material, equipment, labor, and safety costs during the maintenance process (traffic control), along with bridge user costs. These costs depend on the frequency and amount of maintenance performed during the life-cycle. The

maintenance costs included in the model are basic inspection costs, supplemental inspection costs, anticipated repair costs, and deck overlay or deck replacement costs.

Inspection costs include the cost of the quality assurance procedures, testing, and 
record maintenance. Repair costs are similar to maintenance costs, but are done for major items (such as deck replacement) and not on a regular basis.

\subsubsection{Disposal Costs}

The costs include deconstruction costs, safety costs, transportation costs, landfill fee costs, and user costs. The framework of life-cycle cost is depicted in Figures 4.1 and 4.2.

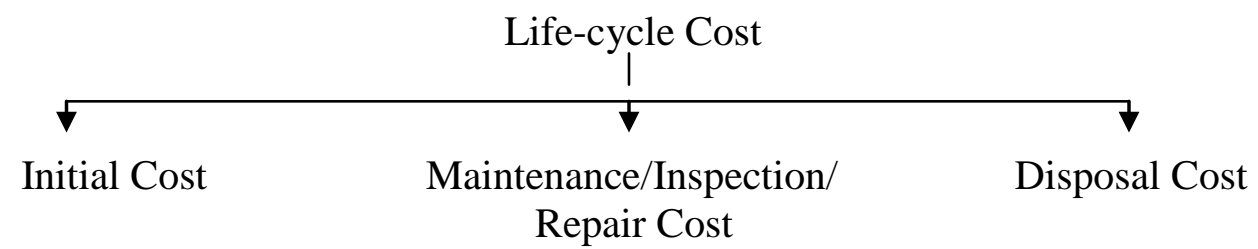

Figure 4.1 Components of Life-Cycle Cost for FRP Bridge Deck

\subsection{Life Cycle Model Analyzer}

A computer program, Life-Cycle Cost Analyzer, was developed for FRP bridge deck cost analysis using Excel ${ }^{\circledR}$ and Visual Basic language. A comparison between FRP bridge decks and steel reinforced concrete (SRC) bridge decks was done based on net present values of costs over the structure life. Future costs in this study are expressed in real dollars and converted to present values using discount rate of three percent. 

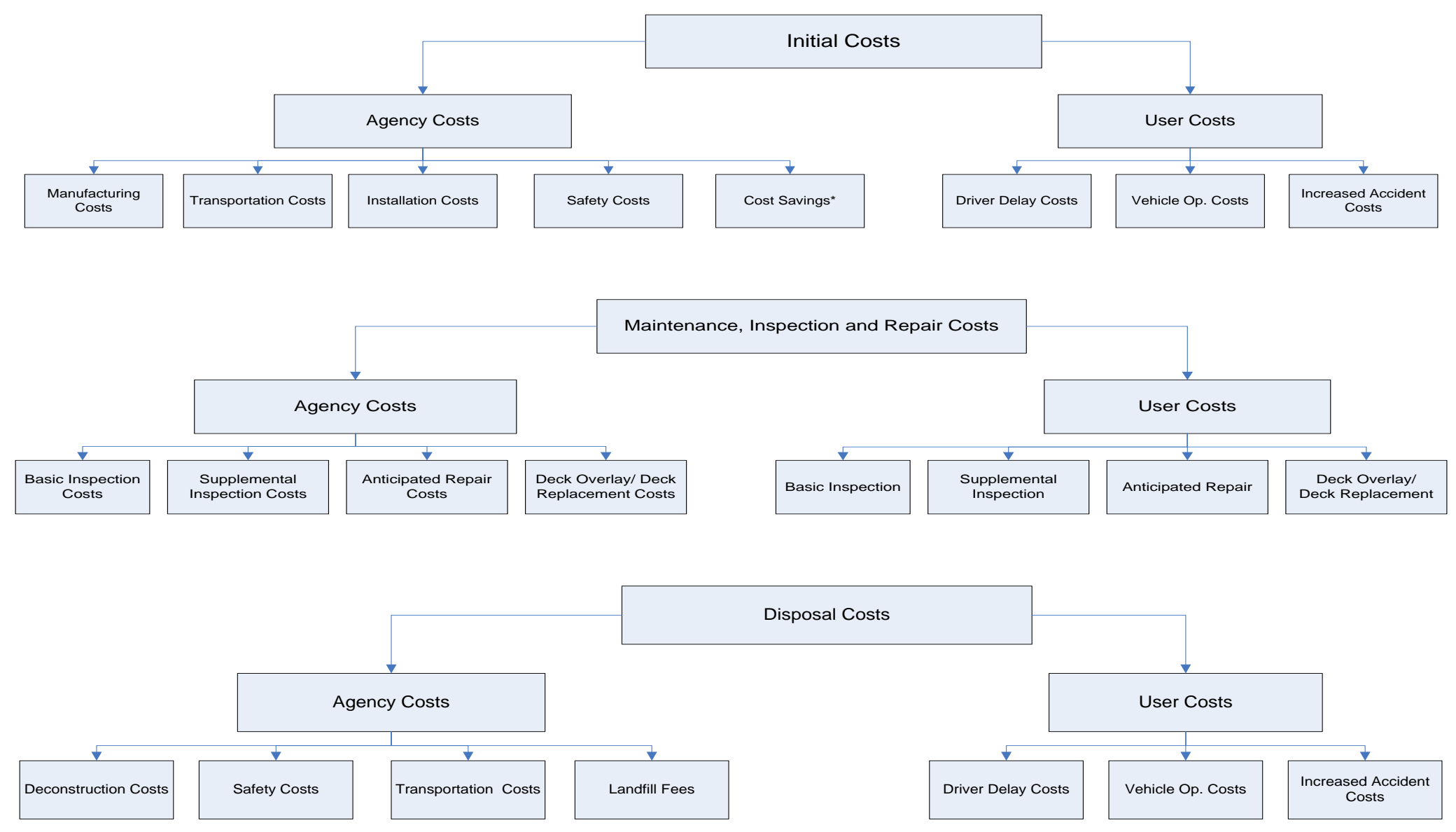

Figure 4.2 Life-cycle Cost Breakdown for FRP Bridge Deck Cost Components 
The Life-cycle Cost Analyzer determines the net present values of costs of the bridge deck alternatives during the study period as well as the equivalent annual cost. The equivalent annual cost or annuity method was chosen as it can be applied for any combination of service life, A and B. This approach was performed by determining a fixed study period based on the life of the girders and abutments. For medium bridges, the study period can range from 50 to 70 years, while for large bridges the study period is 100 years. Based on the given study period, the life-cycle cost of the two bridge decks are calculated and compared. In the program, the study period sets equal to FRP service life. The model is depicted in Figure 4.3.

There are 25 input values for Life-cycle Cost Analyzer (as given in Table 4.3) and the outputs of this program include: (1) total initial cost, (2) total maintenance cost, and (3) total disposal costs, as well as the cost breakdowns. The screen shot of the input is given in Figure 4.4.

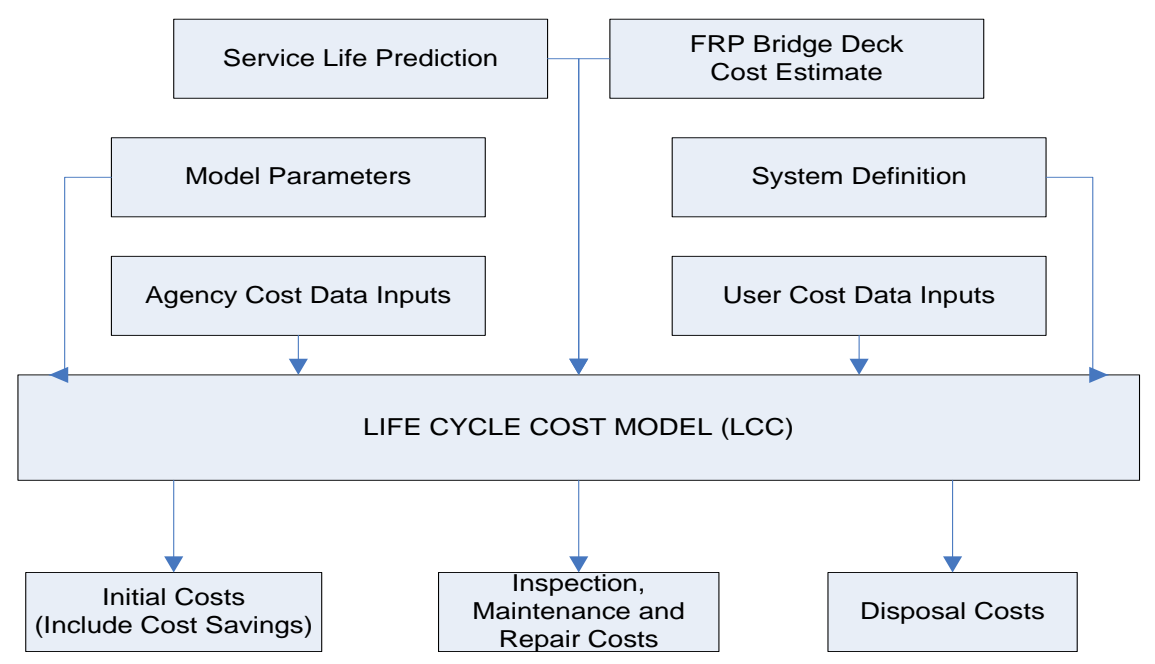

Figure 4.3 Life-cycle Cost Model 
Table 4.1 Life-cycle Cost Model Data Input Items

\begin{tabular}{|c|c|c|c|}
\hline Item & Description & Symbol & Units \\
\hline (1) & Length of bridge deck & $\mathrm{DL}$ & $\mathrm{ft}$ \\
\hline (2) & Width of bridge deck & DW & $\mathrm{ft}$ \\
\hline (3) & Project site & & \\
\hline (4) & FRP manufacturer & & \\
\hline (5) & Thickness of FRP bridge deck & DT & inch \\
\hline (6) & Self weight of FRP bridge deck & DS & $\mathrm{lb} / \mathrm{ft}^{2}$ \\
\hline (7) & Thickness of SRC bridge deck & DTC & inch \\
\hline (8) & Self weight of SRC bridge deck & DSC & $\mathrm{lb} / \mathrm{ft}^{2}$ \\
\hline (9) & SRC bridge deck cost & CC & $\$ / \mathrm{ft}^{2}$ \\
\hline (10) & Year of installation & YR & years \\
\hline (11) & Normal traffic speed & NS & miles/hour \\
\hline (12) & Traffic speed during bridge deck construction & CS & miles/hour \\
\hline (13) & Hourly time of driver & $\mathrm{HC}$ & $\$ / \mathrm{hr}$ \\
\hline (14) & Hourly vehicle operating cost & VC & $\$ / \mathrm{hr}$ \\
\hline (15) & Normal accident rate & NA & \#/vehicle-mile \\
\hline (16) & Accident rate during bridge work & CA & \#/vehicle-mile \\
\hline (17) & Average cost per accident & $\mathrm{AC}$ & \$/accident \\
\hline (18) & Self weight of wearing surface & WS & $\mathrm{lb} / \mathrm{ft}^{2}$ \\
\hline (19) & Type of wearing surface & WST & \\
\hline (20) & Labor cost & $\mathrm{LC}$ & $\$ / h r$ \\
\hline (21) & Average Daily Traffic & ADT & vehicles/day \\
\hline (22) & Freeze-thaw cycles & FTC & \\
\hline (23) & Discount rate & DR & $\%$ \\
\hline (24) & Study Period & SP & years \\
\hline (25) & Reference service life & RSL & years \\
\hline
\end{tabular}

\subsubsection{Service Life Module}

Service life prediction based on the factor method is used to estimate service life of FRP decks. Expert opinion is applied to determine the multipliers for each factor, i.e., $\mathrm{A}, \mathrm{B}, \mathrm{C}$ in the following equation:

Expected service life $=\mathrm{RSL} * \mathrm{~A} * \mathrm{~B} * \mathrm{C}$

The multiplier for the three factors, i.e., ADT, wearing surface and freeze/thaw cycle are depicted in Table 3.4. The expected service life of an FRP deck with low ADT, polymer concrete overlay, and medium freeze-thaw cycle, for example, is 70 years * $1 * 1 * 0.86$ $=60$ years . 
BRIDGE GEOUETRY

Span of Bridge

cut to out Brioge Wath

Number of Span

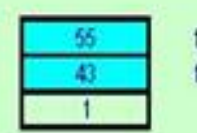

TRAFFC AHO ACCDEIT IIFORMATIOI

Aerage Dality Trafic ( $=$ ADD)

Normal Traffes Speed

Nomal Accisent Rate

Trafic Speed during Construction

Acodert Rate during Constructon

Aserage Cost per Accisent.

Hourty vehicle Opersting Cost

Houty Time Value of Criver

LETAIL OF STEEL STRIIGER FOR FRP BRIDGE DECK

\begin{tabular}{|c|c|c|c|}
\hline & OK & Design Check & \\
\hline Stringer Froperties (Choses ) & 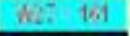 & & \\
\hline \multicolumn{4}{|l|}{ Number of Stringers } \\
\hline Spacing of Stringers & 7 & $t$ & 2 \\
\hline Cooss Sectional Area & 47.4 & in ${ }^{2}$ & \\
\hline Plange with & 14,02 & in & \\
\hline Web Mickness & 0.68 & n & \\
\hline Stinger Degth & 2759 & in & \\
\hline Mbment of herta & 6280 & in ${ }^{\prime}$ & \\
\hline Stringer Weight & 0.161 & kt & \\
\hline Section toduluss & 455 & in ${ }^{2}$ & \\
\hline Young's Modulus of Easticty & $290 \mathrm{E}+07$ & DSi & \\
\hline LETAIL OF STEEL STRUIGER FOR COICRE & $\begin{array}{l}\text { EOECK } \\
\text { OK }\end{array}$ & Design Check & \\
\hline Stringer froperties for Concret (Chose) & $\frac{1}{42}=18$ & & \\
\hline Stinger cost & 1.45 & $S \mathrm{~s} b$ & \\
\hline
\end{tabular}

\section{INPUT PARAMEIERS}

DETRIL OF FRP DECK

If the Bnibge Ded is Buit (choose)

Thidness of Deck

Self weight of Deck

Cost of Deck

Manubadurer

CETAIL OF WEARIIG SURFACE

Mattertal

Weight

Wearng Surace cost

FRP DECK IISTLLUTION

tabor cost per hour

CASCOUIT ANO HIFLATIOHRATES ascourt Rate

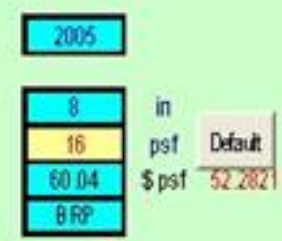

DETAL OF COHCRETE DECK

Thichness of Deck

Self veight of Deos

oss of Deck

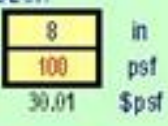

PROJECT SITE

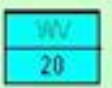

courry

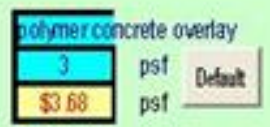

$\$ 12.44$

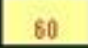

TUDY PERIOD

EF SERVICE LIFE

set=sernice life FRP

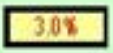

EIMROIMEITAL COHOTIOHS Freere Thav Cycles

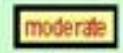

OVERALL TRAFFV:

ADT

medium

OTHER COST IIIFO

Gasolne

Landfill

Federal Mnimum Wage

nspection cost

h Depth inspection Cost

Repair Cost

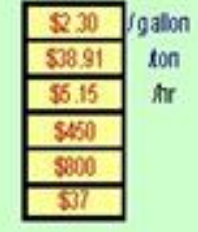

20 yss

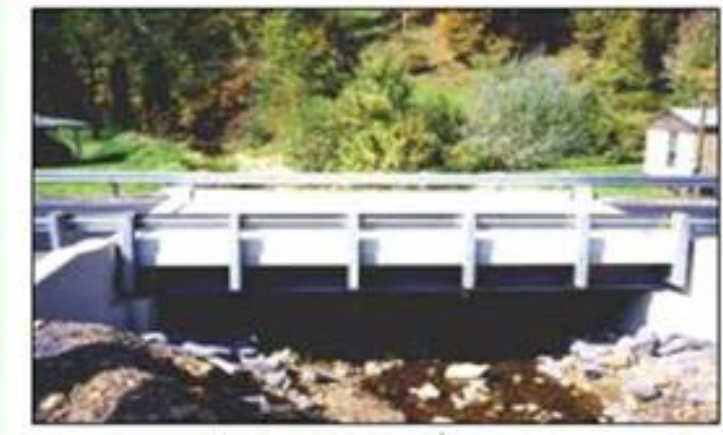

Mairtenance inputs

Figure 4.4 Screen Shot of the Input Screen 


\subsubsection{Initial Cost Module}

The outputs of this module include total initial cost as well as the cost breakdown. The itemized costs include the following:

(1) Agency costs

For an FRP bridge deck, agency initial costs include manufacturing, transportation, installation, and safety costs as follows:

(a) Manufacturing cost

Manufacturing cost per sq $\mathrm{ft}$ is determined based on the learning curve equation as given in the previous studies [80]. However, since it's suggested that the wearing surface was also installed by the same manufacturer, the equation was revisited and revised. Instead of estimating for bridge deck cost only, it includes the bridge deck and initial wearing surface costs. The detailed study was presented in the previous chapter. The formula for manufacturing cost of FRP bridge deck per square foot used for the program is a function of the year the bridge deck is manufactured and total square footage of bridge deck area, i.e.,

$540.95 *\left((\text { year of mfg-1997)*1000) })^{-0.26}\right.$

The default value for a pultruded FRP bridge deck manufactured on or after 2005 was set based on Bedford data. It decreases as the area increases as indicated by the data, i.e.,

$\mathrm{FDC}=115.57 * \mathrm{DA}^{-0.0843}$

(b) Transportation Cost

Transportation cost is a function of distance (between project location and FRP manufacturer).

Transportation costs $=2 * \mathrm{MD} * \mathrm{FE} * \mathrm{FC}+\mathrm{TO} *(2 * \mathrm{MD} / 40+6)$ 
MD = Distance between FRP manufacturer and project site (miles)

$\mathrm{FE}=$ Fuel efficiency of truck (gallon/mile)

$\mathrm{FC}=$ Fuel cost $(\$ /$ gallon$)$

TO = Hourly truck operating cost $(\$ / h r)$

(c) Installation cost

In-service WV FRP bridge decks took between four and ten man-days to install. Hard Core composite decks need two- to four-man crews to install the deck, while installing a MMC deck needs at least a six-person crew. Installation cost per sq $\mathrm{ft}$ is a function of total footage square of the bridge deck, which historically is about $\$ 1.25-\$ 1.50 /$ sq $\mathrm{ft}$ for FRP deck. Based on WV FRP bridge deck installation data, it is estimated that the number of man-days required for installation equals the total square feet/100 for a bridge with total square footage less than 1,000. For bigger bridges, the number of man-days required equals to total square feet/125.

(d) Safety cost

The safety costs considered in the study are only those related to warning signage costs. The total value is a function of number of workers, hourly worker cost and length of the installation process.

(e) Substructure cost reductions when FRP is used

The savings considered in this module were from the reduced weight of the steel girders used in FRP bridge deck construction as compared to the girders used for SRC bridge deck construction. The average stringer cost is \$1.46/lb (2005 value) and estimated installation cost reduction is $\$ 1 / \mathrm{lb}$.

Substructure cost reduction $=$ (total weight of SRC deck steel stringers - total weight of 
FRP deck steel stringers) * (stringer cost/lb + installation cost reduction due to reduced weight)

For SRC bridge deck, agency initial costs include material, transportation, installation, and safety costs as follows:

(a) Material costs

Material costs of an SRC bridge deck are typically quoted in terms of square feet to be built. Hence, data inputs were collected and translated into square feet. Total square footage of bridge $=($ length of bridge $) *($ width of bridge $)$. Material costs were calculated by multiplying this square footage figure by the cost per square foot, i.e., (total sq. $\mathrm{ft}$. of bridge) * (material cost per sq. ft.). The default value of SRC material per sq $\mathrm{ft}$ used in the model is $\$ 30$ (a 2005 value).

(b) Transportation costs

Transportation cost is a function of distance (between project location and concrete manufacturer) as given in Equation 4.4.

(c) Installation costs

Multiplication of the square footage of the bridge and the labor cost per square foot results in the total labor cost of the SRC deck replacement. Labor cost of deck replacement $=($ total sq. ft. of bridge $) *($ labor cost per sq. ft.). Total installation cost of SRC deck is about six to seven percent of deck cost [53]. Hong [45] suggested the average deck and installation cost is \$35 per sq $\mathrm{ft}$. The default value of SRC installation cost per sq ft used in the model is seven percent of deck cost. 


\section{(2) User Costs}

User costs occur during the installation process for either SRC or FRP bridge decks and include three components: driver delay costs, vehicle operating costs, and costs due to the increased incidence of car accidents. The cost equations used to estimate the personal cost to drivers who are delayed by roadwork (user delay costs) and the vehicle operating costs are given in Equation 3.10 and 3.11. The values of each parameter used in the model are as follows:

$\mathrm{RL} \quad=1$ mile for construction, repair, and disposal and 0.5 mile for inspections

$\mathrm{CS} \quad=45 \mathrm{mph}$ for county, US, and WV roads

NS $\quad=55 \mathrm{mph}$ for county, US and WV roads

$\mathrm{ADT}=26,000$ for Interstate routes, 7,000 for US routes, 3,800 for WV routes and 300 for County routes

$\mathrm{HC} \quad=15.85(\$ / \mathrm{hr})$

$\mathrm{VC}=9.52(\$ / \mathrm{hr})$

$\mathrm{CA}=0.463$ (per million-vehicle-miles)

NA $=0.268$ (per million-vehicle-miles) [29]

$\mathrm{AC} \quad=\$ 32,911$

$\mathrm{N} \quad=20$ for SRC deck $<50 \mathrm{ft}$ span, 25 for deck span between $50 \mathrm{ft}$ and $150 \mathrm{ft}$, and 35 for deck spans $>150 \mathrm{ft}$ [53]. For FRP bridge decks, this value is determined based on empirical formula as a function of deck total square feet

The derivation of hourly time value of drivers, work zone accident rate, and average accident cost used in the model are explained based on FHWA (1998 values) as follows: A passenger car's driver $=\$ 11.58 / \mathrm{hr}$ 
A single unit truck's driver $=\$ 18.54 / \mathrm{hr}$

A combination unit truck's driver $=\$ 22.31 / \mathrm{hr}$.

The above 1996 data were updated to reflect 2005 dollar values, the base year for the analysis, using the consumer price index (CPI). For updating the values to future dollar values, the inflation is defined as the ratio between CPI for the current year and the CPI for the year when data was obtained. The CPI is the best measure to use for translating hourly or weekly earnings into real or inflation-free dollars [16]. CPI values for 20032006 are 184.0, 188.9, 195.3, and 200.6 respectively [16]. The updated values are as follows:

A passenger car’s driver $\quad=\$ 11.58 / \mathrm{hr} *$ CPI 2005/CPI 1996

$$
=\$ 11.58 / \mathrm{hr} * 195.3 / 156.9=\$ 14.41 / \mathrm{hr}
$$

A single unit truck’s driver $\quad=\$ 23.08 / \mathrm{hr}$

A combination unit truck's driver $=\$ 27.77 / \mathrm{hr}$

Based on the mix of different cars in the U.S., the value of the driver averages $\$ 15.85 / \mathrm{hr}$.

Roadway construction data across the state of West Virginia showed an average of about 1,000 construction-related traffic crashes each year. There were 51,376 crashes, and 888 of them were construction-related crashes. Given that an average work zone is one mile in length and that bridge deck projects statewide represent one percent of roadways under construction annually, translates into 1,917,397,400 annual vehicle miles traveled in a work zone. Since the number of work zone crashes in WV was 888, the accident rate equals 0.463 crashes per million vehicle miles traveled. Normal accident rates per million vehicle miles averaged approximately 0.268 [29]. For work zone crashes, 0.45 percent were fatal injury crashes, 4.17 percent were type A injury crashes, 
2.59 percent were type B injury crashes, 11.04 percent were type $\mathrm{C}$ injury crashes, and the remaining 81.76 percent were property damage only crashes. Cost per accident on average was $\$ 31,000$ [97]. In the model, this 2003 data was updated to reflect 2005 dollar values using the consumer price index (CPI) to \$32,911. Unlike the 21 construction days needed for a typical SRC deck system, the FRP bridge deck requires less than 10 construction days. Thus, the FRP bridge deck system can expect 50 percent or lower of the number of crashes of an SRC bridge deck.

\subsubsection{Maintenance/Inspection/Repair Module}

For FRP bridge decks, Ehlen [27] limits these costs to include those cost necessary to prevent ultraviolet radiation and moisture from shortening the deck's life span to less than 40 years, to repair the spalling of the polymer-concrete road surface, and for two yearly inspections (it is defined as visual inspection for flaked paint and excessive moisture and mechanical wearing, which takes 28 labor-hours per inspection). A detailed supplementary inspection takes place after 25 years based on NCDOT and six years based on WVDOT.

The SRC deck inspection schedule was based on the WVDOT bridge deck inspection manual, in which it states: (1) Basic inspections are conducted every two years; (2) Supplemental inspections are performed every six years. Estimated repairs are based on current practice, which is expected every three years beginning at the $20^{\text {th }}$ year.

An FRP bridge deck goes through a number of maintenance, repair, and rehabilitation actions throughout its lifetime. The actions enhance the deck performance. The level of enhancement depends on the type and extent of the maintenance, repair, and 
rehabilitation (MRR) actions, as well as the point on the life cycle performance curve at which the structure receives the MRR action [43]. Currently, there is no existing model that can predict the deterioration of the FRP bridge deck to ascertain the point in time during the life cycle of the bridge when it would require maintenance or repair. Several articles that consider FRP bridge deck life-cycle costs assume a set of maintenance and repair schedules that are generally adapted from those for SRC decks.

Currently, FRP bridge decks have approximately 10 years worth of maintenance history. Bridge engineers have no experience to predict what might happen in the near future, except with respect to the possibility of wearing surface cracks. Applications of a deterioration model are not possible due to short historical usage of FRP for bridge deck applications as well as the scarcity of the historical maintenance data. For that reason, the inspection and anticipated repair schedules applied in this program are similar to those applied by Lopez-Anido [53].

The current WV FRP bridge deck inspection schedule follows the same schedule as the one for SRC bridge decks, which also serves as the default in this study. To minimize the subjectivity of the results, the sensitivity of the schedules was examined. A modified schedule based on expert opinions was applied. It basically followed the expert estimations that FRP bridge decks need fewer inspections and repair activities as compared to SRC bridge decks. For each strategy, a life-cycle cost model and the associated constraints are identified. The inspection, maintenance, and repair default schedule for FRP bridge decks and SRC bridge decks are presented in Figure 4.5 and 4.6. Different manufacturing technologies and designs of FRP bridge decks may result in different performances. The strategies applied in this model were determined based on 
experimental data for pultruded FRP bridge decks, as that was the only data available. The governing mode of failure considered for the FRP bridge deck was the delamination of face sheets.

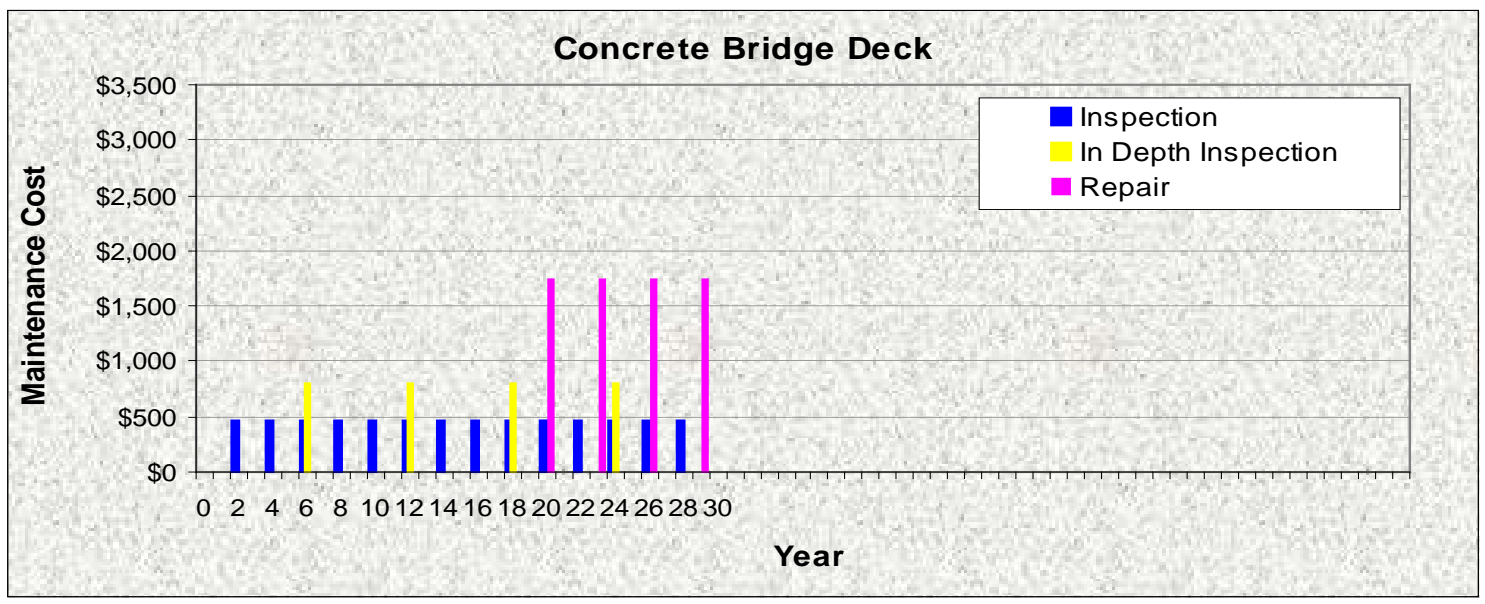

Figure 4.5 Default Inspection/Maintenance Schedule for SRC Bridge Decks

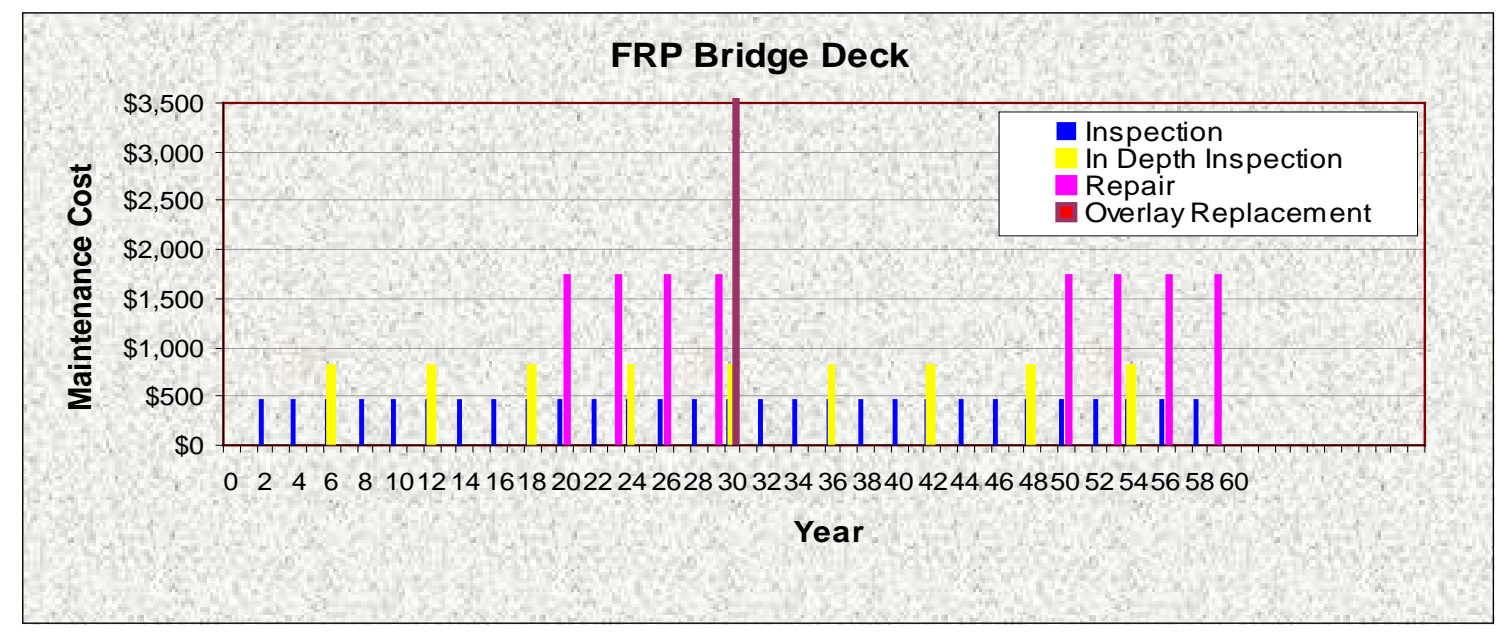

Figure 4.6 Default Inspection/Maintenance Schedule for FRP Bridge Decks

The following steps were applied for the inspection/maintenance/repair costs in the model.

(1) Calculate NPV of the maintenance/repair/cost for the life of the SRC bridge deck referred to as MR. In the module, utilizing the logical function in Excel ${ }^{\circledR}$, costs 
that occurred every year for each type of activity were automated on the spreadsheet for the life of the bridge deck based on a given schedule

(2) For each year, the agency costs and the user costs were summed, resulting in only two values for each row. These two values for each year were then converted into present values. The sum of (PV total agency cost column) is the NPV of total maintenance agency cost. The sum of (PV total user cost column) is the NPV of total maintenance user cost. The sum of those two values is MR.

(3) If the study period is $\mathrm{N}$ years and the SRC bridge deck service life is $\mathrm{m}$, where $2 \mathrm{~m}<\mathrm{N}$ then

$$
\text { PVIR }=\text { MR }+\mathrm{MR}(\mathrm{A} / \mathrm{P}, \mathrm{i} \%, \mathrm{~m})(\mathrm{P} / \mathrm{A}, \mathrm{i} \%, \mathrm{~N}-\mathrm{m}) *(\mathrm{P} / \mathrm{F}, \mathrm{i} \%, \mathrm{~m})
$$

(4) An approximate value for the annual costs of the inspection/maintenance/repair costs $=$ MR (A/P, i\%, m). This assumes the costs remain constant over the study period of $\mathrm{N}$ years, even though $\mathrm{m}$ is not a multiple of $\mathrm{N}$.

\subsubsection{Deck Disposal Cost}

Disposal time and cost of an FRP bridge deck is much less than that of an SRC bridge deck. Ehlen and Marshall [29] reported that it requires two days, 150 labor hours each, and \$4/sq ft to dispose an FRP SCRIMP bridge deck with a span of $71.6 \mathrm{~m}$. The de-construction costs are somewhat different for different types of FRP decks. Woodcore and pultruded-plank decks only require 200 labor hours for the same bridge deck size. The cost is about 12 percent of an SRC deck disposal cost [27]. An SRC deck with the same size requires 10 days disposal time and \$20/sq ft to dispose. An average cost is \$9.19 per square foot and takes nine days to complete. Based on the survey, Lopez- 
Anido [53] suggested that on average it costs $\$ 9.19 / \mathrm{sq} \mathrm{ft}$ (US) and $\$ 5.00 / \mathrm{sq} \mathrm{ft}$ (NC) to dispose of an SRC deck.

In this study, deck disposal costs are defined as material removal costs and disposal costs. Material removal costs include cost of workers for deck de-construction, cost of demolition equipment rental, and safety costs during de-construction activities. Disposal costs include transportation cost and landfill tipping fees. In general, costs for transporting the de-constructed deck from the site depend on the volume and weight of the material and distance to the dumping site. The distance between the project site and the closest dumping site is used for calculating the removal cost. The distance matrix for West Virginia is given in Table 4.2. Transportation costs and landfill costs for disposal were formulated as:

Transportation cost $=\mathrm{TT} *(2 * \mathrm{DD} / 40+2) * \mathrm{TO}+\mathrm{TT} * \mathrm{DD} * \mathrm{FE} * \mathrm{FC} \quad 4.7$

Landfill cost $\quad=\mathrm{TT} * 22 * \mathrm{LF} \quad 4.8$

TT = Number of truck trips

DD = Distance between disposal site and project site (miles)

FE $\quad=$ Fuel efficiency of truck (gallon/mile)

FC $\quad=$ Fuel cost $(\$ /$ gallon $)$

TO = hourly truck operating cost $(\$ / \mathrm{hr})$

$\mathrm{LF} \quad=$ Landfill tipping fee $(\$ /$ ton$)$

WV landfill tipping fees averaged \$10.67/ton in 1988, \$35.17/ton in 2001, \$39.84 in 2006, and $\$ 45.18 /$ ton in 2008 [88]. The tipping fees for other years are depicted in Table 4.3. 
Table 4.2 WV Landfill Locations and the Distances from Project Sites

\begin{tabular}{|c|c|c|c|c|c|c|c|c|c|c|c|c|c|c|c|c|c|c|c|}
\hline Landfill Place & $\begin{array}{l}\text { Meadowill } \\
\text { Landill }\end{array}$ & $\begin{array}{l}\text { Mercer County } \\
\text { Landfill }\end{array}$ & $\begin{array}{l}\text { Northwestern } \\
\text { Company } \\
\text { Disposal Landfill }\end{array}$ & $\begin{array}{l}\text { Raleigh County } \\
\text { SWA }\end{array}$ & $\begin{array}{l}\text { Short Creek } \\
\text { Sanitary } \\
\text { Landfill }\end{array}$ & $\begin{array}{l}\text { Tucker County } \\
\text { Solid Waste } \\
\text { Authority LF }\end{array}$ & \begin{tabular}{|l|} 
Wetzel County \\
Landfill
\end{tabular} & $\begin{array}{l}\text { Brooke County } \\
\text { LF (subtitle D) }\end{array}$ & $\begin{array}{l}\text { City of } \\
\text { Charleston } \\
\text { Landifill }\end{array}$ & Elkins Landfill & \begin{tabular}{|l|} 
Greenbrier \\
County Landilil
\end{tabular} & $\begin{array}{l}\text { Ham Sanitary } \\
\text { Landfill Inc. }\end{array}$ & $\begin{array}{l}\text { LCS Services } \\
\text { Landilll }\end{array}$ & $\begin{array}{l}\text { Midwest } \\
\text { Disposal } \\
\text { Landfill }\end{array}$ & \begin{tabular}{|l} 
North Fork \\
Landfill
\end{tabular} & $\begin{array}{l}\text { Pocahontas } \\
\text { County Landfill }\end{array}$ & $\begin{array}{l}\text { Raleigh County } \\
\text { Landfill \& } \\
\text { Recycling Center }\end{array}$ & $\begin{array}{l}\text { S\& \& G Grading } \\
\text { Inc. Landfill }\end{array}$ & $\begin{array}{l}\text { Sycamore } \\
\text { Landill }\end{array}$ \\
\hline City & Bridgeport & Princeton & Parkersburg & Beckley & Short Creek & Thomas & $\begin{array}{l}\text { New } \\
\text { Martinsville }\end{array}$ & Colliers & Charleston & Ekkins & Lewisburg & Peterstown & Hedgesville & Hinton & West Liberty & Dunmore & Beckley & Clarksburg & Hurricane \\
\hline County & Harrison & Mercer & Wood & Raleigh & Ohio & Tucker & Wetzel & Brooke & Kanawha & Randolph & Greenbrier & Monroe & Berkeley & Summers & Ohio & Pocahontas & Raleigh & Harison & Putnam \\
\hline Cabel Co & 164 & 137 & 119 & 103 & 230 & 211 & 173 & 250 & 46 & 178 & 156 & 153 & 324 & 132 & 231 & 213 & 103 & 165 & 18 \\
\hline Jackson Co & 114 & 134 & 42 & 99.3 & 153 & 204 & 96.1 & 175 & 42.7 & 171 & 153 & 150 & 274 & 129 & 154 & 210 & 99.3 & 109 & 64.1 \\
\hline Lewis Co & 32 & 146 & 101 & 107 & 138 & 79 & 88.5 & 135 & 98.2 & 46.1 & 120 & 162 & 191 & 141 & 134 & 102 & 107 & 33.1 & 120 \\
\hline Marion Co & 22 & 195 & 88 & 156 & 98 & 74.9 & 51.1 & 96 & 147 & 79 & 169 & 210 & 152 & 190 & 94.1 & 135 & 156 & 26 & 168 \\
\hline Monongalia & 25 & 198 & 97 & 160 & 82.9 & 74.3 & 65.4 & 79.8 & 150 & 82.4 & 172 & 214 & 144 & 193 & 79 & 138 & 160 & 29.4 & 172 \\
\hline Monroe Co & 173 & 43 & 212 & 73.8 & 276 & 164 & 267 & 273 & 132 & 128 & 25.6 & 216 & 241 & 39.1 & 272 & 85.7 & 73.8 & 171 & 161 \\
\hline Ohio Co & 104 & 279 & 109 & 244 & 9.5 & 138 & 46 & 27.3 & 187 & 162 & 252 & 294 & 208 & 274 & 6.6 & 218 & 244 & 109 & 209 \\
\hline Pendleton Co & 118 & 195 & 187 & 161 & 224 & 58.1 & 175 & 221 & 200 & 59.3 & 116 & 149 & 144 & 153 & 221 & 58.6 & 161 & 120 & 221 \\
\hline Raleigh Co & 139 & 38.4 & 138 & 3.3 & 249 & 187 & 192 & 243 & 57.6 & 154 & 57.2 & 54.2 & 278 & 33.3 & 242 & 115 & 3.3 & 141 & 86.2 \\
\hline Randolph Co & 76 & 184 & 144 & 166 & 182 & 52.4 & 132 & 179 & 157 & 16.6 & 103 & 145 & 178 & 142 & 178 & 41.9 & 166 & 76.9 & 178 \\
\hline Taylor Co & 13 & 189 & 85 & 151 & 109 & 51.5 & 70.7 & 106 & 142 & 42.6 & 163 & 205 & 155 & 184 & 105 & 98.6 & 151 & 18 & 163 \\
\hline
\end{tabular}


Table 4.3 Landfill Tipping Fees

\begin{tabular}{|c|c|c|c|c|c|}
\hline YEAR & 2000 & 2001 & 2002 & 2003 & 2004 \\
\hline$\overline{L F}$ (\$/ton) & 33.3 & 35.2 & 36.1 & 37.0 & 38.0 \\
\hline YEAR & 2005 & 2006 & 2007 & 2008 & \\
\hline LF (\$/ton) & 38.9 & 39.8 & 42.5 & 45.2 & \\
\hline
\end{tabular}

User costs are indirect costs, which include vehicle operating costs (both running and standing costs), time costs for delays due to congestion and road work, and road accident costs [33]. They were given in Equation 3.10 to 3.12.

Total disposal cost is a summation of material removal costs, disposal costs, and user costs that occurred during disposal activities. The total disposal costs for FRP decks and SRC decks are converted to the present values. Since the study period sets to be equal to FRP deck service life ( $\mathrm{N}$ years), then for FRP deck the present value of total disposal cost (PVDC):

$\mathrm{PVDC}=\mathrm{TDC} *(\mathrm{P} / \mathrm{F}, \mathrm{i} \%, \mathrm{~N})$

Assuming SRC bridge deck service life is $\mathrm{m}$, where $2 \mathrm{~m}<\mathrm{N}$ then the present value of total disposal cost for SRC deck:

PVDC $=\mathrm{TDC}+\mathrm{TDC}(\mathrm{A} / \mathrm{P}, \mathrm{i} \%, \mathrm{~m})(\mathrm{P} / \mathrm{A}, \mathrm{i} \%, \mathrm{~N}-\mathrm{m}) *(\mathrm{P} / \mathrm{F}, \mathrm{i} \%, \mathrm{~m})$

An approximate value for the average annual disposal costs is PVDC (A/P,i\%,N). This assumes the costs remain constant over the study period of $\mathrm{N}$ years even though $\mathrm{m}$ is not a multiple of $\mathrm{N}$. The reason for the average annual cost value is to determine the annual cost of the deck over its life and the annual cost of the structure over its life and the sum of the annual costs. The life of the two items are only approximate values, and if the support structure has a life of 70 years and the deck has a life of 30 years, for 
example, when the second deck needs to be replaced, the designers need to decide at that time whether to replace only the deck, do major repair on the deck for the remaining structure life of 10 years, or to build a new bridge, replacing the support structure as well as the deck. It is extremely difficult to evaluate that decision some 70 years before it must occur with any degree of accuracy.

\subsubsection{Life-cycle cost}

This module combined the calculations performed by three modules, i.e., initial cost module, maintenance/inspection/repair module, and disposal cost module. Each of the three categories is measured in present value terms, i.e., converted to a common point in time (bridge deck project year as the present).

PV LCC $=$ IC + PVIR + PVDC

Where

$$
\begin{aligned}
& \text { PVLCC = Present value of total life-cycle cost, } \\
& \text { IC } \quad \text { Initial costs, } \\
& \text { PVIR = Present value of inspection, maintenance and repair costs, } \\
& \text { PVDC = Present value of disposal costs }
\end{aligned}
$$

The life-cycle costs for both FRP and SRC alternative bridges are given as the final outputs. The average annual cost for both alternative bridge decks for the study period and pie charts of the first level costs are also given. 


\subsection{Summary}

This chapter explained the key differences between present research and previous studies. It began by explaining life-cycle cost (LCC) breakdown and default values on each life-cycle components. It concluded with explanation of the Excel program and formulas used to conduct LCC comparisons for the case studies. 


\section{Chapter 5}

\section{Model Results}

\subsection{Background}

Life-cycle costing was used to compare pultruded fiber reinforced polymer (FRP) bridge decks to conventional steel reinforced concrete (SRC) bridge decks. The FRP decks were assumed to have the same self weight as Bedford Reinforced Plastics (BRP) bridge decks, unless otherwise noted.

\subsubsection{The Bridge Example}

Reader Run Bridge is on WV route 20 over Reader Run. It is 55 feet in length and 43 feet in width and had an average daily traffic (ADT) of 3,800. The bridge deck was constructed in 2005. The bridge is a single span bridge with steel superstructure.

\subsubsection{Basic Scenario}

The default parameters used as a basic scenario for the example bridge are given in Table 5.1. Cost information collected from different sources was converted to reflect 2005 values. The FRP bridge deck cost was estimated to be $\$ 60.04 / \mathrm{sq} \mathrm{ft}$, and SRC bridge deck was based on a deck cost of $\$ 30 / \mathrm{sq} \mathrm{ft}$, the average reported SRC deck cost in the U.S. for 1998 after being converted to a 2005 value. The transportation cost was calculated based on the distance between the manufacturer and project site. 
Table 5.1 Default Parameters for Model (2005 values)

\begin{tabular}{|c|c|c|c|c|}
\hline YEAR & & 2005 & & Source of data \\
\hline \multicolumn{5}{|l|}{ TRAFFIC AND ACCIDENT INFORMATION } \\
\hline Average Daily Traffic & $\mathrm{ADT}=$ & 3,800 & vehicles per day & \begin{tabular}{|l|} 
Travel Statistics, 2001 \\
(http://www.wvdot.com. Viewed \\
December 7, 2003)
\end{tabular} \\
\hline Normal Traffic Speed & $\mathrm{NS}=$ & 55 & $\mathrm{mph}$ & \\
\hline Normal Accident Rate & $\mathrm{NA}=$ & 0.268 & per million-vehicle-miles & \\
\hline Traffic Speed during Construction & $\mathrm{CS}=$ & 45 & $\mathrm{mph}$ & \\
\hline Accident Rate during Construction & $\mathrm{CA}=$ & 0.463 & per million-vehicle-miles & \\
\hline Average Cost per Accident & $A C=$ & 32,904 & $\$$ & WVDOT, 2003 \\
\hline Hourly Vehicle Operating Cost & $\mathrm{VC}=$ & 9.52 & $\$ / h r$ & Minnesota DOT, 2003 \\
\hline Hourly Time Value of Driver & $\mathrm{HC}=$ & 15.85 & $\$ / \mathrm{hr}$ & Ehlen and Marshall, 1996 \\
\hline \multicolumn{5}{|l|}{ DETAIL OF STEEL STRINGER } \\
\hline Stringer Cost & SSC $=$ & 1.46 & $\$ / \mathrm{lb}$ & BDR Bridge Cost Estimating, 2006 \\
\hline Installation cost reduction due to steel weight reduction & $\mathrm{ICR}=$ & 1 & $\$ / \mathrm{lb}$ & Hota, 2007 \\
\hline \multicolumn{5}{|l|}{ DETAIL OF WEARING SURFACE } \\
\hline Material & WST $=$ & \multicolumn{2}{|c|}{ polymer concrete overlay } & \\
\hline Weight & WS $=$ & \begin{tabular}{|c|}
3 \\
\end{tabular} & $\mathrm{lb} / \mathrm{sq} \mathrm{ft}$ & \\
\hline Wearing Surface Cost & WSC $=$ & 3.68 & $\$ / \mathrm{sq} \mathrm{ft}$ & Tom Wright, 2005 \\
\hline \multicolumn{5}{|l|}{ DISCOUNT AND INFLATION RATES } \\
\hline Discount Rate & $\mathrm{DR}=$ & $3 \%$ & & Ehlen and Marshall, 1996 \\
\hline \multicolumn{5}{|l|}{ DETAIL OF FRP DECK } \\
\hline Reference Service Life & $\mathrm{RSL}=$ & 70 & years & \\
\hline Thickness of Deck & DT $=$ & 8 & in & \\
\hline Self weight of Deck & DS $=$ & 16 & $\mathrm{Ib} / \mathrm{sq} \mathrm{ft}$ & \\
\hline Cost of Deck & FDC $=$ & 60.04 & $\$ / \mathrm{sq} \mathrm{ft}$ & BRP, 2005 \\
\hline Labor cost per hour & LC $=$ & 12.44 & $\$$ & payscale.com \\
\hline Distance between Manufacturer and Project Site & $\mathrm{MD}=$ & 300 & miles & \\
\hline \multicolumn{5}{|l|}{ DETAIL OF CONCRETE DECK } \\
\hline Thickness of Deck & SDT $=$ & 8 & inches & \\
\hline Self weight of Deck & SDS $=$ & 100 & $\mathrm{Ib} / \mathrm{sq} \mathrm{ft}$ & \\
\hline Cost of Deck & $\mathrm{SDC}=$ & 30 & $\$ / \mathrm{sq} \mathrm{ft}$ & Lopez Anido, 1998 \\
\hline Distance between Manufacturer and Project Site & $\mathrm{MD}=$ & 109 & miles & \\
\hline \multicolumn{5}{|l|}{ Reader Run DECK } \\
\hline Deck Length & $\mathrm{DL}=$ & 55 & $\mathrm{ft}$ & \\
\hline Deck Width & DW $=$ & 43 & $\mathrm{ft}$ & \\
\hline Project Duration & $\mathrm{N}=$ & 6(FRP), 25(SRC) & days & \\
\hline Distance between Project Site and Landfill & $\mathrm{DD}=$ & \begin{tabular}{|l|}
25.6 \\
\end{tabular} & miles & \\
\hline \multicolumn{5}{|l|}{ OTHER COSTS } \\
\hline Fuel Cost & $\mathrm{FC}=$ & 2.3 & \$/gallon & \\
\hline Fuel Efficiency of Truck & $\mathrm{FE}=$ & 0.34 & gallon/mile & \\
\hline Truck Operating Cost & $\mathrm{TO}=$ & 50.75 & $\$ / \mathrm{hr}$ & \\
\hline Landfill Cost & $\begin{array}{ll}L F= \\
\end{array}$ & 38.91 & $\$ /$ ton & Lopez Anido, 1998 \\
\hline Federal Minimum Wage & FMW $=$ & 5.15 & $\$ / h r$ & \\
\hline Repair Cost & $\mathrm{DRC}=$ & 36.72 & $\$ / \mathrm{sq} \mathrm{ft}$ & Ehlen and Marshall, 1996 \\
\hline Periodic Inspection & $\mathrm{PIC}=$ & $\$ 450$ & per occasion & Adrian Lusk, 2008 \\
\hline In Depth Periodic Inspection & $\mathrm{SIC}=$ & $\$ 800$ & per occasion & Jeff Ball, 2008 \\
\hline
\end{tabular}

\section{Inspection, maintenance and repair costs for SRC bridge decks were based on}

biannual inspection of the bridge deck, in-depth inspection every six years, and

anticipated repatching of spawled portions of the road surface. Anticipated repair of the

deck should occur after 20 years when portions of the deck may have spalled or cracked.

Every three years, two percent of the surface deck is repatched; the damaged areas are

chipped away and new wearing surface is patched in. 
FRP researchers believe that FRP needs less maintenance compared to traditional material like concrete. Reduced maintenance is one of the advantages of FRP for civil constructions. Nevertheless, in the default used for comparison, the frequency of maintenance and repairs are the same as that for SRC. A modified schedule based on expert opinions is used for comparison purposes. The modified version is given in Table 5.2b using different values for periodic inspection and repair of the FRP bridge decks.

Table 5.2a Inspection /Anticipated Repair Schedules

\begin{tabular}{|l|c|c|c|}
\hline INSPECTION/MAINTENANCE SCHEDULE \\
\hline Concrete Bridge Deck & Start Year & End Year & $\begin{array}{c}\text { Time } \\
\text { Between }\end{array}$ \\
\hline Periodic Inspection & 2nd & 28th & 2 yrs \\
\hline In Depth Period Inspection & 6th & 24th & 6 yrs \\
\hline Anticipated Repairs & 20th & 29th & 3 yrs \\
\hline Deck Replacement & 30th & 30th & \\
\hline & & & \\
\hline FRP Bridge Deck & & & \\
\hline Periodic Inspection & 2nd & 58th & 2 yrs \\
\hline In Depth Period Inspection & 6th & 54th & 6 yrs \\
\hline Repair & 20th & 59th & 3 yrs \\
\hline Overlay Replacement & 30th & 30th & \\
\hline
\end{tabular}

Table 5.2b Modified Inspection/Anticipated Repair Schedules

\begin{tabular}{|l|c|c|c|}
\hline \multicolumn{4}{|l|}{ MODIFIED INSPECTION/MAINTENANCE SCHEDULE } \\
\hline Concrete Bridge Deck & Start Year & End Year & $\begin{array}{c}\text { Time } \\
\text { Between }\end{array}$ \\
\hline Periodic Inspection & 2nd & 28th & 2 yrs \\
\hline In Depth Period Inspection & 6th & 24th & 6 yrs \\
\hline Anticipated Repairs & 20th & 29th & 3 yrs \\
\hline Deck Replacement & 30th & 30th & \\
\hline & & & \\
\hline FRP Bridge Deck & & & \\
\hline Periodic Inspection & 3th & 57th & 3 yrs \\
\hline In Depth Period Inspection & 6th & 54th & 6 yrs \\
\hline Repair & 25th & 55th & 5 yrs \\
\hline Overlay Replacement & 30th & 30th & \\
\hline
\end{tabular}




\subsubsection{Life-cycle Cost Analysis}

\subsubsection{Bridge Deck Service Life and Study Period}

An SRC bridge deck with a service life of 30 years was considered. The FRP bridge reference service life was 70 years. However, moderate freeze-thaw cycles resulted in an expected service life of 60 years based on a service life prediction model for the FRP Bridge in Section 4.2.1. The study period was set at 60 years for the two structures.

\subsubsection{Initial Costs}

Following the LCC cost classification in Figure 4.2, the initial costs are the sum of the agency and user costs. Agency construction costs include manufacturing cost, transportation cost, installation cost, safety cost, and cost saving. For FRP decks, the agency costs are as follow:

Manufacturing cost $=\mathrm{DL} * \mathrm{DW} *$ (manufacturing cost per sq ft)

The manufacturing cost per sq $\mathrm{ft}$ was $540.95 *\left((\text { year of mfg-1997)*1000) })^{-0.26}\right.$ for an FRP bridge deck between 1997 and 2004. For those bridge decks manufactured in 2005 and afterwards, the value was based on the Bedford data. Since the example bridge deck was built in 2005 and the deck area was 2,365, the manufacturing cost was $\$ 60.04 / \mathrm{sq} \mathrm{ft}$. Hence, manufacturing cost was $55 * 43 * 60.04=\$ 141,995$.

The transportation costs were: $2 * \mathrm{MD} * \mathrm{FE} * \mathrm{FC}+\mathrm{TO} *(2 * \mathrm{MD} / 40+6)=2 * 300 *$ $0.34 * 2.3+50.75 *(300 * 2 / 40+6)=\$ 1,535$.

The installation costs were: DL $* \mathrm{DW} *($ Installation cost per sq ft $)=55 * 43 * 1.21=$ $\$ 2,850$. 
The safety costs were: $2 * \mathrm{~N} * 8 *$ FMW $=2 * 6 * 8 * 5.15=\$ 494$.

For SRC deck, the costs are as follow:

Manufacturing cost: DL * DW * (Material cost per sq ft) $=55 * 43 * 30=\$ 70,965$

Transportation costs: $2 * \mathrm{MD} * \mathrm{FE} * \mathrm{FC}+\mathrm{TO} *(2 * \mathrm{MD} / 40+6)$

$$
=2 * 109 * 0.34 * 2.3+50.75 *(2 * 109 / 40+6)=\$ 752
$$

Installation cost: $\mathrm{DL} * \mathrm{DW} *($ Labor cost per sq ft) $=\mathrm{DL} * \mathrm{DW} * 7 \% *$ (material cost per sq t) $=55 * 43 * 7 \% * 30=\$ 4,968$

Overlay cost: $\mathrm{DL} * \mathrm{DW} * \mathrm{WSF}=55 * 43 * 3.68=\$ 8,705$

The total installation cost was: $\$ 4,968+\$ 8,705=\$ 13,673$.

Safety cost $=2 * \mathrm{~N} * 8 * \mathrm{FMW}=2 * 25 * 8 * 5.15=\$ 2,060$

User costs are calculated as the sum of Equation 3.10 to Equation 3.12 to compute user delay cost, vehicle operating cost, and accident cost. $\mathrm{RL}=1$ for both bridge decks, $\mathrm{N}$ is 6 for FRP bridge deck, and 25 for SRC bridge deck.

Driver delay costs $\quad=(\mathrm{RL} / \mathrm{CS}-\mathrm{RL} / \mathrm{NS}) * \mathrm{ADT} * \mathrm{~N} * \mathrm{HC}$

Vehicle operating costs $=(\mathrm{RL} / \mathrm{CS}-\mathrm{RL} / \mathrm{NS}) * \mathrm{ADT} * \mathrm{~N} * \mathrm{VC}$

Accident costs $\quad=\mathrm{RL} * \mathrm{ADT} * \mathrm{~N} *(\mathrm{CA}-\mathrm{NA}) * \mathrm{AC}$

User costs for FRP bridge deck = Driver delay costs + Vehicle operating costs + Accident costs $=(1 / 45-1 / 55) * 3,800 * 6 *(15.85+9.52)+1 * 3,800 * 6 *(0.463-$ $0.268) / 1,000,000 * 32,911=\$ 1,460+\$ 877+\$ 147=\$ 2,484$

User costs for SRC bridge deck = Driver delay costs + Vehicle operating costs + Accident costs $=(1 / 45-1 / 55) * 3,800 * 25 *(15.85+9.52)+1 * 3,800 * 25 *(0.463-$ $0.268) / 1,000,000 * 32,911=\$ 6,084+\$ 3,655+\$ 610=\$ 10,349$

The structural cost savings were: (total weight of SRC deck steel stringers - total 
weight of FRP deck steel stringers $) *(\mathrm{SSC}+\mathrm{ICR})=6,451.8 \mathrm{lb} * \$ 2.46 / \mathrm{lb}=\$ 15,874$. So, Level 1 Initial Costs are $(\$ 146,874+\$ 2,483-\$ 15,874=\$ 133,483)$ and $\quad(\$ 87,450+$ $\$ 10,349=\$ 97,799)$ for FRP bridge decks and SRC bridge decks, respectively.

\subsubsection{Maintenance, Inspection, and Repair Costs}

Agency maintenance, inspection, and repair costs are based on a biannual basic inspection for damage, decay, and other signs of deficiency with a supplemental (indepth) inspection every six years. WVDOT bridge engineers estimate that a standard inspection costs \$ 450 per occasion, while a detailed inspection costs \$ 800 per occasion. Anticipated repair of the deck occurs after 20 years and is repeated every three years for two percent of the deck following deck replacement or overlay. Repair cost is $\$ 36.72 /$ sq ft. Overlay for an FRP deck is renewed every 30 years, at a cost of \$3.68/sq ft.

The agency maintenance/repair costs of FRP decks are as follows:

$$
\text { Basic Inspection }=\sum_{\mathrm{n}=2,4,8,10,14,16,20,22,26,28,32,34,38,40,44,46,50,52,56,58} \text { PIC } *(1+D R)^{-n}=\$ 4,210
$$

Supplemental Inspection $=\sum_{n=6,12,18,24,30,36,42,48,54} \operatorname{SIC}^{*}(1+D R)^{-n}=\$ 3,287$

$$
\text { Anticipated Repair }=\sum_{\mathrm{n}=20,23,26,29,50,53,56,59} \mathrm{DRC}^{* 2 \%} * \mathrm{DA}^{*}(1+\mathrm{DR})^{-\mathrm{n}} \quad=\$ 4,779
$$

Overlay Replacement $=\sum_{\mathrm{n}=30} \mathrm{WSC} * \mathrm{DA} *(1+\mathrm{DR})^{-\mathrm{n}}=\$ 3,587$

Total agency maintenance/repair costs for FRP deck $=\$ 4,210+\$ 3,287+\$ 4,779+\$ 3,587$ $=\$ 15,863$.

User costs during inspection and repair are also computed using Equations 3.10 to

3.12. The parameters are the same as for initial construction, except that $R L=0.5$ for 
the inspections, and $\mathrm{N}=1$ for the biannual inspection, and 1.5 for the detailed inspection. User costs for repair activities are calculated based on $\mathrm{RL}=1$ and $\mathrm{N}=3$ and 4 for FRP decks and SRC decks, respectively.

The user cost for each inspection $=(0.5 / 45-0.5 / 55) * 3,800 * 1 *(15.85+9.52)+0.5 *$ $3,800 * 1 *(0.463-0.268) / 1,000,000 * 32,911=\$ 207$.

The user cost for each in-depth (supplemental) inspection $=(0.5 / 45-0.5 / 55) * 3,800 *$ $1.5 *(15.85+9.52)+0.5 * 3,800 * 1.5 *(0.463-0.268) / 1,000,000 * 32,911=\$ 310$.

The user cost for each FRP repair occurrence is $(1 / 45-1 / 55) * 3,800 * 3 *(15.85+9.52)$ $+1 * 3,800 * 3 *(0.463-0.268) / 1,000,000 * 32,911=\$ 1,242$.

The user cost for each SRC repair occurrence is $(1 / 45-1 / 55) * 3,800 * 4 *(15.85+$ $9.52)+1 * 3,800 * 4 *(0.463-0.268) / 1,000,000 * 32,911=\$ 1,656$.

The user cost for wearing surface overlay is $(1 / 45-1 / 55) * 3,800 * 5 *(15.85+9.52)+$ $1 * 3,800 * 5 *(0.463-0.268) / 1,000,000 * 32,911=\$ 2,070$.

The user costs for maintenance/repair of FRP decks are as follows:

$$
\text { Basic Inspection }=\sum_{\mathrm{n}=2,4,8,10,14,16,20,22,26,28,32,34,38,40,44,46,50,52,56,58} \$ 207 *(1+\mathrm{DR})^{-\mathrm{n}}=\$ 1,937
$$

$$
\text { Supplemental Inspection }=\sum_{n=6,12,18,24,30,36,42,48,54} \$ 310 *(1+D R)^{-n}=\$ 1,274
$$

$$
\text { Anticipated Repair }=\sum_{\mathrm{n}=20,23,26,29,50,53,56,59} \$ 1,242 *(1+D R)^{-\mathrm{n}}=\$ 3,417
$$

Overlay Replacement $=\sum_{\mathrm{n}=30} \$ 2,070 * \mathrm{DA} *(1+\mathrm{DR})^{-\mathrm{n}}=\$ 853$

Total user costs for maintenance/repair of FRP deck $=\$ 7,481$. Total maintenance/repair costs for FRP deck during study period of 60 years $=\$ 15,863+\$ 7,481=\$ 23,344$.

The agency maintenance/repair costs of SRC deck are as follows: 
Basic Inspection $=\sum_{\mathrm{n}=2,4,8,10,14,16,20,22,26,28,32,34,38,40,44,46,50,52,56,58} \operatorname{SIC}^{-\mathrm{n}}(1+\mathrm{DR})^{-\mathrm{n}}=\$ 4,210$

Supplemental Inspection $=\sum_{\mathrm{n}=6,12,18,24,36,42,48,54}$ PIC $*(1+\mathrm{DR})^{-\mathrm{n}}=\$ 2,958$

Anticipated Repair $=\sum_{n=20,23,26,29,50,53,56,59} \operatorname{DRC}^{*}(1+D R)^{-n} \quad=\$ 4,779$

Deck Replacement $=\sum_{n=30} \$ 87,450 *(1+D R)^{-n}=\$ 36,028$

Total agency maintenance/repair costs of SRC deck $=\$ 4,210+\$ 2,958+\$ 4,779+$ $\$ 36,028=\$ 47,975$.

The user costs for maintenance/repair of SRC deck are as follows:

Basic Inspection $=\sum_{\mathrm{n}=2,4,8,10,14,16,20,22,26,28,32,34,38,40,44,46,50,52,56,58}=\$ 207 *(1+\mathrm{DR})^{-\mathrm{n}}$

Supplemental Inspection $=\sum \$ 310 *(1+\mathrm{DR})^{-\mathrm{n}} \quad=\$ 1,147$ $n=6,12,18,24,36,42,48,54$

Anticipated Repair $=\sum_{\mathrm{n}=20,23,26,29,50,53,56,59} \$ 1,656 *(1+\mathrm{DR})^{-\mathrm{n}}=\$ 4,556$

Deck Replacement $=\sum_{n=30} \$ 10,349 *(1+D R)^{-n}=\$ 4,264$

Total user costs for maintenance/repair of SRC deck $=\$ 11,902$. Total maintenance/inspection/repair costs for SRC deck during study period of 60 years = $\$ 47,975+\$ 11,902=\$ 59,878$.

\subsubsection{Disposal Cost}

FRP deck is assumed to have no salvage value at the end of the service life. Disposal costs are simply the cost for hand labor to disassemble the deck, warning 
signage cost, transportation, and deposit at a landfill facility. Since all costs occur in year 60 , then the multiplier of $(1+\mathrm{DR})^{-60} \approx 0.17$ is applied.

Deconstruction Cost $=0.17 *(1 * 80$ man hours $* 12.44)=0.17 * \$ 995=\$ 169$

Safety cost $\quad=0.17 *(1 * 2 * 8 * 5.15)=0.17 * \$ 82=\$ 14$

Transportation Cost $=0.17 *(\mathrm{TT} *(2 * \mathrm{DD} / 40+2) * \mathrm{TO}+\mathrm{TT} * \mathrm{DD} * \mathrm{FE} * \mathrm{FC})$

$$
=0.17 *(4 *(2 * 25.6 / 40+2) * 25.37+4 * 25.6 * 0.34 * 2.3)
$$$$
=0.17 * \$ 413=\$ 70
$$

Landfill Cost

$$
\begin{aligned}
& =0.17 *(\mathrm{TT} * 22 * \mathrm{LF}=4 * 22 * 38.91) \\
= & 0.17 * \$ 3,424=\$ 581
\end{aligned}
$$

Total agency costs is $\$ 169+\$ 14+\$ 70+\$ 581=\$ 834$.

User disposal costs are calculated using Equation 3.10 to 3.12 with $\mathrm{N}=1$, i.e. $0.17 *$ ( $\$ 243$

$+\$ 146+\$ 24)=\$ 41+\$ 25+\$ 4=\$ 70$.

Total disposal costs is $\$ 834+\$ 70=\$ 904$.

SRC deck is assumed to have no salvage value at the end of the service life. Disposal costs are simply the cost for deconstruction, warning signage cost, transportation and deposit at a landfill facility. The disposal costs of SRC deck take place in year $30^{\text {th }}$ and year $60^{\text {th }}$. For that reason, multiplier of $\left((1+D R)^{-30}+(1+D R)^{-60}\right) \approx$ 0.58 is applied.

Deconstruction Worker Cost $=5$ days $* 120$ man hours/day $* 12.44=\$ 7,466$

Equipment Cost $\quad=2,365 * 0.9=\$ 2,131$

Deconstruction Cost $=0.58 *(\$ 7,466+\$ 2,131)=\$ 5,583$

Safety Cost $\quad=0.58 *(5 * 2 * 8 * 5.15)=0.58 * \$ 412=\$ 240$

Transportation Cost $=0.58 *(\mathrm{TT} * \mathrm{~N} * 8 * \mathrm{TO}+\mathrm{TT} * \mathrm{DD} * \mathrm{FE} * \mathrm{FC})$ 


$$
=0.58 *(4 * 5 * 8 * 25.37+4 * 25.6 * 0.34 * 2.3)=\$ 2,408
$$

Landfill Cost

$$
=0.58 *(\mathrm{TT} * 22 * \mathrm{LF}=4 * 22 * 38.91)=0.58 * \$ 3,424=\$ 1,992
$$

Total agency costs is $\$ 5,583+\$ 240+\$ 2,408+\$ 1,992=\$ 10,222$.

User disposal costs are based on five days of disrupted traffic and also on a calculation using Equation 3.10 to 3.12 , i.e. $0.58 *(\$ 1,217+\$ 731+\$ 122)=\$ 708+\$ 425+\$ 71=$ $\$ 1,204$. Total disposal costs is $\$ 10,222+\$ 1,204=\$ 11,426$.

Table 5.3 lists the total LCC as well as its breakdown by initial, maintenance/repair, and disposal categories in terms of total life-cycle costs and unit costs of dollars per square foot. Table 5.4 tabulates all life-cycle cost for the FRP deck and the years in which they occur.

\subsubsection{Agency Costs}

The total agency cost for FRP bridge deck, considering substructure cost savings for the entire 60 years, is higher than the one for SRC. For both bridges, the largest component is the initial cost, which is $\$ 62.1 / \mathrm{sq} \mathrm{ft}$ for the FRP deck and $\$ 37.0 / \mathrm{sq} \mathrm{ft}$ for the SRC deck. It is clear that the agency initial costs for the FRP deck are much higher than the corresponding costs for the SRC deck. The agency initial cost of FRP bridge deck, including savings of $\$ 6.7 / \mathrm{sq} \mathrm{ft}$, is $\$ 57.4 / \mathrm{sq} \mathrm{ft}$.

Distributions of agency costs for both bridges are depicted in Figure 5.1 and Figure 5.2. Figure 5.1 is based on the case where cost savings are considered. The results indicate that initial cost still dominates agency life-cycle cost. Initial cost for the example bridge is about 89 percent of the FRP total agency cost. For this bridge deck, an improved FRP deck life over that of SRC bridges by itself significantly reduces the effect 
of higher initial costs. Furthermore, the combination of two FRP advantages over SRC (i.e., higher service life and initial cost savings) results in lower agency costs for an FRP deck.

The inspection/repair costs are not significantly different for the basic model due to the assumption that both types of bridge decks share the same anticipated schedules. For a basic scenario, inspection/repair cost is accounted for eight percent of both FRP and SRC agency costs, i.e., \$5.2/sq ft and \$5.1/sq ft, respectively, as shown in Figure 5.1 and Figure 5.2.

The disposal costs of FRP decks are significantly lower than those of SRC decks. The main reasons are the faster removal of an FRP deck compared to an SRC deck and the reduced weight. The SRC is removed by crushing the deck and hauling off the debris. For both types of bridge decks, it is assumed that they do not have salvage value, so disposal costs are simply the cost to destroy and to transport the debris to a landfill facility. The transportation cost itself is a function of the distance between the project site and landfill facility. For this basic scenario, disposal cost is 0.6 percent of FRP deck LCC cost and 6.8 percent of SRC deck LCC cost.

\subsubsection{User Costs}

The user costs for FRP for the initial and disposal processes were 24 percent and 5.8 percent of the corresponding costs for SRC, mainly because of the significant difference in time required to perform those activities. The user costs were highest in the initial costs of SRC decks where costs were highest in inspection/repair for the FRP decks. However, the SRC decks had higher user costs per square foot for all categories 
than the FRP decks. These values were obtained based on the conservative assumption

that FRP bridge decks need the same frequent inspection and anticipated repair activities

as SRC decks.

Table 5.3 Life-cycle Cost Breakdown for Reader Run

\begin{tabular}{|c|c|c|c|c|c|c|}
\hline Bridge Deck Alternative & & FRP & & & SRC & \\
\hline ADT (vehicles/day) & & 3800 & & & 3800 & \\
\hline Total Area & & 2365 & & & 2365 & \\
\hline Study Period (yrs) & & 60 & & & 60 & \\
\hline Service Life (yrs) & & 60 & & & 30 & \\
\hline \multirow[t]{2}{*}{ Deck Cost $(\$ / s q \mathrm{ft})$} & & $\$ 60.0$ & & & $\$ 30.0$ & \\
\hline & Item & Total & \$/sq ft & Item & Total & $\$ / \mathrm{sq} \mathrm{ft}$ \\
\hline \multicolumn{7}{|l|}{ Initial Costs } \\
\hline \multicolumn{7}{|l|}{ Agency Costs } \\
\hline Manufacturing Costs & $\$ 141,995$ & & & $\$ 70,965$ & & \\
\hline Transportation Costs & $\$ 1,535$ & & & $\$ 752$ & & \\
\hline Installation (incl. overlay) Costs & $\$ 2,850$ & & & $\$ 13,673$ & & \\
\hline Safety Costs & $\$ 494$ & & & $\$ 2,060$ & & \\
\hline Total Agency Costs & & $\$ 146,874$ & $\$ 62.1$ & & $\$ 87,450$ & $\$ 37.0$ \\
\hline \multicolumn{7}{|l|}{ User Costs } \\
\hline Driver Delay Costs & $\$ 1,460$ & & & $\$ 6,084$ & & \\
\hline Vehicle Operating Costs & $\$ 877$ & & & $\$ 3,655$ & & \\
\hline Increased Accident Costs & $\$ 147$ & & & $\$ 610$ & & \\
\hline Total User Costs & & $\$ 2,484$ & $\$ 1.1$ & & $\$ 10,349$ & $\$ 4.4$ \\
\hline \multicolumn{7}{|l|}{ Structural Savings } \\
\hline Steel & $\$ 15,874$ & & & - & & \\
\hline Concrete & (not incl.) & & & - & & \\
\hline Total Structural Savings & & $\$ 15,874$ & $\$ 6.7$ & & & \\
\hline Total Initial Costs & & $\$ 133,484$ & $\$ 56.4$ & & $\$ 97,799$ & $\$ 41.4$ \\
\hline \multicolumn{7}{|l|}{ Maintenance/Repair Costs } \\
\hline \multicolumn{7}{|l|}{ Agency Costs } \\
\hline Basic Inspection & $\$ 4,210$ & & & $\$ 4,210$ & & \\
\hline Supplemental Inspection & $\$ 3,287$ & & & $\$ 2,958$ & & \\
\hline Anticipated Repairs & $\$ 4,779$ & & & $\$ 4,779$ & & \\
\hline Inspection /Repair & & $\$ 12,276$ & $\$ 5.2$ & & $\$ 11,947$ & $\$ 5.1$ \\
\hline Deck Overlay Replacement & $\$ 3,587$ & & & & & \\
\hline Deck Replacement & & & & $\$ 36,028$ & & \\
\hline Deck Overlay or Replacement & & $\$ 3,587$ & $\$ 1.5$ & & $\$ 36,028$ & $\$ 15.2$ \\
\hline Total Agency Costs & & $\$ 15,863$ & $\$ 6.7$ & & $\$ 47,975$ & $\$ 20.3$ \\
\hline \multicolumn{7}{|l|}{ User Costs } \\
\hline Basic Inspection & $\$ 1,937$ & & & $\$ 1,936$ & & \\
\hline Supplemental Inspection & $\$ 1,274$ & & & $\$ 1,147$ & & \\
\hline Anticipated Repairs & $\$ 3,417$ & & & $\$ 4,556$ & & \\
\hline Inspection /Repair & & $\$ 6,628$ & $\$ 2.8$ & & $\$ 7,639$ & $\$ 3.2$ \\
\hline Deck Overlay Replacement & $\$ 853$ & & & & & \\
\hline Deck Replacement & & & & $\$ 4,264$ & & \\
\hline Deck Overlay or Replacement & & $\$ 853$ & $\$ 0.4$ & & $\$ 4,264$ & $\$ 1.8$ \\
\hline Total User Costs & & $\$ 7,481$ & $\$ 3.2$ & & $\$ 11,902$ & $\$ 5.0$ \\
\hline Total Maintenance/Repair Costs & & $\$ 23,344$ & $\$ 9.9$ & & $\$ 59,878$ & $\$ 25.3$ \\
\hline & & & & & & \\
\hline \multicolumn{7}{|l|}{ Disposal Costs } \\
\hline \multicolumn{7}{|l|}{ Agency Costs } \\
\hline Deconstruction Costs & $\$ 169$ & & & $\$ 5,583$ & & \\
\hline Safety Costs & $\$ 14$ & & & $\$ 240$ & & \\
\hline Transportation Costs & $\$ 70$ & & & $\$ 2,408$ & & \\
\hline Landfill Fees & $\$ 581$ & & & $\$ 1,992$ & & \\
\hline Total Agency Costs & & $\$ 834$ & $\$ 0.4$ & & $\$ 10,222$ & $\$ 4.3$ \\
\hline \multicolumn{7}{|l|}{ User Costs } \\
\hline Driver Delay Costs & $\$ 41$ & & & $\$ 708$ & & \\
\hline Vehicle Operating Costs & $\$ 25$ & & & $\$ 425$ & & \\
\hline Increased Accident Costs & $\$ 4$ & & & $\$ 71$ & & \\
\hline Total User Costs & & $\$ 70$ & $\$ 0.0$ & & $\$ 1,204$ & $\$ 0.5$ \\
\hline Total Disposal Costs & & $\$ 904$ & $\$ 0.4$ & & $\$ 11,426$ & $\$ 4.8$ \\
\hline \multicolumn{7}{|l|}{ LIFE CYCLE COST } \\
\hline Total Agency Costs & & $\$ 147,697$ & $\$ 62.5$ & & $\$ 145,647$ & $\$ 61.6$ \\
\hline Total User Costs & & $\$ 10,035$ & $\$ 4.2$ & & $\$ 23,456$ & $\$ 9.9$ \\
\hline Total Life Cycle Costs & & $\$ 157,733$ & $\$ 66.7$ & & $\$ 169,104$ & $\$ 71.5$ \\
\hline
\end{tabular}


Table 5.4 FRP Deck Life-cycle Cost Tabulation

Reader Run

\begin{tabular}{|c|c|c|c|c|c|c|}
\hline Cost Tabulation of FRP Deck & Quantity & Unit & UC & Start & End & Freq \\
\hline & & & & & & \\
\hline \multicolumn{7}{|l|}{ L1: Initial Costs } \\
\hline \multicolumn{7}{|l|}{ L2: Agency Costs } \\
\hline Construct a new deck & 2,365 & $\mathrm{sq} \mathrm{ft}$ & $\$ 62.1$ & 0 & 0 & 1 \\
\hline \multicolumn{7}{|l|}{ L2: User Costs } \\
\hline Driver delay, vehicle, and accidents & 6 & days & $\$ 414$ & 0 & 0 & 1 \\
\hline \multicolumn{7}{|l|}{ L2: Structural Savings } \\
\hline Steel & 2,365 & $\mathrm{sq} \mathrm{ft}$ & $\$ 6.7$ & 0 & 0 & 1 \\
\hline \multicolumn{7}{|l|}{ L1: Maintenance/Repair Costs } \\
\hline \multicolumn{7}{|l|}{ L2: Agency Costs } \\
\hline Basic Inspection & 1 & Is & $\$ 450$ & 2 & 58 & $20^{*}$ \\
\hline Supplemental Inspection & 1 & Is & $\$ 800$ & 6 & 54 & 9 \\
\hline Anticipated Repairs & 47 & $\mathrm{sq} \mathrm{ft}$ & $\$ 36.7$ & 20 & 59 & 8 \\
\hline Deck Overlay Replacement & 2,365 & $\mathrm{sqft}$ & $\$ 3.7$ & 30 & 30 & 1 \\
\hline \multicolumn{7}{|l|}{ L2: User Costs } \\
\hline Basic Inspection: Driver delay, vehicle, and accidents & 1 & Is & $\$ 207$ & 2 & 58 & $\left.20^{*}\right)$ \\
\hline Supplemental Inspection: Driver delay, vehicle, and accidents & 1 & Is & $\$ 310$ & 6 & 54 & 9 \\
\hline Anticipated Repairs: Driver delay, vehicle, and accidents & 1 & Is & $\$ 1,242$ & 20 & 59 & 8 \\
\hline Deck Overlay Replacement: Driver delay, vehicle, and accidents & 1 & Is & $\$ 2,070$ & 30 & 30 & 1 \\
\hline \multicolumn{7}{|l|}{ L1: Disposal Costs } \\
\hline \multicolumn{7}{|l|}{ L2: Agency Costs } \\
\hline Disposal of deck & 2,365 & $\mathrm{sq} \mathrm{ft}$ & $\$ 2.1$ & 60 & 60 & 1 \\
\hline \multicolumn{7}{|l|}{ L2: User Costs } \\
\hline Driver delay, vehicle, and accidents & 1 & days & $\$ 414$ & 60 & 60 & 1 \\
\hline
\end{tabular}

*) include the following years: 2,4,8,10,14,16,20,22,26,28,32,34,38,40,44,46,50,52,56,58

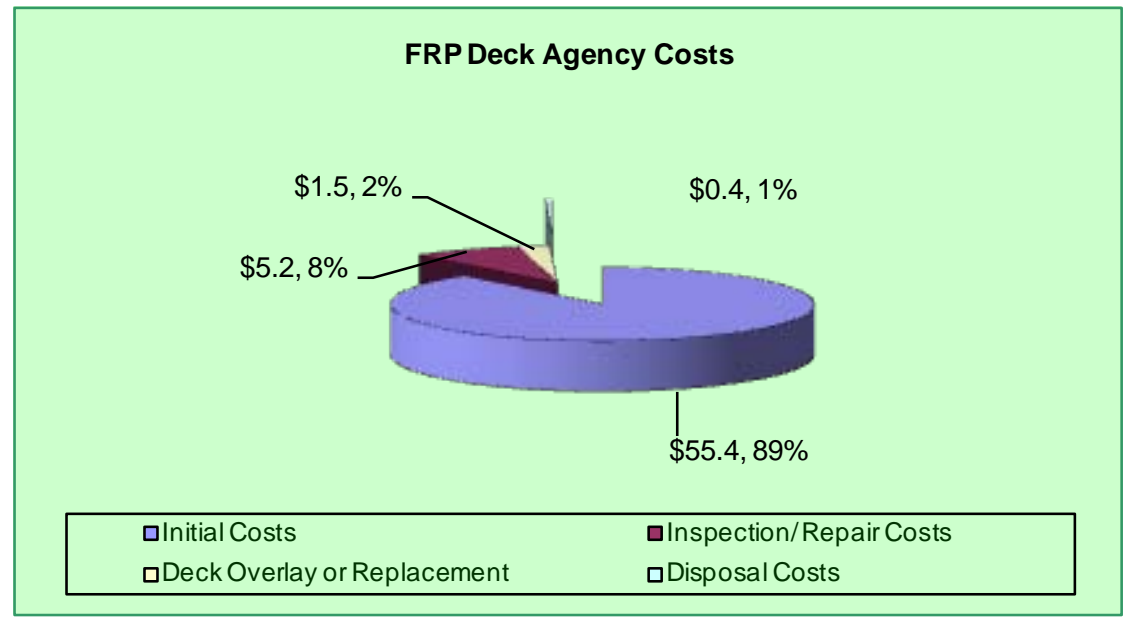

Figure 5.1 Agency Cost Distribution of Reader Run FRP Bridge Deck 


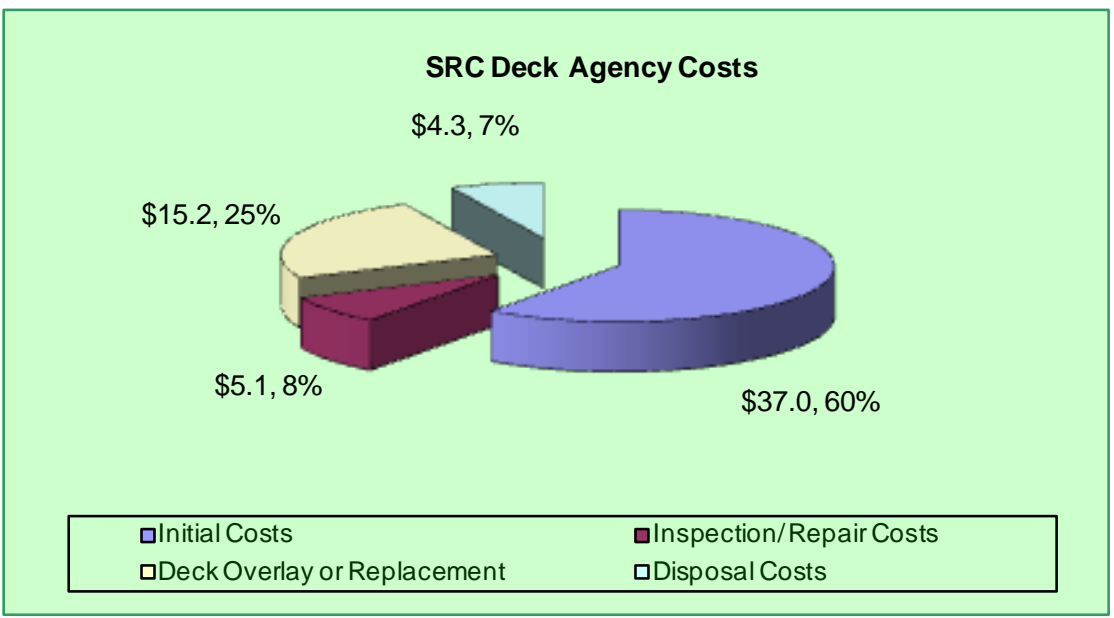

Figure 5.2 Agency Cost Distribution of Reader Run SRC Bridge Deck

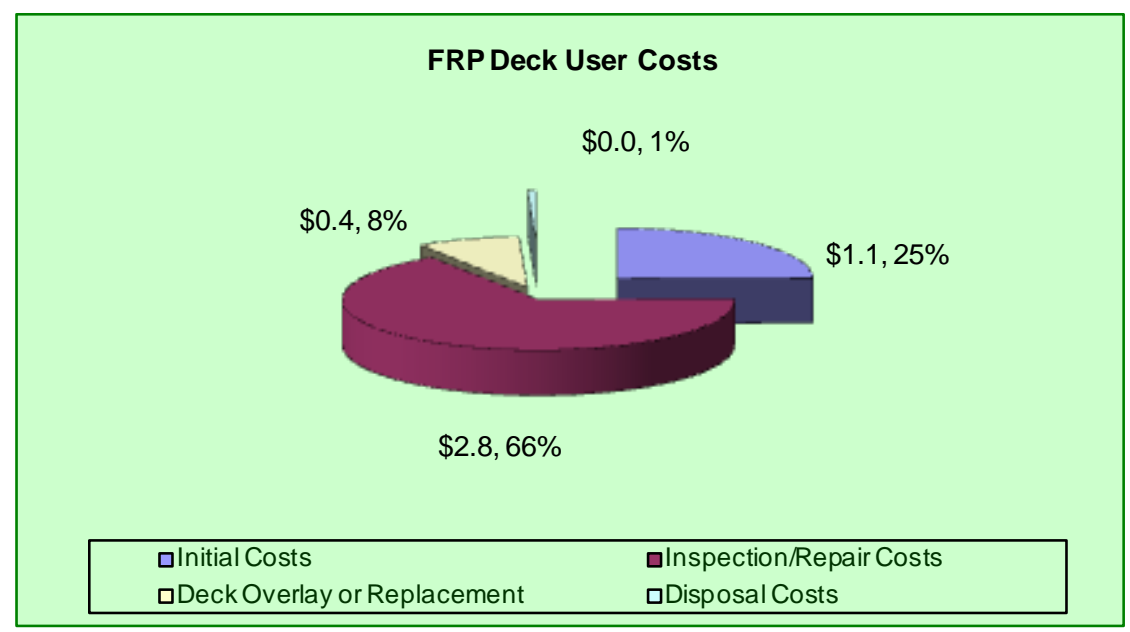

Figure 5.3 User Cost Distribution of Reader Run FRP Bridge Deck

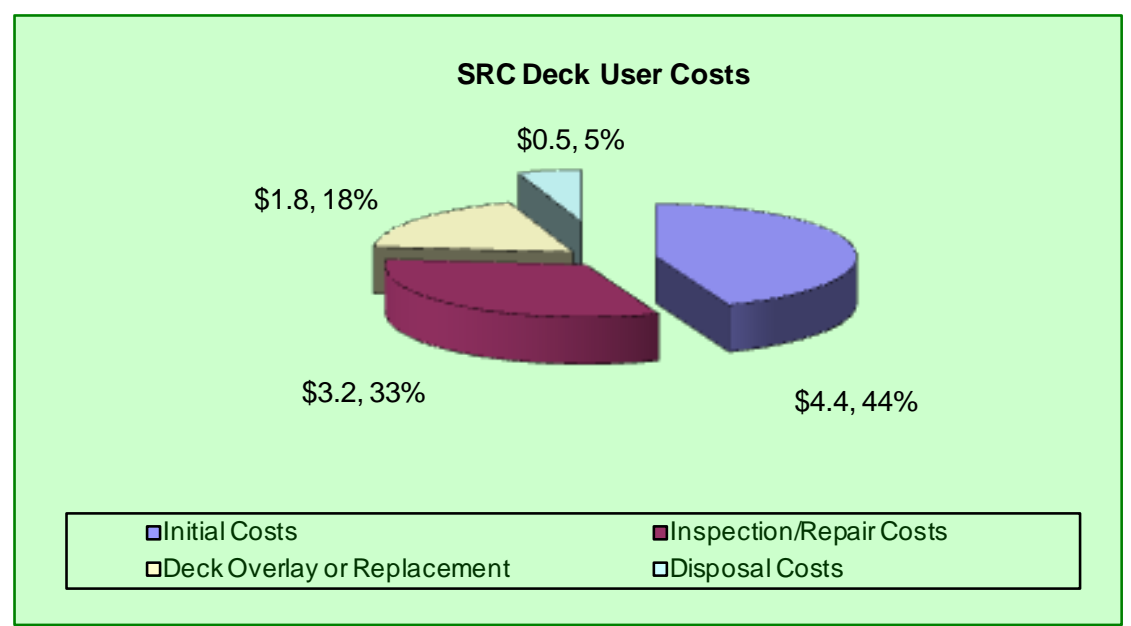

Figure 5.4 User Cost Distribution of Reader Run SRC Bridge Deck 


\subsubsection{Total Costs}

The basic scenarios suggested that if SRC deck cost is $\$ 30 /$ sq ft, FRP deck cost is $\$ 60.04 / \mathrm{sq} \mathrm{ft}$, the site has normal ADT, and if both type of bridge decks share the same maintenance/inspection and anticipated repair frequencies, the LCC of an FRP bridge deck is lower than that for an SRC bridge deck when cost saving is considered, i.e., $\$ 66.7 / \mathrm{sq} \mathrm{ft}$ as opposed to $\$ 71.5$. Additionally, the study suggests that FRP deck is not financially viable if one makes a conclusion based on initial cost consideration only. Initial cost analysis is not suitable for showing the entire situation. Level 1 life-cycle cost breakdown for the alternate decks are given in Figure 5.5. The following section discusses the effect of various scenarios. Both cases (with and without cost saving) are considered.

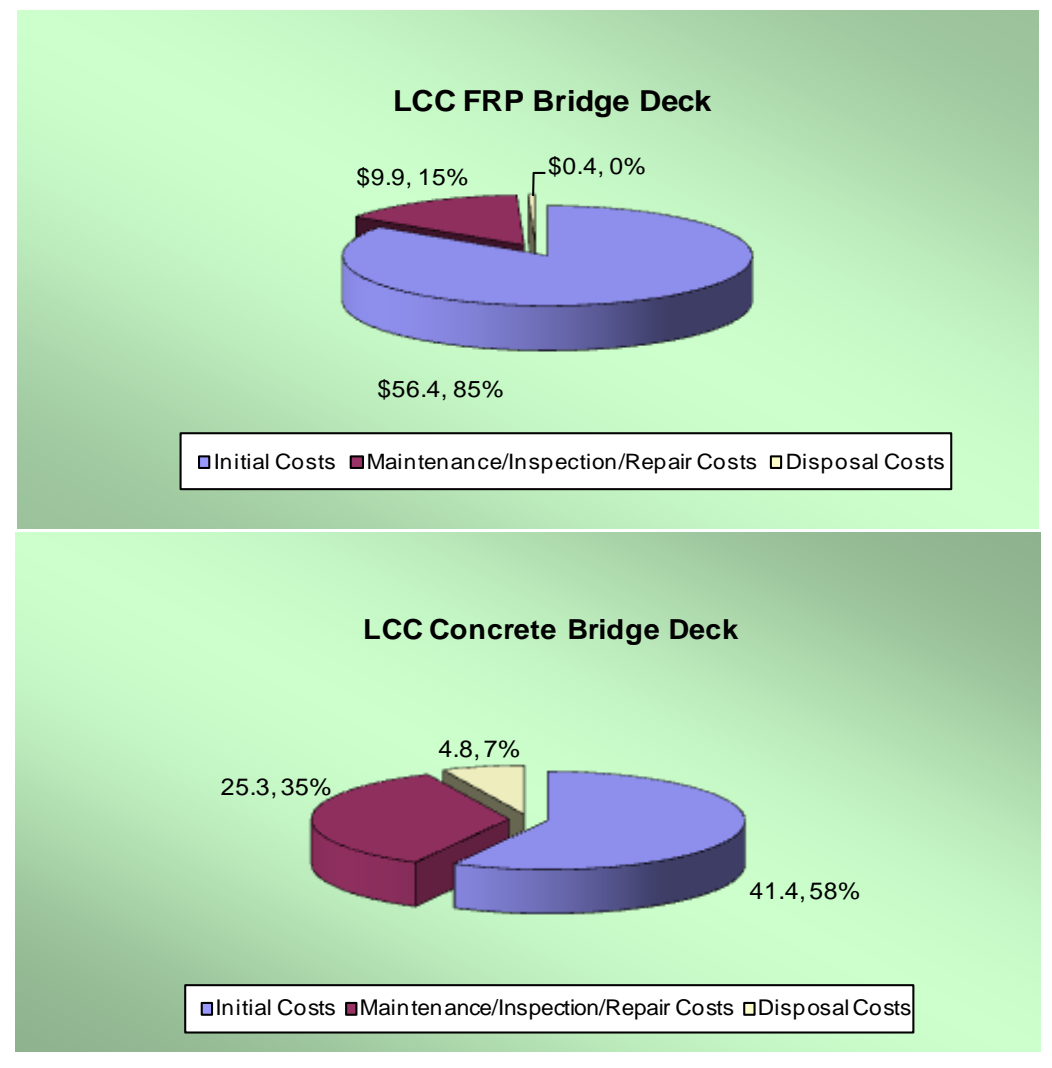

Figure 5.5 Life-cycle Cost of Alternate Decks 


\subsubsection{Savings Comparison of Decks and Sensitivity Analysis}

Break-even analysis indicates the maximum or minimum values of key parameters necessary for an alternative material to be cost effective. The break-even analysis was done by re-computing the costs for FRP bridge deck by changing one parameter at a time to determine the level at which the total life-cycle cost of the FRP bridge becomes competitive or not.

The basic scenario of this case study is as follows: SRC deck costs \$30/sq ft, FRP deck costs $\$ 60.04 /$ sq $\mathrm{ft}$, and $\mathrm{ADT}=3800$ vehicles/day. Under these conditions, it was estimated that the LCC costs are \$73.4/sq ft and \$71.5/sq ft for FRP and SRC decks, respectively. When cost saving is considered, the LCC cost for FRP is $\$ 66.7 / \mathrm{sq} \mathrm{ft}$. Hence, FRP is financially viable when substructure savings are considered.

The initial and disposal activities of the SRC deck consume more time and result in higher sensitivity to ADT as depicted in Figure 5.4. Therefore, higher ADT is more beneficial for an FRP deck. The effects of increased ADT for FRP bridge deck cost as well as SRC bridge deck cost are depicted in Figure 5.6. With the same anticipated inspection and maintenance schedules for the two bridge decks, the maximum cost for an FRP bridge deck to be cost competitive with SRC deck is $\$ 64.8 / \mathrm{sq} \mathrm{ft}$, if SRC deck costs \$ 30 /sq ft. When the SRC deck cost is lower than expected, i.e., \$ 25/sq ft, FRP bridge deck is still financially viable if the maximum manufacturing cost is about $\$ 57.2 / \mathrm{sq} \mathrm{ft}$. 


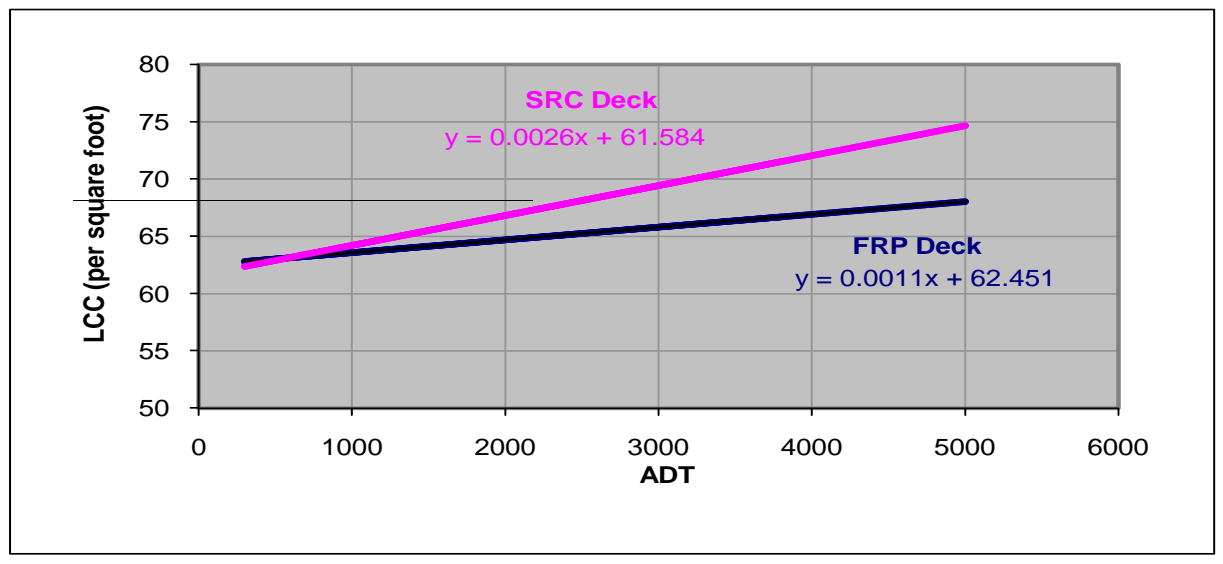

Figure 5.6 Effects of ADT

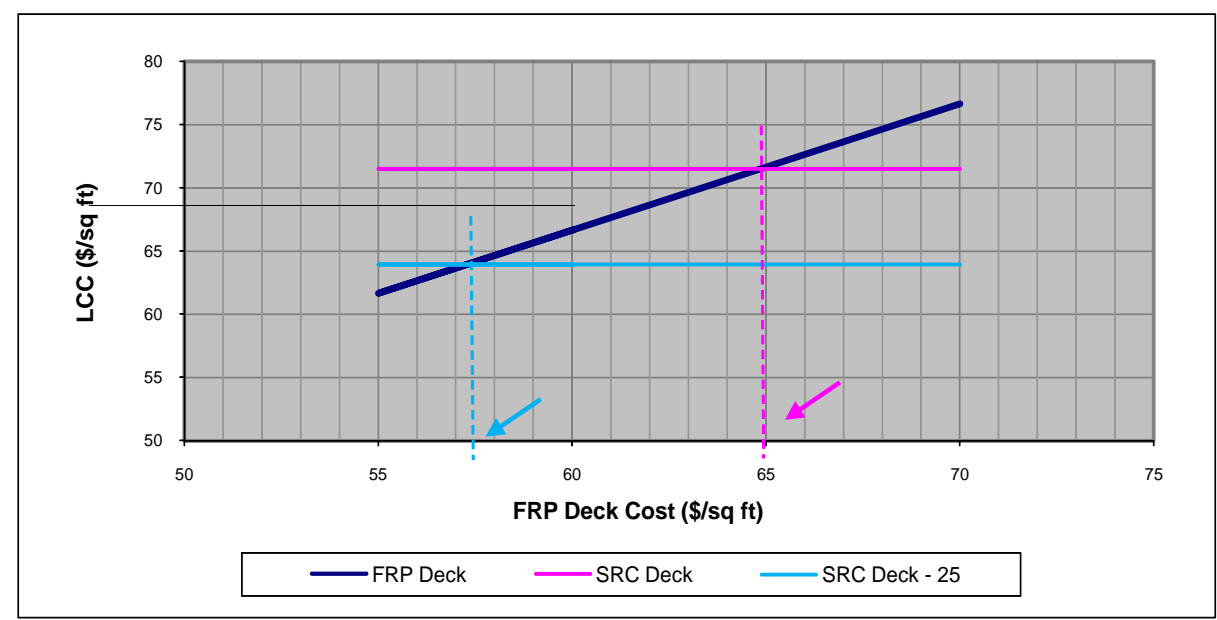

Figure 5.7 Effects of Manufacturing Costs

\subsection{The Case Study Bridges}

Using similar steps as explained above, the life-cycle cost analysis for three case study bridges were performed. The bridges studied were the Goat Farm Bridge, the La Chein Bridge, and the Katy Truss Bridge. The estimates were based on estimated costs of when the bridge was repaired, and the structural steel savings were included as if the bridge was a new project. The Goat Farm Bridge is on County Route 21 in Jackson County, WV. It is 39 feet in length and 15 feet in width and had an average daily traffic 
(ADT) of 20 and was constructed in 2003. The La Chein Bridge is on County Road 12, in Monroe County, WV. The 32.5 foot long and 24.3 foot wide bridge was constructed in 2001 with ADT of 100 vehicles per day. The Katy Truss Bridge is located in Marion County, WV. The bridge had an ADT of 700 and is 91.3 feet in length and 14.3 feet in width, and it was constructed in 2000. Those three bridges are single-span, FRP bridge decks with steel superstructures.

\subsection{Life-cycle Cost Analysis}

The initial costs for FRP bridge decks were based on the learning curve formula, and $\$ 56.3$ /sq ft, \$62.6 /sq ft and \$67.5/sq ft were obtained respectively for Goat Farm, La Chein, and Katy Truss bridge decks. As with the example bridge, the FRP deck and SRC bridge deck used a service life of 60 and 30 years. The study period is set at 60 years.

\subsubsection{Agency Costs}

For the three case studies, the agency life-cycle costs for the FRP deck were higher than the corresponding costs for the SRC deck if the structural cost savings were not considered. The largest component of the FRP agency cost is the initial cost, which was 79-89 percent of the total agency costs, as depicted in Figures 5.8 to 5.10.

Figures 5.11 to 5.13 are based on cases where substructure cost reductions are considered. The initial costs still dominate the life-cycle cost and are 77-87 percent of the FRP total agency cost. The results implied that the improved FRP deck life over that of the SRC bridges does not offset the effect of higher initial costs. Furthermore, the 
combination of two FRP advantages over SRC (i.e., higher service life and substructure cost reductions) does not always offset the effect of the higher initial costs either.

In general, the results showed that the higher the FRP manufacturing cost, the higher the initial cost will be. This phenomenon emphasizes the important role of the FRP bridge deck manufacturing cost in determining the economic viability of a FRP bridge deck. The importance of this particular input, its effects to total initial costs, as well as the life-cycle cost are discussed in the sensitivity analysis section.

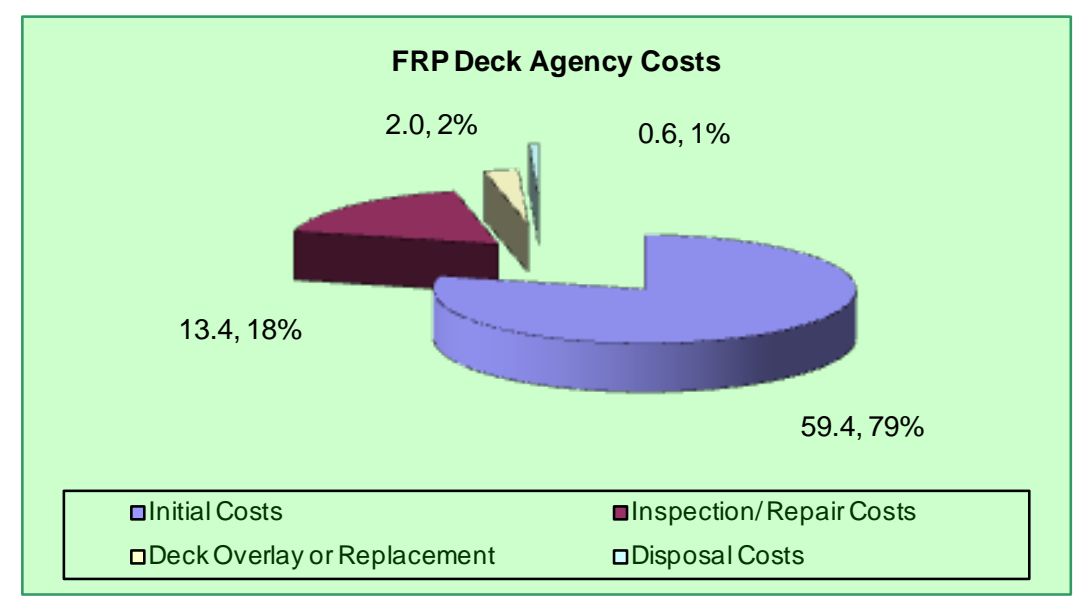

Figure 5.8 Agency Cost Distribution of Goat Farm FRP Bridge Deck (Basic Scenario)

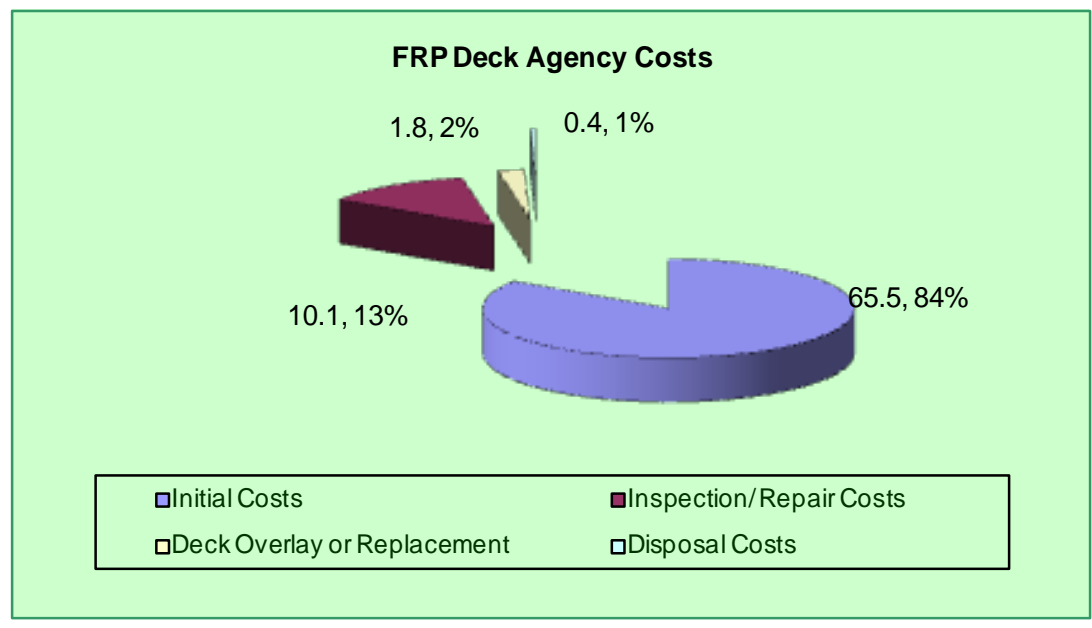

Figure 5.9 Agency Cost Distribution of La Chein FRP Bridge Deck (Basic Scenario) 


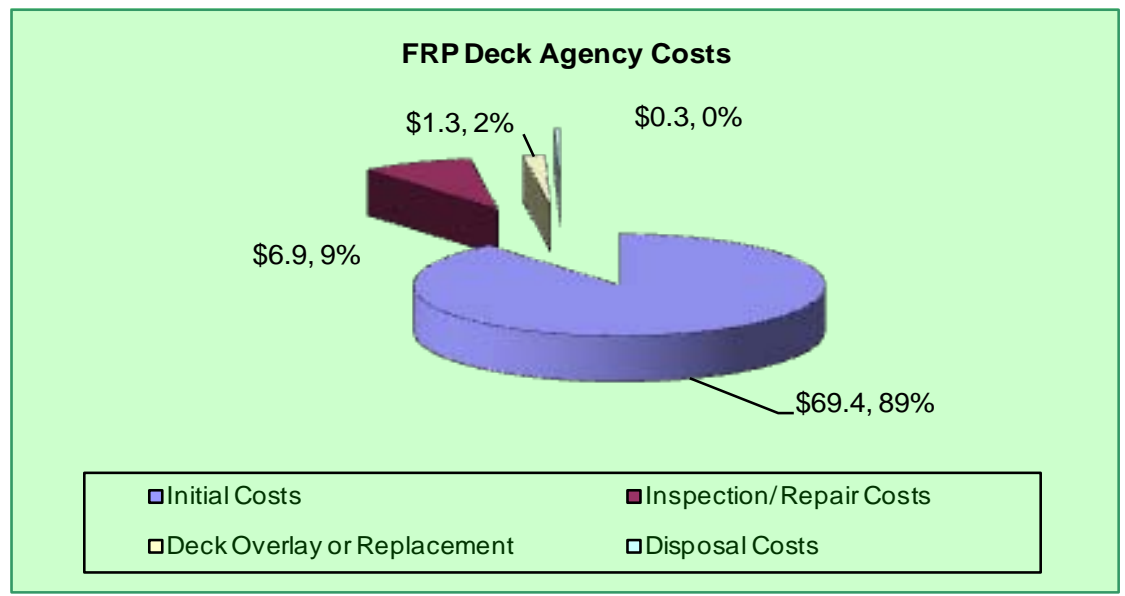

Figure 5.10 Agency Cost Distribution of Katy Truss FRP Bridge Deck (Basic Scenario)

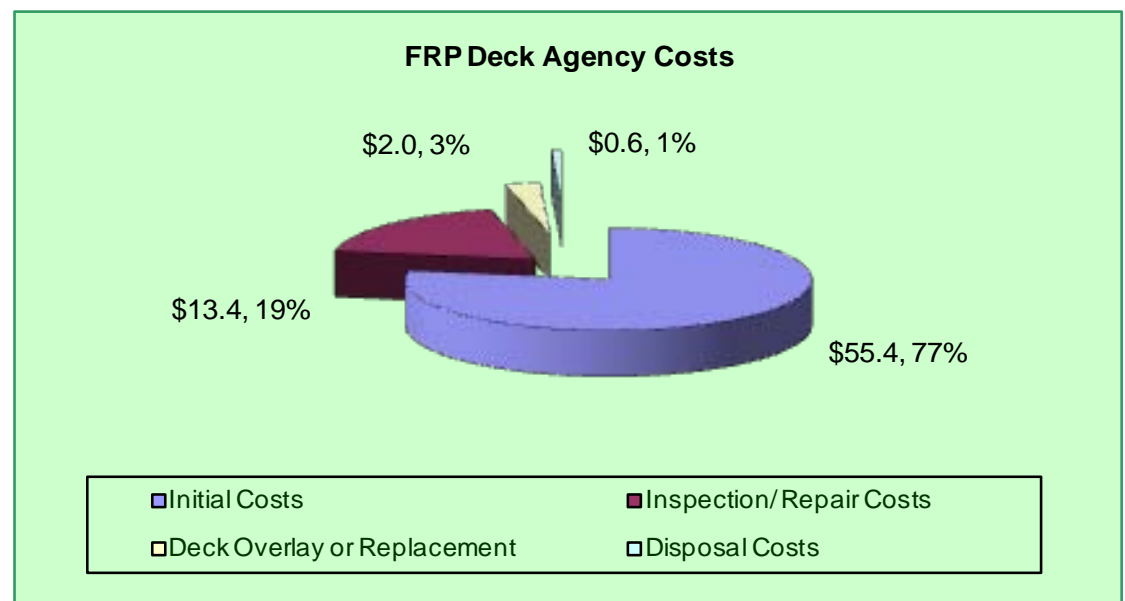

Figure 5.11 Agency Cost Distribution of Goat Farm FRP Bridge Deck (Basic Scenario; Cost Saving Considered)

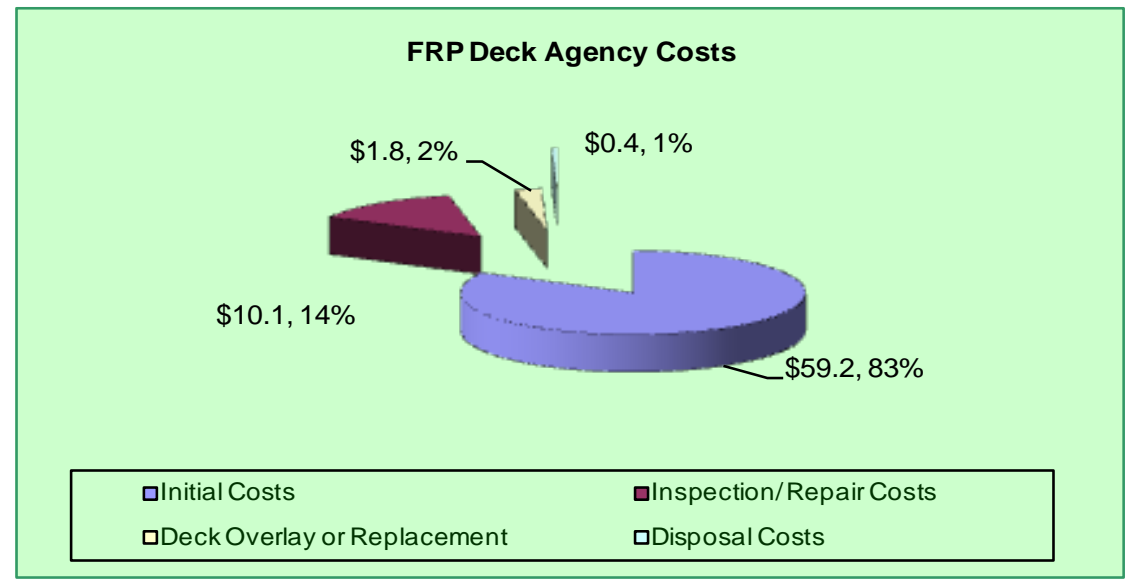

Figure 5.12 Agency Cost Distribution of La Chein FRP Bridge Deck (Basic Scenario; Cost Saving Considered) 


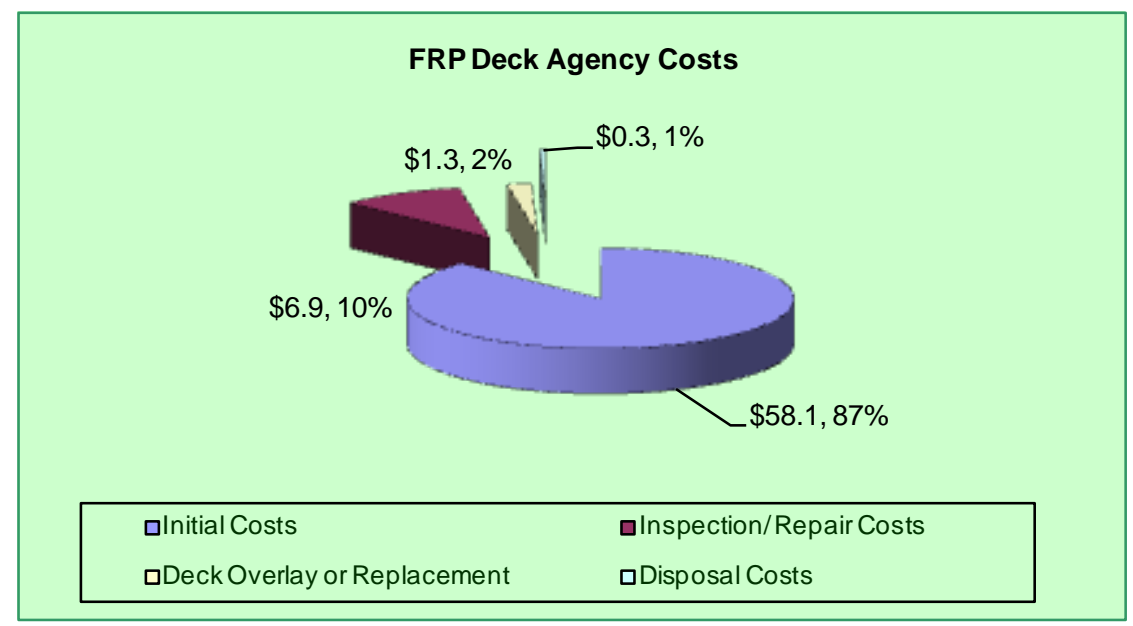

Figure 5.13 Agency Cost Distribution of Katy Truss FRP Bridge Deck (Basic Scenario; Cost Saving Considered)

The inspection/repair costs are not significantly different for the basic models due to the assumption that both types of bridge decks share the same anticipated schedules. Overall, inspection/repair costs accounted for 10 percent to 19 percent of FRP life-cycle cost and 11 percent to 18 percent of SRC cost. The values are translated to $\$ 6.9$ /sq ft to $\$ 13.5 /$ sq ft for FRP deck and \$6.6/sq ft to \$13.4/sq ft for SRC deck.

The disposal costs for FRP decks are significantly lower than those of SRC decks. The main reason is that it is easier and faster to remove an FRP deck compared to an SRC deck. For SRC, the deck is removed by crushing the deck and hauling off the debris. For both type of bridge decks, it is assumed that they do not have salvage value, so disposal costs are simply the cost to destroy and to transport them to a landfill facility. The transportation cost itself is a function of distance between the project site and landfill facility. For basic scenarios, disposal cost ranges from $\$ 0.3 / \mathrm{sq} \mathrm{ft}$ to $\$ 0.6 / \mathrm{sq} \mathrm{ft}$ for FRP deck, and it ranges from $\$ 5.3 /$ sq ft to $\$ 7.4 /$ sq ft for SRC deck. Overall, disposal cost is accounted for 0.5 percent to 0.8 percent of FRP deck LCC cost and 8.2 percent to 10 percent of SRC deck LCC cost. 


\subsubsection{User Costs}

The user costs for both FRP and SRC bridge decks under the basic scenarios are small, i.e., at most \$1.15/sq ft for FRP deck and \$2.92/sq ft for SRC deck. The main reason is the extremely low ADT for these bridge decks, i.e., 20 to 700 vehicles per day. Hence, the construction, maintenance, or disposal activities only affect a small number of road users, and the associated cost is minimal.

In general, the percentage of user cost to the total cost increases when ADT increases. As an example, user costs of SRC decks are 0.2 percent, 0.9 percent and 4.7 percent of the total costs for bridge deck when ADT are 20,100, and 700, respectively.

\subsubsection{Total Costs}

The basic scenarios suggested that if the default SRC deck cost and FRP deck cost applied, the site has very low ADT, the structural steel savings are included, and if both type of bridge decks share the same maintenance/inspection and anticipated repair frequencies, the LCC of FRP bridge deck is lower than the SRC bridge deck for the Goat Farm. For La Chein and Katy Truss bridges, increases in the ADT can cause the FRP bridge deck to be more economical than the SRC bridge deck. Life-cycle Cost per square foot for the three bridges under basic scenarios are given in Table 5.5.

\subsection{Savings Comparison of Decks and Sensitivity Analysis}

Sensitivity analysis was performed to learn the effects of important parameters to the total life-cycle cost of both FRP and SRC decks. The higher the effect of the parameter, the more sensitive the parameter is. The analysis was performed by 
examining life-cycle cost using different parameter values.

\subsubsection{Goat Farm Bridge}

The basic scenario of this case study is as follows: FRP deck costs $\$ 56.3 / \mathrm{sq} \mathrm{ft}$, and $\mathrm{ADT}=20$ vehicles/day. Under these conditions, it was estimated that the LCC costs are $\$ 75.5 / \mathrm{sq} \mathrm{ft}$ and $\$ 73.8 / \mathrm{sq} \mathrm{ft}$ for FRP and SRC decks respectively. When the steel substructure cost reductions are considered, the FRP deck becomes competitive to SRC. The LCC cost for FRP is lowered to $\$ 71.4 / \mathrm{sq} \mathrm{ft}$. Figure 5.14 shows that, for this study, FRP is more economical than SRC if FRP deck costs less than $\$ 58.6 / \mathrm{sq} \mathrm{ft}$.

The higher the ADT, the higher the user cost will be, and since the SRC deck

initial and disposal activities consume more time than the FRP initial and disposal activities do, SRC decks have a higher sensitivity to ADT as depicted in Figure 5.15. 
Table 5.5 Life-cycle Cost Breakdown under Basic Scenario

\begin{tabular}{|c|c|c|c|c|c|c|}
\hline Bridge Deck Project & Goat Farm & Goat Farm & La Chein & La Chein & Katy Truss & Katy Truss \\
\hline $\mathrm{Yr}$ & 2003 & 2003 & 2001 & 2001 & 2000 & 2000 \\
\hline Bridge Deck Alternative & FRP & SRC & FRP & SRC & FRP & SRC \\
\hline ADT (vehicles/day) & 20 & 20 & 100 & 100 & 700 & 700 \\
\hline Study Period (yrs) & 60 & 60 & 60 & 60 & 60 & 60 \\
\hline Service Life (yrs) & 60 & 30 & 60 & 30 & 60 & 30 \\
\hline Deck Cost (\$/sq ft) & $\$ 56.3$ & $\$ 28.3$ & $\$ 62.6$ & $\$ 27.2$ & $\$ 67.5$ & $\$ 26.5$ \\
\hline \multicolumn{7}{|l|}{ Initial Costs } \\
\hline \multicolumn{7}{|l|}{ Agency Costs } \\
\hline Manufacturing Costs & $\$ 56.34$ & $\$ 28.30$ & $\$ 62.61$ & $\$ 27.24$ & $\$ 67.65$ & $\$ 26.56$ \\
\hline Transportation Costs & $\$ 1.14$ & $\$ 0.79$ & $\$ 0.95$ & $\$ 0.81$ & $\$ 0.28$ & $\$ 0.43$ \\
\hline Installation (incl. overlay) Costs & $\$ 1.54$ & $\$ 5.45$ & $\$ 1.52$ & $\$ 5.24$ & $\$ 1.26$ & $\$ 5.11$ \\
\hline Safety Costs & $\$ 0.42$ & $\$ 2.82$ & $\$ 0.42$ & $\$ 2.09$ & $\$ 0.25$ & $\$ 1.58$ \\
\hline Total Agency Costs & $\$ 59.45$ & $\$ 37.36$ & $\$ 65.48$ & $\$ 35.37$ & $\$ 69.26$ & $\$ 33.60$ \\
\hline \multicolumn{7}{|l|}{ User Costs } \\
\hline Driver Delay Costs & $\$ 0.01$ & $\$ 0.04$ & $\$ 0.03$ & $\$ 0.15$ & $\$ 0.14$ & $\$ 0.76$ \\
\hline Vehicle Operating Costs & $\$ 0.00$ & $\$ 0.02$ & $\$ 0.02$ & $\$ 0.09$ & $\$ 0.08$ & $\$ 0.45$ \\
\hline Increased Accident Costs & $\$ 0.00$ & $\$ 0.00$ & $\$ 0.00$ & $\$ 0.01$ & $\$ 0.01$ & $\$ 0.08$ \\
\hline Total User Costs & $\$ 0.01$ & $\$ 0.07$ & $\$ 0.05$ & $\$ 0.25$ & $\$ 0.23$ & $\$ 1.28$ \\
\hline \multicolumn{7}{|l|}{ Structural Savings } \\
\hline Steel & $\$ 4.06$ & $\$ 0.00$ & $\$ 6.28$ & $\$ 0.00$ & $\$ 11.38$ & $\$ 0.00$ \\
\hline Concrete & $\$ 0.00$ & $\$ 0.00$ & $\$ 0.00$ & $\$ 0.00$ & $\$ 0.00$ & $\$ 0.00$ \\
\hline Total Structural Savings & $\$ 4.06$ & $\$ 0.00$ & $\$ 6.28$ & $\$ 0.00$ & $\$ 11.35$ & $\$ 0.00$ \\
\hline Total Initial Costs & $\$ 55.40$ & $\$ 37.43$ & $\$ 59.25$ & $\$ 35.62$ & $\$ 58.14$ & $\$ 34.88$ \\
\hline \multicolumn{7}{|l|}{ Maintenance/Repair Costs } \\
\hline \multicolumn{7}{|l|}{ Agency Costs } \\
\hline Basic Inspection & $\$ 6.78$ & $\$ 6.78$ & $\$ 4.83$ & $\$ 4.83$ & $\$ 2.84$ & $\$ 2.84$ \\
\hline Supplemental Inspection & $\$ 5.29$ & $\$ 4.76$ & $\$ 3.77$ & $\$ 3.40$ & $\$ 2.22$ & $\$ 2.00$ \\
\hline Anticipated Repairs & $\$ 1.90$ & $\$ 1.90$ & $\$ 1.83$ & $\$ 1.83$ & $\$ 1.79$ & $\$ 1.79$ \\
\hline Inspection/Maintenance & $\$ 13.98$ & $\$ 13.45$ & $\$ 10.44$ & $\$ 10.06$ & $\$ 6.85$ & $\$ 6.63$ \\
\hline Deck Overlay Replacement & $\$ 1.43$ & $\$ 0.00$ & $\$ 1.37$ & $\$ 0.00$ & $\$ 1.34$ & $\$ 0.00$ \\
\hline Deck Replacement & $\$ 0.00$ & $\$ 15.39$ & $\$ 0.00$ & $\$ 14.58$ & $\$ 0.00$ & $\$ 13.88$ \\
\hline Deck Overlay or Replacement & $\$ 1.43$ & $\$ 15.39$ & $\$ 1.37$ & $\$ 14.58$ & $\$ 1.34$ & $\$ 13.88$ \\
\hline Total Agency Costs & $\$ 15.40$ & $\$ 28.84$ & $\$ 11.81$ & $\$ 24.63$ & $\$ 8.17$ & $\$ 20.45$ \\
\hline \multicolumn{7}{|l|}{ User Costs } \\
\hline Basic Inspection & $\$ 0.02$ & $\$ 0.02$ & $\$ 0.06$ & $\$ 0.06$ & $\$ 0.24$ & $\$ 0.24$ \\
\hline Supplemental Inspection & $\$ 0.01$ & $\$ 0.01$ & $\$ 0.04$ & $\$ 0.03$ & $\$ 0.16$ & $\$ 0.14$ \\
\hline Anticipated Repairs & $\$ 0.03$ & $\$ 0.04$ & $\$ 0.10$ & $\$ 0.14$ & $\$ 0.43$ & $\$ 0.57$ \\
\hline Deck Overlay Replacement & $\$ 0.01$ & $\$ 0.00$ & $\$ 0.03$ & $\$ 0.00$ & $\$ 0.11$ & $\$ 0.00$ \\
\hline Deck Replacement & $\$ 0.00$ & $\$ 0.03$ & $\$ 0.00$ & $\$ 0.10$ & $\$ 0.00$ & $\$ 0.53$ \\
\hline Total User Costs & $\$ 0.06$ & $\$ 0.09$ & $\$ 0.23$ & $\$ 0.33$ & $\$ 0.93$ & $\$ 1.48$ \\
\hline Total Maintenance/Repair Costs & $\$ 15.47$ & $\$ 28.93$ & $\$ 12.04$ & $\$ 24.96$ & $\$ 9.10$ & $\$ 21.93$ \\
\hline \multicolumn{7}{|l|}{ Disposal Costs } \\
\hline \multicolumn{7}{|l|}{ Agency Costs } \\
\hline Deconstruction Costs & $\$ 0.27$ & $\$ 5.19$ & $\$ 0.19$ & $\$ 3.85$ & $\$ 0.11$ & $\$ 3.46$ \\
\hline Safety Costs & $\$ 0.02$ & $\$ 0.41$ & $\$ 0.02$ & $\$ 0.30$ & $\$ 0.01$ & $\$ 0.18$ \\
\hline Transportation Costs & $\$ 0.04$ & $\$ 0.97$ & $\$ 0.02$ & $\$ 0.69$ & $\$ 0.02$ & $\$ 0.81$ \\
\hline Landfill Fees & $\$ 0.24$ & $\$ 0.81$ & $\$ 0.17$ & $\$ 0.57$ & $\$ 0.19$ & $\$ 0.65$ \\
\hline Total Agency Costs & $\$ 0.57$ & $\$ 7.38$ & $\$ 0.40$ & $\$ 5.41$ & $\$ 0.34$ & $\$ 5.09$ \\
\hline \multicolumn{7}{|l|}{ User Costs } \\
\hline Driver Delay Costs & $\$ 0.00$ & $\$ 0.01$ & $\$ 0.00$ & $\$ 0.02$ & $\$ 0.01$ & $\$ 0.09$ \\
\hline Vehicle Operating Costs & $\$ 0.00$ & $\$ 0.00$ & $\$ 0.00$ & $\$ 0.01$ & $\$ 0.00$ & $\$ 0.05$ \\
\hline Increased Accident Costs & $\$ 0.00$ & $\$ 0.00$ & $\$ 0.00$ & $\$ 0.00$ & $\$ 0.00$ & $\$ 0.01$ \\
\hline Total User Costs & $\$ 0.00$ & $\$ 0.01$ & $\$ 0.00$ & $\$ 0.04$ & $\$ 0.01$ & $\$ 0.15$ \\
\hline Total Disposal Costs & $\$ 0.57$ & $\$ 7.39$ & $\$ 0.40$ & $\$ 5.44$ & $\$ 0.34$ & $\$ 5.24$ \\
\hline \multicolumn{7}{|l|}{ LIFE CYCLE COST } \\
\hline Total Agency Costs & $\$ 71.36$ & $\$ 73.58$ & $\$ 71.41$ & $\$ 65.40$ & $\$ 66.41$ & $\$ 59.13$ \\
\hline Total User Costs & $\$ 0.08$ & $\$ 0.18$ & $\$ 0.28$ & $\$ 0.62$ & $\$ 1.17$ & $\$ 2.91$ \\
\hline Total Life Cycle Costs & $\$ 71.43$ & $\$ 73.75$ & $\$ 71.69$ & $\$ 66.03$ & $\$ 67.58$ & $\$ 62.05$ \\
\hline $\begin{array}{l}\text { Total Life Cycle Costs Savings Not } \\
\text { Considered }\end{array}$ & $\$ 75.50$ & $\$ 73.75$ & $\$ 77.97$ & $\$ 66.03$ & $\$ 78.94$ & $\$ 62.05$ \\
\hline
\end{tabular}




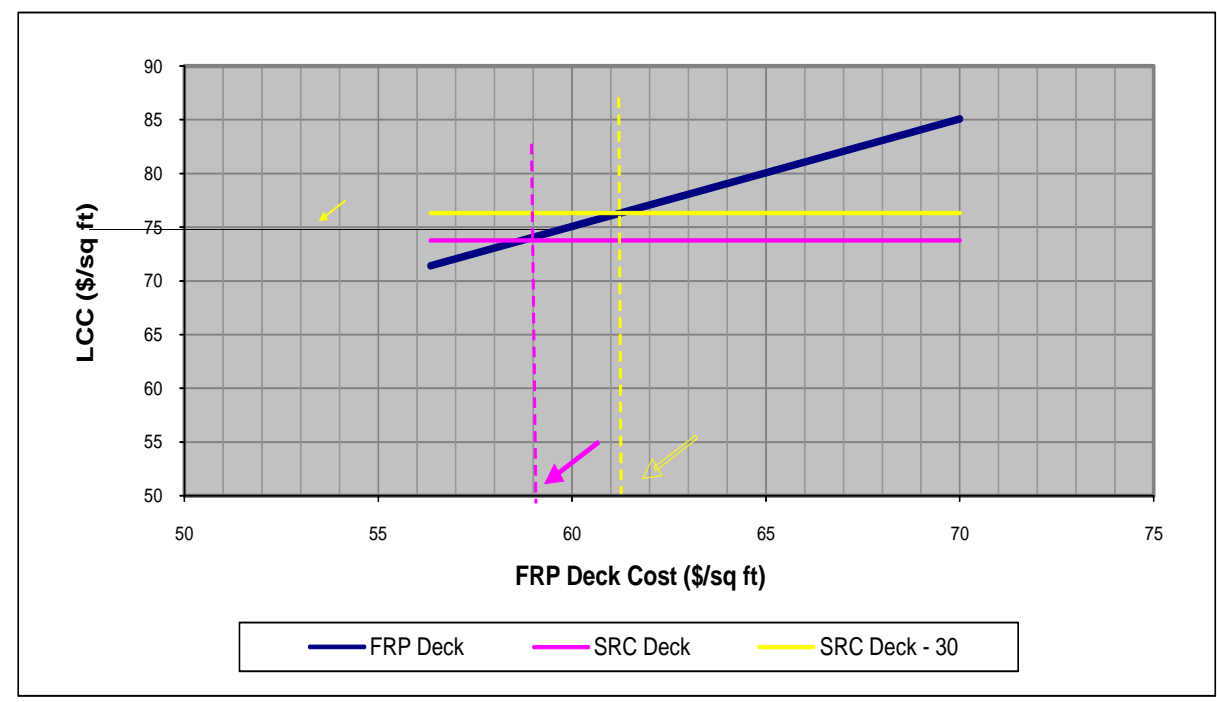

Figure 5.14 LCC Cost of Goat Farm Bridge as a Function of Deck Cost

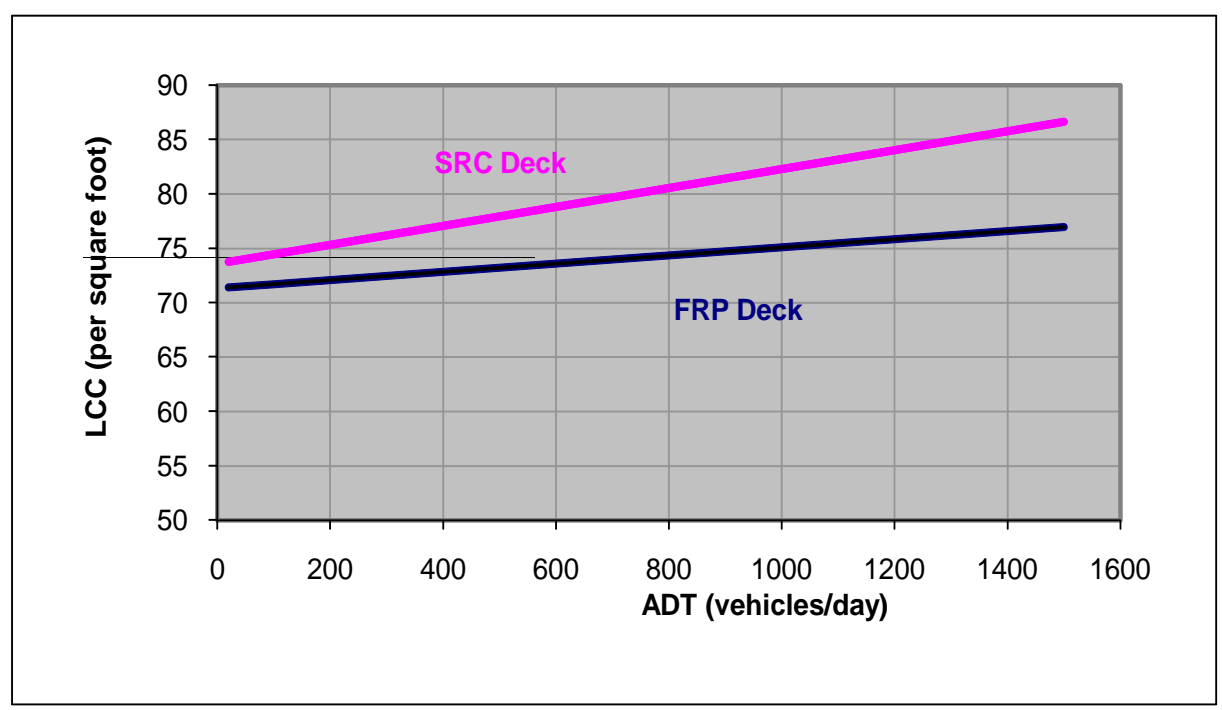

Figure 5.15 Effects of ADT on LCC Costs of Goat Farm Bridge

\subsubsection{La Chein Bridge}

The basic scenario of this case study is as follows: FRP deck costs $\$ 62.6 / \mathrm{sq} \mathrm{ft}$, and ADT $=100$ vehicles/day. Under these conditions, it was estimated that the LCC costs are \$77.9/sq ft and \$66.0/sq ft for FRP and SRC decks respectively. When structural cost 
savings are considered, the LCC cost for FRP is $\$ 71.7 / \mathrm{sq} \mathrm{ft}$. Figure 5.16 shows that, for this study, FRP is more economical than SRC if FRP deck costs less than \$ 56.9/sq ft.

Similar to the finding for Goat Farm Bridge, the higher the ADT, the higher the user cost for La Chein Bridge. SRC deck initial and disposal activities consume more time; therefore it results in higher sensitivity to ADT, as depicted in Figure 5.17. Therefore, higher ADT is more beneficial for FRP decks. If the ADT is set to 1,800 for example, FRP is financially viable under the basic scenario.

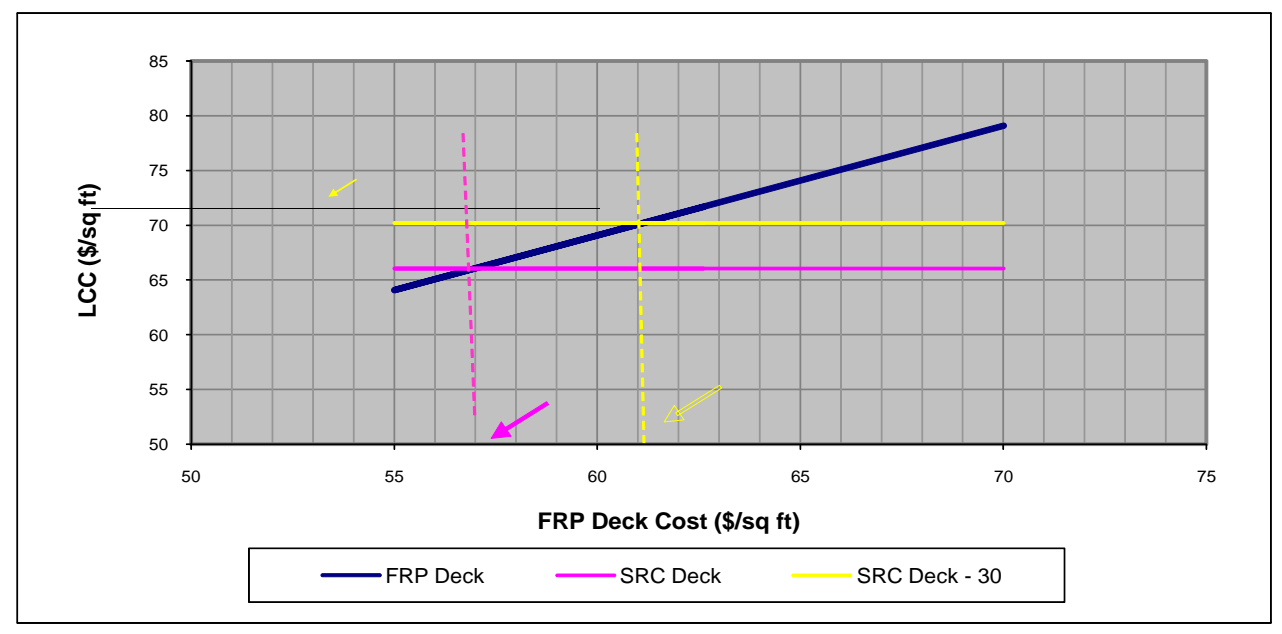

Figure 5.16 LCC Costs of La Chein Bridge

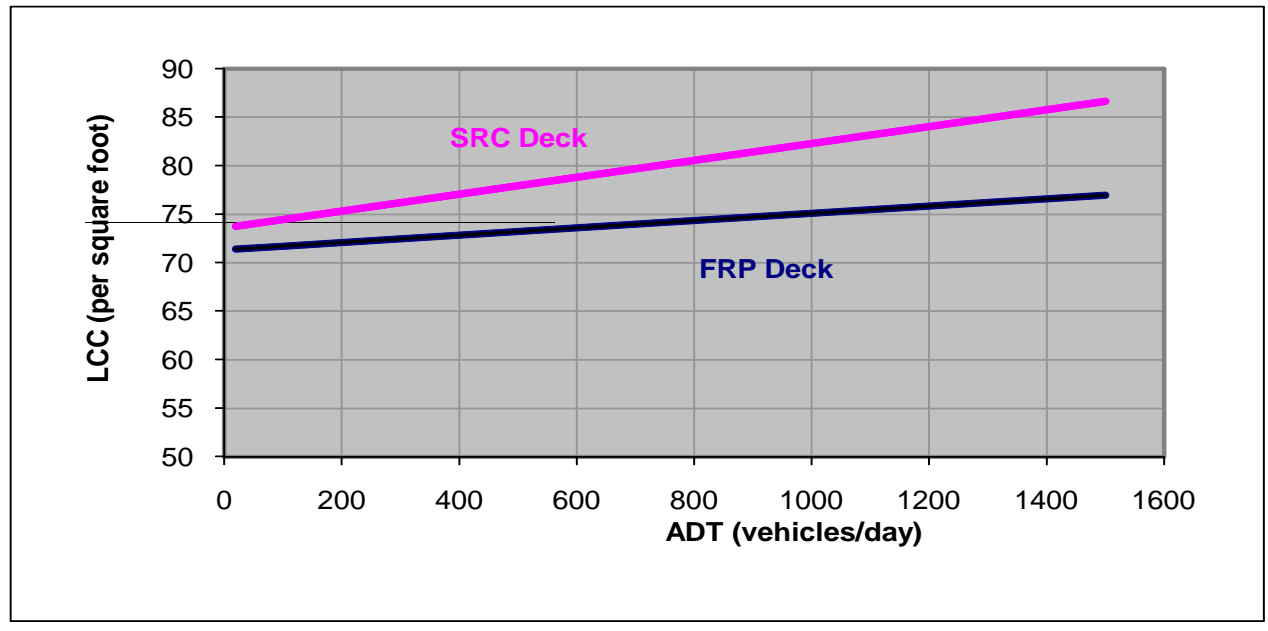

Figure 5.17 Effects of ADT on LCC Costs of La Chein Bridge 


\subsubsection{Katy Truss Bridge}

The basic scenario of this case study is as follows: FRP deck costs $\$ 67.5 / \mathrm{sq} \mathrm{ft}$, when $\mathrm{ADT}=700$ vehicles/day. When substructure cost saving is considered, the LCC cost for FRP and SRC are \$67.6/sq ft and \$62.1/sq ft, respectively. Hence, FRP is not financially viable under the basic scenario. For Katy Truss Bridge, FRP is more economical than SRC if FRP deck costs less than $\$ 61.8 / \mathrm{sq} \mathrm{ft}$.

The higher the ADT, the higher the user cost. Since SRC deck initial and disposal activities consume more time, it results in higher sensitivity to ADT, as shown by a steeper slope in Figure 5.18. Therefore, higher ADT is more beneficial for FRP deck. For this bridge, FRP bridge deck is more competitive than SRC bridge deck under basic scenario if ADT equals to 3,000.

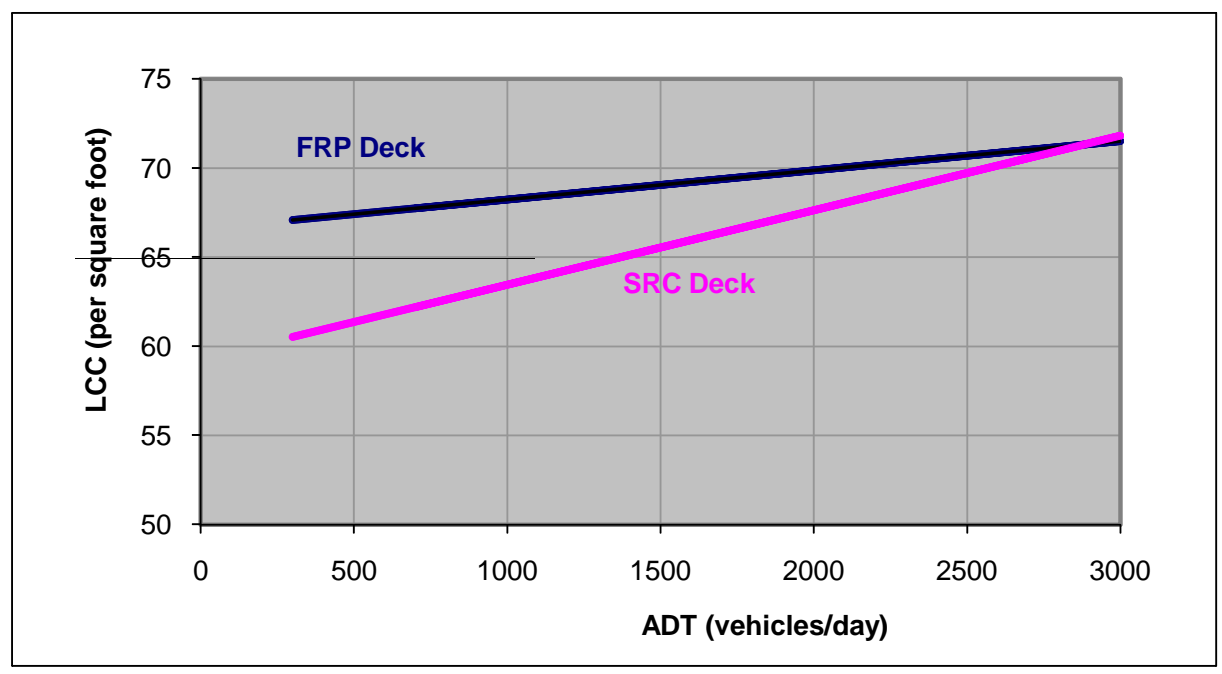

Figure 5.18 Effects of ADT on LCC Costs of Katy Truss Bridge

\subsection{Discussion}

\subsubsection{Effects of FRP Manufacturing Cost}

As discussed previously, FRP manufacturing costs play an important role in 
determining the viability of this type of deck. If steel support cost savings are considered, and the service life of FRP deck is constant, the relationship between FRP manufacturing cost and its life-cycle cost/sq ft for the Goat Farm Bridge deck is illustrated in Figure 5.14. If the same anticipated inspection and maintenance schedules for the two bridge decks are assumed, an FRP bridge deck with maximum cost of \$61.2/sq ft is competitive with an SRC deck at \$ 30/sq ft, as shown in Figure 5.14. The initial cost ratio seems high, 1.54, because of the difference in their service lives. Taking the cost of the second bridge deck into account, the maximum allowable cost ratio for the Goat Farm FRP deck is 1.09. The actual initial cost ratio for Goat Farm under the basic scenario is 1.05 , which is lower than 1.09. Hence, it’s financially viable.

The same analysis was performed for La Chein Bridge deck, and the results are depicted in Figure 5.16. Similar to the finding for Goat Farm Bridge deck, with the assumed same anticipated inspection and maintenance schedules for the two bridge decks, maximum FRP bridge deck to be cost competitive with \$30/sq ft SRC deck is \$ 61.1 /sq ft, i.e., maximum allowable initial cost ratio of 1.06. The actual price ratio is 1.18, which explains why Goat Farm FRP bridge deck is not financially viable this under basic scenario.

\subsubsection{Effects of Inspection/Anticipated Maintenance Schedules}

Given the basic scenarios, in which FRP deck has a service life of 60 years, while SRC deck has a service life of 30 years, the maximum FRP bridge deck to be cost competitive with SRC deck is \$58.6/sq ft and \$56.9/sq ft for Goat Farm Bridge and La Chein bridge, respectively, as shown in Figure 5.14 and Figure 5.16. The ADT for those 
bridges are 20 and 100, respectively. The basic assumption for the results was the assumed same schedules for the two bridge decks. If the FRP maintenance frequency is less than SRC as expected by FRP experts, the conclusions would change.

To illustrate the effect of maintenance cost, the same analysis was done using different assumption. If we assumed that FRP maintenance is less frequent than SRC, as given in Section 5.2.1, the maximum FRP bridge deck to be cost competitive with SRC deck can be slightly higher, i.e., \$ 63.5/sq ft and \$ 60.8/sq ft, respectively, for Goat Farm and La Chein bridges. The maximum allowable initial cost ratio between FRP and SRC decks are 1.67 and 1.61 for those bridges (1.21 and 1.17 if SRC deck replacement costs are included). This condition allows FRP deck to become better in competitiveness for La Chein. A combination of less maintenance and higher ADT allows FRP to become a viable alternative deck. LCC breakdowns for different scenarios are given in Table 5.6. 
Table 5.6 LCC Breakdown for Goat Farm and La Chein Bridge Decks

\begin{tabular}{|c|c|c|c|c|c|c|}
\hline Bridge Deck Project & Goat Farm & Goat Farm & Goat Farm & La Chein & La Chein & La Chein \\
\hline $\mathrm{Yr}$ & 2003 & 2003 & 2003 & 2001 & 2001 & 2001 \\
\hline Bridge Deck Alternative & FRP & SRC & FRP & FRP & SRC & FRP \\
\hline ADT (vehicles/day) & 20 & 20 & 20 & 100 & 100 & 100 \\
\hline Inspections/Ancitipated Repairs & Same & Same & $\begin{array}{l}\text { Less } \\
\text { Frequency }\end{array}$ & Same & Same & $\begin{array}{l}\text { Less } \\
\text { Frequency }\end{array}$ \\
\hline Study Period (yrs) & 60 & 60 & 60 & 60 & 60 & 60 \\
\hline Service Life (yrs) & 60 & 30 & 60 & 60 & 30 & 60 \\
\hline \multicolumn{7}{|l|}{ Initial Costs } \\
\hline \multicolumn{7}{|l|}{ Agency Costs } \\
\hline Manufacturing Costs & $\$ 56.34$ & $\$ 28.30$ & $\$ 56.34$ & $\$ 62.61$ & $\$ 27.24$ & $\$ 62.61$ \\
\hline Transportation Costs & $\$ 1.14$ & $\$ 0.79$ & $\$ 1.14$ & $\$ 0.95$ & $\$ 0.81$ & $\$ 0.95$ \\
\hline Installation (incl. overlay) Costs & $\$ 1.54$ & $\$ 5.45$ & $\$ 1.54$ & $\$ 1.52$ & $\$ 5.24$ & $\$ 1.52$ \\
\hline Safety Costs & $\$ 0.42$ & $\$ 2.82$ & $\$ 0.42$ & $\$ 0.42$ & $\$ 2.09$ & $\$ 0.42$ \\
\hline Total Agency Costs & $\$ 59.45$ & $\$ 37.36$ & $\$ 59.45$ & $\$ 65.48$ & $\$ 35.37$ & $\$ 65.48$ \\
\hline \multicolumn{7}{|l|}{ User Costs } \\
\hline Driver Delay Costs & $\$ 0.01$ & $\$ 0.04$ & $\$ 0.01$ & $\$ 0.03$ & $\$ 0.15$ & $\$ 0.03$ \\
\hline Vehicle Operating Costs & $\$ 0.00$ & $\$ 0.02$ & $\$ 0.00$ & $\$ 0.02$ & $\$ 0.09$ & $\$ 0.02$ \\
\hline Increased Accident Costs & $\$ 0.00$ & $\$ 0.00$ & $\$ 0.00$ & $\$ 0.00$ & $\$ 0.01$ & $\$ 0.00$ \\
\hline Total User Costs & $\$ 0.01$ & $\$ 0.07$ & $\$ 0.01$ & $\$ 0.05$ & $\$ 0.25$ & $\$ 0.05$ \\
\hline \multicolumn{7}{|l|}{ Structural Savings } \\
\hline Steel & $\$ 4.06$ & $\$ 0.00$ & $\$ 4.06$ & $\$ 6.28$ & $\$ 0.00$ & $\$ 6.28$ \\
\hline Concrete & $\$ 0.00$ & $\$ 0.00$ & $\$ 0.00$ & $\$ 0.00$ & $\$ 0.00$ & $\$ 0.00$ \\
\hline Total Structural Savings & $\$ 4.06$ & $\$ 0.00$ & $\$ 4.06$ & $\$ 6.28$ & $\$ 0.00$ & $\$ 0.00$ \\
\hline Total Initial Costs & $\$ 55.40$ & $\$ 37.43$ & $\$ 55.40$ & $\$ 59.25$ & $\$ 35.62$ & $\$ 59.25$ \\
\hline & & & & & & \\
\hline \multicolumn{7}{|l|}{ Maintenance/Repair Costs } \\
\hline \multicolumn{7}{|l|}{ Agency Costs } \\
\hline Basic Inspection & $\$ 6.78$ & $\$ 6.78$ & $\$ 3.39$ & $\$ 4.83$ & $\$ 4.83$ & $\$ 2.42$ \\
\hline Supplemental Inspection & $\$ 5.29$ & $\$ 4.76$ & $\$ 5.29$ & $\$ 3.77$ & $\$ 3.40$ & $\$ 3.77$ \\
\hline Anticipated Repairs & $\$ 1.90$ & $\$ 1.90$ & $\$ 0.47$ & $\$ 1.83$ & $\$ 1.83$ & $\$ 0.45$ \\
\hline Deck Overlay Replacement & $\$ 1.43$ & $\$ 0.00$ & $\$ 1.43$ & $\$ 1.37$ & $\$ 0.00$ & $\$ 1.37$ \\
\hline Deck Replacement & $\$ 0.00$ & $\$ 15.39$ & $\$ 0.00$ & $\$ 0.00$ & $\$ 14.58$ & $\$ 0.00$ \\
\hline Total Agency Costs & $\$ 15.40$ & $\$ 28.84$ & $\$ 10.58$ & $\$ 11.81$ & $\$ 24.63$ & $\$ 8.01$ \\
\hline \multicolumn{7}{|l|}{ User Costs } \\
\hline Basic Inspection & $\$ 0.02$ & $\$ 0.02$ & $\$ 0.01$ & $\$ 0.06$ & $\$ 0.06$ & $\$ 0.03$ \\
\hline Supplemental Inspection & $\$ 0.01$ & $\$ 0.01$ & $\$ 0.01$ & $\$ 0.04$ & $\$ 0.03$ & $\$ 0.04$ \\
\hline Anticipated Repairs & $\$ 0.03$ & $\$ 0.04$ & $\$ 0.01$ & $\$ 0.10$ & $\$ 0.14$ & $\$ 0.03$ \\
\hline Deck Overlay Replacement & $\$ 0.01$ & $\$ 0.00$ & $\$ 0.01$ & $\$ 0.03$ & $\$ 0.00$ & $\$ 0.03$ \\
\hline Deck Replacement & $\$ 0.00$ & $\$ 0.03$ & $\$ 0.00$ & $\$ 0.00$ & $\$ 0.10$ & $\$ 0.00$ \\
\hline Total User Costs & $\$ 0.06$ & $\$ 0.09$ & $\$ 0.03$ & $\$ 0.23$ & $\$ 0.33$ & $\$ 0.12$ \\
\hline Total Maintenance/Repair Costs & $\$ 15.47$ & $\$ 28.93$ & $\$ 10.61$ & $\$ 12.04$ & $\$ 24.96$ & $\$ 8.13$ \\
\hline \multicolumn{7}{|l|}{ Disposal Costs } \\
\hline \multicolumn{7}{|l|}{ Agency Costs } \\
\hline Deconstruction Costs & $\$ 0.27$ & $\$ 5.19$ & $\$ 0.27$ & $\$ 0.19$ & $\$ 3.85$ & $\$ 0.19$ \\
\hline Safety Costs & $\$ 0.02$ & $\$ 0.41$ & $\$ 0.02$ & $\$ 0.02$ & $\$ 0.30$ & $\$ 0.02$ \\
\hline Transportation Costs & $\$ 0.04$ & $\$ 0.97$ & $\$ 0.04$ & $\$ 0.02$ & $\$ 0.69$ & $\$ 0.02$ \\
\hline Landfill Fees & $\$ 0.24$ & $\$ 0.81$ & $\$ 0.24$ & $\$ 0.17$ & $\$ 0.57$ & $\$ 0.17$ \\
\hline Total Agency Costs & $\$ 0.57$ & $\$ 7.38$ & $\$ 0.57$ & $\$ 0.40$ & $\$ 5.41$ & $\$ 0.40$ \\
\hline \multicolumn{7}{|l|}{ User Costs } \\
\hline Driver Delay Costs & $\$ 0.00$ & $\$ 0.01$ & $\$ 0.00$ & $\$ 0.00$ & $\$ 0.02$ & $\$ 0.00$ \\
\hline Vehicle Operating Costs & $\$ 0.00$ & $\$ 0.00$ & $\$ 0.00$ & $\$ 0.00$ & $\$ 0.01$ & $\$ 0.00$ \\
\hline Increased Accident Costs & $\$ 0.00$ & $\$ 0.00$ & $\$ 0.00$ & $\$ 0.00$ & $\$ 0.00$ & $\$ 0.00$ \\
\hline Total User Costs & $\$ 0.00$ & $\$ 0.01$ & $\$ 0.00$ & $\$ 0.00$ & $\$ 0.04$ & $\$ 0.00$ \\
\hline Total Disposal Costs & $\$ 0.57$ & $\$ 7.39$ & $\$ 0.57$ & $\$ 0.40$ & $\$ 5.44$ & $\$ 0.40$ \\
\hline \multicolumn{7}{|l|}{ LIFE CYCLE COST } \\
\hline Total Agency Costs & $\$ 71.36$ & $\$ 73.58$ & $\$ 66.53$ & $\$ 71.41$ & $\$ 65.40$ & $\$ 67.61$ \\
\hline Total User Costs & $\$ 0.08$ & $\$ 0.18$ & $\$ 0.05$ & $\$ 0.28$ & $\$ 0.62$ & $\$ 0.18$ \\
\hline Total Life Cycle Costs & $\$ 71.43$ & $\$ 73.75$ & $\$ 66.58$ & $\$ 71.69$ & $\$ 66.03$ & $\$ 67.78$ \\
\hline
\end{tabular}




\subsubsection{Effects of Average Daily Traffic (ADT)}

There is a relationship between ADT and LCC cost, and the higher the ADT the more favorable the FRP deck becomes. As discussed in the previous section, the main reason for the phenomenon is the higher the ADT, the larger the difference between an FRP deck relative to an SRC deck. Table 5.7 shows total agency and user costs for the La Chein bridge deck under different ADT. For this case study bridge, increasing ADT to 1,800 enables the FRP deck to be competitive to SRC deck under the same maintenance assumption.

\subsubsection{Effects of Discount Rate (DR)}

Effects of discount rate (DR) are studied by varying DR values for Goat Farm Bridge (basic scenario) between two to five percent. Figure 5.19 suggests the higher the DR, the less likely the FRP deck is what?. For the basic case of Goat Farm Bridge, FRP deck is a viable alternate if DR is not higher than 3.3percent.

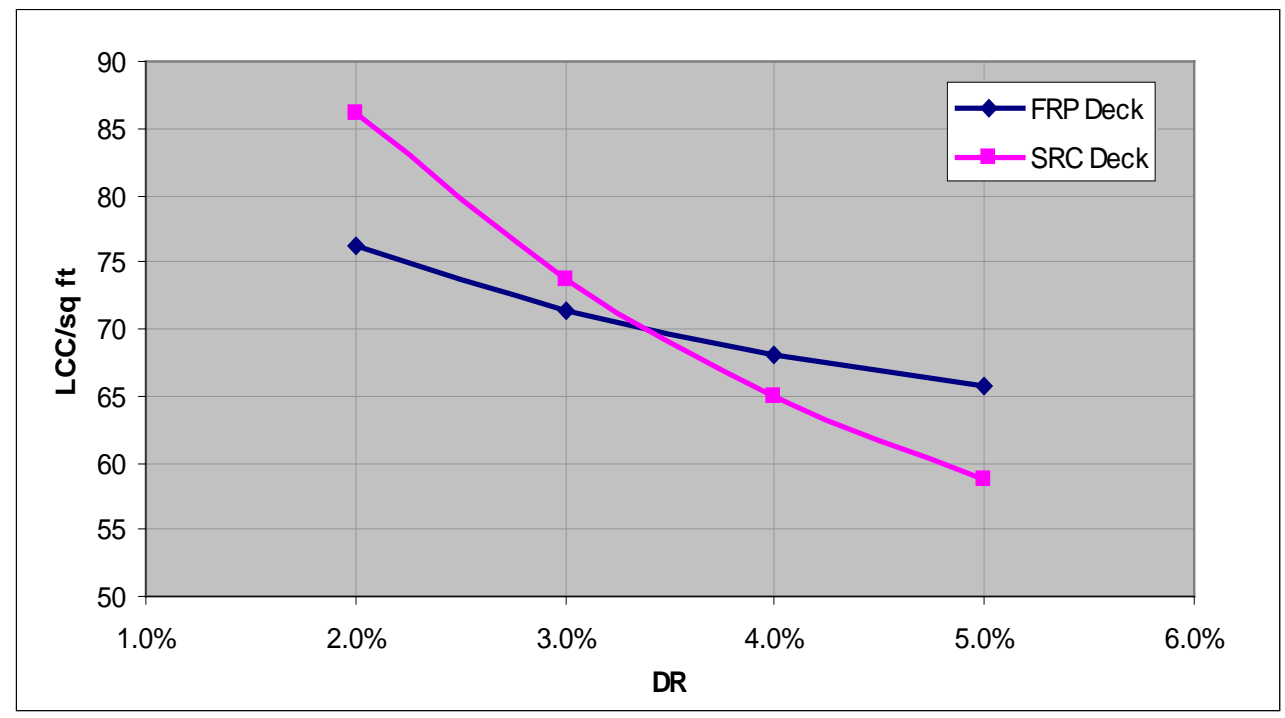

Figure 5.19 Effects of Discount Rate on Life-cycle Cost of Goat Farm Bridge 
Table 5.7 LCC Breakdown for La Chein Bridge Deck under Different ADTs

\begin{tabular}{|c|c|c|c|c|c|c|c|c|c|c|}
\hline Bridge Deck Project & La Chein & La Chein & La Chein & La Chein & La Chein & La Chein & La Chein & La Chein & La Chein & La Chein \\
\hline $\mathrm{Yr}$ & 2001 & 2001 & 2001 & 2001 & 2001 & 2001 & 2001 & 2001 & 2001 & 2001 \\
\hline Bridge Deck Alternative & FRP & FRP & FRP & FRP & FRP & SRC & SRC & SRC & SRC & SRC \\
\hline ADT (vehicles/day) & 100 & 300 & 500 & 750 & 1800 & 100 & 300 & 500 & 750 & 1800 \\
\hline Study Period (yrs) & 60 & 60 & 60 & 60 & 60 & 60 & 60 & 60 & 60 & 60 \\
\hline Service Life (yrs) & 60 & 60 & 60 & 60 & 60 & 30 & 30 & 30 & 30 & 30 \\
\hline Deck Cost (\$/sq ft) & $\$ 62.6$ & $\$ 62.6$ & $\$ 62.6$ & $\$ 62.6$ & $\$ 62.6$ & $\$ 27.2$ & $\$ 27.2$ & $\$ 27.2$ & $\$ 27.2$ & $\$ 27.2$ \\
\hline \multicolumn{11}{|l|}{ Initial Costs } \\
\hline \multicolumn{11}{|l|}{\begin{tabular}{|l} 
Agency Costs \\
\end{tabular}} \\
\hline Manufacturing Costs & $\$ 62.61$ & $\$ 62.61$ & $\$ 62.61$ & $\$ 62.61$ & $\$ 62.61$ & $\$ 27.24$ & $\$ 27.24$ & $\$ 27.24$ & $\$ 27.24$ & $\$ 27.24$ \\
\hline Transportation Costs & $\$ 0.95$ & $\$ 0.95$ & $\$ 0.95$ & $\$ 0.95$ & $\$ 0.95$ & $\$ 0.81$ & $\$ 0.81$ & $\$ 0.81$ & $\$ 0.81$ & $\$ 0.81$ \\
\hline Installation (incl. overlay) Costs & $\$ 1.52$ & $\$ 1.52$ & $\$ 1.52$ & $\$ 1.52$ & $\$ 1.52$ & $\$ 5.24$ & $\$ 5.24$ & $\$ 5.24$ & $\$ 5.24$ & $\$ 5.24$ \\
\hline Safety Costs & $\$ 0.42$ & $\$ 0.42$ & $\$ 0.42$ & $\$ 0.42$ & $\$ 0.42$ & $\$ 2.09$ & $\$ 2.09$ & $\$ 2.09$ & $\$ 2.09$ & $\$ 2.09$ \\
\hline Total Agency Costs & $\$ 65.48$ & $\$ 65.48$ & $\$ 65.48$ & $\$ 65.48$ & $\$ 65.48$ & $\$ 35.37$ & $\$ 35.37$ & $\$ 35.37$ & $\$ 35.37$ & $\$ 35.37$ \\
\hline \multicolumn{11}{|l|}{ User Costs } \\
\hline Driver Delay Costs & $\$ 0.03$ & $\$ 0.10$ & $\$ 0.16$ & $\$ 0.24$ & $\$ 0.58$ & $\$ 0.15$ & $\$ 0.44$ & $\$ 0.74$ & $\$ 1.10$ & $\$ 2.65$ \\
\hline Vehicle Operating Costs & $\$ 0.02$ & $\$ 0.06$ & $\$ 0.10$ & $\$ 0.15$ & $\$ 0.35$ & $\$ 0.09$ & $\$ 0.27$ & $\$ 0.44$ & $\$ 0.66$ & $\$ 1.59$ \\
\hline Increased Accident Costs & $\$ 0.00$ & $\$ 0.01$ & $\$ 0.01$ & $\$ 0.02$ & $\$ 0.05$ & $\$ 0.01$ & $\$ 0.04$ & $\$ 0.07$ & $\$ 0.11$ & $\$ 0.27$ \\
\hline Total User Costs & $\$ 0.05$ & $\$ 0.16$ & $\$ 0.27$ & $\$ 0.41$ & $\$ 0.99$ & $\$ 0.25$ & $\$ 0.75$ & $\$ 1.25$ & $\$ 1.88$ & $\$ 4.50$ \\
\hline \multicolumn{11}{|l|}{ Structural Savings } \\
\hline Steel & $\$ 6.28$ & $\$ 6.28$ & $\$ 6.28$ & $\$ 6.28$ & $\$ 6.28$ & $\$ 0.00$ & $\$ 0.00$ & $\$ 0.00$ & $\$ 0.00$ & $\$ 0.00$ \\
\hline Concrete & $\$ 0.00$ & $\$ 0.00$ & $\$ 0.00$ & $\$ 0.00$ & $\$ 0.00$ & $\$ 0.00$ & $\$ 0.00$ & $\$ 0.00$ & $\$ 0.00$ & $\$ 0.00$ \\
\hline Total Structural Savings & $\$ 6.28$ & $\$ 6.28$ & $\$ 6.28$ & $\$ 6.28$ & $\$ 6.28$ & $\$ 0.00$ & $\$ 0.00$ & $\$ 0.00$ & $\$ 0.00$ & $\$ 0.00$ \\
\hline Total Initial Costs & $\$ 59.25$ & $\$ 59.36$ & $\$ 59.47$ & $\$ 59.61$ & $\$ 60.19$ & $\$ 35.62$ & $\$ 36.12$ & $\$ 36.62$ & $\$ 37.24$ & $\$ 39.87$ \\
\hline \multicolumn{11}{|l|}{ Maintenance/Repair Costs } \\
\hline \multicolumn{11}{|l|}{ Agency Costs } \\
\hline Basic Inspection & $\$ 4.83$ & $\$ 4.83$ & $\$ 4.83$ & $\$ 4.83$ & $\$ 4.83$ & $\$ 4.83$ & $\$ 4.83$ & $\$ 4.83$ & $\$ 4.83$ & $\$ 4.83$ \\
\hline Supplemental Inspection & $\$ 3.77$ & $\$ 3.77$ & $\$ 3.77$ & $\$ 3.77$ & $\$ 3.77$ & $\$ 3.40$ & $\$ 3.40$ & $\$ 3.40$ & $\$ 3.40$ & $\$ 3.40$ \\
\hline Anticipated Repairs & $\$ 1.83$ & $\$ 1.83$ & $\$ 1.83$ & $\$ 1.83$ & $\$ 1.83$ & $\$ 1.83$ & $\$ 1.83$ & $\$ 1.83$ & $\$ 1.83$ & $\$ 1.83$ \\
\hline Deck Overlay Replacement & $\$ 1.37$ & $\$ 1.37$ & $\$ 1.37$ & $\$ 1.37$ & $\$ 1.37$ & $\$ 0.00$ & $\$ 0.00$ & $\$ 0.00$ & $\$ 0.00$ & $\$ 0.00$ \\
\hline Deck Replacement & $\$ 0.00$ & $\$ 0.00$ & $\$ 0.00$ & $\$ 0.00$ & $\$ 0.00$ & $\$ 14.58$ & $\$ 14.58$ & $\$ 14.58$ & $\$ 14.58$ & $\$ 14.58$ \\
\hline Total Agency Costs & $\$ 11.81$ & $\$ 11.81$ & $\$ 11.81$ & $\$ 11.81$ & $\$ 11.81$ & $\$ 24.63$ & $\$ 24.63$ & $\$ 24.63$ & $\$ 24.63$ & $\$ 24.63$ \\
\hline \multicolumn{11}{|l|}{ User Costs } \\
\hline Basic Inspection & $\$ 0.06$ & $\$ 0.18$ & $\$ 0.29$ & $\$ 0.44$ & $\$ 1.05$ & $\$ 0.06$ & $\$ 0.18$ & $\$ 0.29$ & $\$ 0.44$ & $\$ 1.05$ \\
\hline Supplemental Inspection & $\$ 0.04$ & $\$ 0.12$ & $\$ 0.19$ & $\$ 0.29$ & $\$ 0.69$ & $\$ 0.03$ & $\$ 0.10$ & $\$ 0.17$ & $\$ 0.26$ & $\$ 0.62$ \\
\hline Anticipated Repairs & $\$ 0.10$ & $\$ 0.31$ & $\$ 0.52$ & $\$ 0.77$ & $\$ 1.86$ & $\$ 0.14$ & $\$ 0.41$ & $\$ 0.69$ & $\$ 1.03$ & $\$ 2.48$ \\
\hline Deck Overlay Replacement & $\$ 0.03$ & $\$ 0.08$ & $\$ 0.13$ & $\$ 0.19$ & $\$ 0.46$ & $\$ 0.00$ & $\$ 0.00$ & $\$ 0.00$ & $\$ 0.00$ & $\$ 0.00$ \\
\hline Deck Replacement & $\$ 0.00$ & $\$ 0.00$ & $\$ 0.00$ & $\$ 0.00$ & $\$ 0.00$ & $\$ 0.10$ & $\$ 0.31$ & $\$ 0.52$ & $\$ 0.77$ & $\$ 1.85$ \\
\hline Total User Costs & $\$ 0.23$ & $\$ 0.68$ & $\$ 1.13$ & $\$ 1.69$ & $\$ 4.07$ & $\$ 0.33$ & $\$ 1.00$ & $\$ 1.67$ & $\$ 2.50$ & $\$ 6.01$ \\
\hline Total Maintenance/Repair Costs & $\$ 12.04$ & $\$ 12.49$ & $\$ 12.94$ & $\$ 13.51$ & $\$ 15.88$ & $\$ 24.96$ & $\$ 25.63$ & $\$ 26.30$ & $\$ 27.13$ & $\$ 30.64$ \\
\hline \multicolumn{11}{|l|}{ Disposal Costs } \\
\hline \multicolumn{11}{|l|}{ Agency Costs } \\
\hline Deconstruction Costs & $\$ 0.19$ & $\$ 0.19$ & $\$ 0.19$ & $\$ 0.19$ & $\$ 0.19$ & $\$ 3.85$ & $\$ 3.85$ & $\$ 3.85$ & $\$ 3.85$ & $\$ 3.85$ \\
\hline Safety Costs & $\$ 0.02$ & $\$ 0.02$ & $\$ 0.02$ & $\$ 0.02$ & $\$ 0.02$ & $\$ 0.30$ & $\$ 0.30$ & $\$ 0.30$ & $\$ 0.30$ & $\$ 0.30$ \\
\hline Transportation Costs & $\$ 0.02$ & $\$ 0.02$ & $\$ 0.02$ & $\$ 0.02$ & $\$ 0.02$ & $\$ 0.69$ & $\$ 0.69$ & $\$ 0.69$ & $\$ 0.69$ & $\$ 0.69$ \\
\hline Landfill Fees & $\$ 0.17$ & $\$ 0.17$ & $\$ 0.17$ & $\$ 0.17$ & $\$ 0.17$ & $\$ 0.57$ & $\$ 0.57$ & $\$ 0.57$ & $\$ 0.57$ & $\$ 0.57$ \\
\hline Total Agency Costs & $\$ 0.40$ & $\$ 0.40$ & $\$ 0.40$ & $\$ 0.40$ & $\$ 0.40$ & $\$ 5.41$ & $\$ 5.41$ & $\$ 5.41$ & $\$ 5.41$ & $\$ 5.41$ \\
\hline \multicolumn{11}{|l|}{ User Costs } \\
\hline Driver Delay Costs & $\$ 0.00$ & $\$ 0.00$ & $\$ 0.01$ & $\$ 0.01$ & $\$ 0.02$ & $\$ 0.02$ & $\$ 0.06$ & $\$ 0.11$ & $\$ 0.16$ & $\$ 0.38$ \\
\hline Vehicle Operating Costs & $\$ 0.00$ & $\$ 0.00$ & $\$ 0.00$ & $\$ 0.01$ & $\$ 0.01$ & $\$ 0.01$ & $\$ 0.04$ & $\$ 0.06$ & $\$ 0.10$ & $\$ 0.23$ \\
\hline Increased Accident Costs & $\$ 0.00$ & $\$ 0.00$ & $\$ 0.00$ & $\$ 0.00$ & $\$ 0.00$ & $\$ 0.00$ & $\$ 0.01$ & $\$ 0.01$ & $\$ 0.02$ & $\$ 0.04$ \\
\hline Total User Costs & $\$ 0.00$ & $\$ 0.01$ & $\$ 0.01$ & $\$ 0.02$ & $\$ 0.04$ & $\$ 0.04$ & $\$ 0.11$ & $\$ 0.18$ & $\$ 0.27$ & $\$ 0.65$ \\
\hline Total Disposal Costs & $\$ 0.40$ & $\$ 0.40$ & $\$ 0.41$ & $\$ 0.41$ & $\$ 0.44$ & $\$ 5.44$ & $\$ 5.52$ & $\$ 5.59$ & $\$ 5.68$ & $\$ 6.06$ \\
\hline \multicolumn{11}{|l|}{ LIFE CYCLE COST } \\
\hline Total Agency Costs & $\$ 71.41$ & $\$ 71.41$ & $\$ 71.41$ & $\$ 71.41$ & $\$ 71.41$ & $\$ 65.40$ & $\$ 65.40$ & $\$ 65.40$ & $\$ 65.40$ & $\$ 65.40$ \\
\hline Total User Costs & $\$ 0.28$ & $\$ 0.85$ & $\$ 1.41$ & $\$ 2.12$ & $\$ 5.09$ & $\$ 0.62$ & $\$ 1.86$ & $\$ 3.10$ & $\$ 4.65$ & $\$ 11.16$ \\
\hline Total Life Cycle Costs & $\$ 71.69$ & $\$ 72.26$ & $\$ 72.82$ & $\$ 73.53$ & $\$ 76.50$ & $\$ 66.03$ & $\$ 67.27$ & $\$ 68.51$ & $\$ 70.06$ & $\$ 76.57$ \\
\hline
\end{tabular}




\subsubsection{Effects of Other Parameters}

The above life-cycle cost model under the basic scenario assumed that FRP manufacturing cost is a function of time. Hence, FRP bridge deck costs decrease with time as the learning curve reaches the steady state. This model implicitly assumed that resin and fiber costs will be steady. An analysis on effect of resin and fiber costs to manufacturing costs using the Production Cost Model was conducted [22]. This model required twelve basic inputs as well as other inputs, including raw material costs, and provides the manufacturing cost and its components. The parameters used for this simulation analysis are raw material cost input, which include mat, roving, resin costs, and the output studied is FRP manufacturing cost/ft. The values are expressed as a percentage of the default values, i.e., ratio of material cost $=$ material cost inputted/default cost and price ratio = FRP manufacturing output/default output.

FRP manufacturing cost simulation performed, based on Creese and Patrawala's model, showed that FRP bridge deck cost for a given year is a function of material costs. A 10 percent increase of material costs results in about a six percent increase of bridge deck price. Based on the above relationship, one must be careful when performing lifecycle cost analysis of FRP bridge deck. Since the FRP bridge deck cost is not a fixed value, this parameter is an important factor that must be considered in the decision making. 
Utilizing the model, an estimation of FRP bridge deck costs was performed for different deck specifications. For FRP bridge deck with specifications similar to Prodeck8 (Bedford Plastic Inc, weight 15.7 lbs per sq ft and 27 in sq of section area) was \$53.72/sq ft, compared to a Superdeck (Creative Pultrusion, weight 20 lbs per sq ft and 20 in sq of section area) was $\$ 60.04 / \mathrm{sq} \mathrm{ft}$. The results, which were based on labor rate $\$ 20 / \mathrm{hr}$, show that cost of $\$ 50 / \mathrm{sq} \mathrm{ft}$ is a reasonable estimate for 8-inch FRP bridge deck similar to Bedford specifications for the current year.

\subsection{Summary}

The results of life-cycle cost comparison between FRP deck and SRC deck for the base case and for the three case study bridges were presented. Detail results for Reader Run, the example bridge, along with the sensitivity analysis for important parameters for the three case study bridges suggested general findings for FRP versus SRC bridges. 


\section{Chapter 6 \\ Conclusions and Recommendations}

\subsection{Conclusions}

Fiber reinforced polymer (FRP) bridge decks have higher initial costs than traditional steel reinforced concrete (SRC) bridge decks. The improved corrosion resistance of FRP decks increases the deck life over that of SRC bridges, but this by itself does not offset the effect of the higher initial costs. The weight reduction would have an effect on the initial costs, as the structure to support the deck would be reduced because the weight of an FRP deck is approximately 20 to 25 percent that of a SRC deck. This weight reduction results in a structural cost reduction. The major reductions would be for the steel bridge girders/beams/rollers required to support the bridge deck and the concrete foundation. The case studies have shown that the combination of both effects (higher service life and structural cost savings) does not always offset the effect of the higher initial costs. La Chein FRP bridge deck with actual initial cost ratio of 1.18 and maximum allowable price ratio of 1.17 has a higher life-cycle cost than its SRC bridge deck alternative.

Another key parameter for FRP competitiveness is the maintenance cost. The basic scenarios suggested that if the site has low ADT (between 20 and 700) and if both types of bridge decks have the same inspection and anticipated repair frequencies, the LCC of the FRP bridge deck was lower than that for the SRC bridge deck for one out of the three case study bridges. If the scheduled maintenance and anticipated repair costs of FRP bridge decks are lower than the SRC decks as predicted by experts, the FRP bridge deck was lower than SRC bridge deck for one out of three study bridges. However all 
FRP bridge scenarios become competitive to SRC decks when ADT equals 750 for La Chein and 3,000 for Katy Truss. Having those ADT values, all FRP decks are viable even when the same maintenance assumption is applied.

The higher the ADT, the more competitive the FRP deck becomes. The La Chein case showed that FRP was competitive to SRC if ADT increased from 100 to 750 . It can be concluded that FRP deck viability is a function of its service life, maintenance/anticipated repair schedule, and initial price ratio (substructure saving included).

Overall, the results suggest that a $\$ 61 / \mathrm{sq}$ ft FRP deck is a viable alternative to \$30/sq ft SRC deck. Reeve [70] suggested maximum cost of FRP to be 1.25 times the cost of SRC. Taking into account the second bridge deck cost, which is equal to $1.25 *(1.412 *$ cost of SRC) or 1.77 times the cost of SRC would be $\$ 53 / \mathrm{sq} \mathrm{ft}$. The multiplier 1.412 accounts for both SRC decks installed in year zero and year 30 with a three percent discount rate, i.e., $1+(1+\mathrm{DR})^{-30}=1+1.03^{-30}$. The difference is reasonable as it was not take into account the effects of additional substructure cost savings between the two bridge decks.

\subsection{Recommendations for Future Research}

The focus of this dissertation was to study financial viability of FRP bridge deck compared to SRC bridge deck. The study offers significant improvements that distinguish it from previous research and provides a better comparison by taking into account the weight and maintenance advantages of FRP deck in financial terms. A procedure for including the structural weight savings resulting from the lighter FRP decks, as well as a life cycle model for FRP bridge deck, have been developed for this 
purpose. Aside from that, an expression to estimate the service life of FRP decks has been developed. This approach had not been done previously, although there is extensive literature available that explains these advantages of FRP bridge decks.

A more accurate overall view of the life-cycle cost process should include a greater variety of bridge deck projects. The possible improvements include modifying the cost saving module to enable analysis for bridges with multiple spans, modeling the FRP deterioration rate to better estimate maintenance/anticipated repair costs, and estimate the structural concrete savings due to the lower dead weight of FRP decks. The improvement rate is decreasing, and the learning curve should be updated accordingly. Application of exponential smoothing method as an alternate method to predict the future cost of FRP deck should be examined. These would permit analysis of a wider range of bridge deck projects and give a better understanding of FRP deck financial viability.

The deterioration rate model is one of the key elements in determining the lifecycle cost of FRP bridge deck. The FRP bridge deck may fail in the top surface, bottom surface, or in the core. It is believed that design plays an important role in these problems. Some of FRP bridge deck design factors to be considered would be deflection, strain, connections, overlay, and thermal difference problems.

Data must be collected and analyzed on the maintenance and repair of FRP decks to more reliably predict the maintenance repair schedule and costs. The maintenance and repair costs for FRP should be lower than those of the SRC structures, especially in areas where salt is applied to deck surfaces in winter weather. These values should be converted to a function of per square foot of the bridge area. 
The following framework is suggested to come up with improved FRP bridge decks deterioration and its associated costs:

(1) Determine the major factors that contribute to the damage of an FRP bridge deck and the corresponding damage. A laboratory study should be performed to study the following possible factors associated with FRP bridge deck damages: thermal effects, wearing surface type, shrinkage, alkali attack, chemical attack, and UV radiation exposure.

(2) Determine the correlation between the inputs of the deterioration process and the outputs measured to predict the type of repair/maintenance and the amount of the area affected. The deterioration model would be used to estimate the damage area for repair for a certain year. 


\section{BIBLIOGRAPHY}

1. Aarseth, L.-I. and Hovde, P. J. 1999. "A stochastic approach to the factor method for estimating service life". Proceedings of the 8th International Conference on Durability of Building Materials and Components, May 30 - June 3, Vancouver, Canada, 1247-1256.

2. Abed-Al-Rahim, I.J. and Johnston, D.W. 1995. Bridge Element Deterioration Rates. Transportation Research Record 1490: 9-18.

3. Abu-Tair, A.I., McParland, C., Lyness, J.F., Nadjai, A. 2002. "Predictive models of deterioration rates of concrete bridges using the factor method based on historic inspection data". Proceedings of the $9^{\text {th }}$ International Conference on Durability of Building Materials and Components (9DBMC), March 17-21, Brisbane, Australia, paper 262.

4. Alagusundaramoorthy, P., I. Harik, and C. Choo. 2006. Structural Behavior of FRP Composite Bridge Deck Panels. Journal of Bridge Engineering, July/Aug: 384-392.

5. Alampalli, S. and J. Kunin. 2001. Load Testing of an FRP Bridge Deck on a Truss Bridge. New York: New York State Department of Transportation, New York.

6. Alampalli, S., J.O’Connor, A.P. Yannotti. 2000. Design, Fabrication, Construction, and Testing of an FRP Superstructure. New York: Transportation Research and Development Bureau, New York State Department of Transportation.

7. American Composites Manufacturers Association. Overview of the FRP Composites Industry - A Historical Perspective. http://www.mdacomposites.org/mda/overview.html.

8. Applied Science for Pultrusion Excellence. The Pultrusion Process. http://puldyn.neohio.net/pultrusion.html. Last viewed October 25, 2006.

9. Assaf, Sadi A., A. Al-Hammad, O.A. Jannadi, and S.A. Saad. 2002. Assessment of the Problem of Application of Life-Cycle Costing in Construction Projects. Cost Engineering 44(2): 17-22.

10. Balendran, R.V., T.M. Rana, and A. Nadeem. 2001. Strengthening of concrete structures with FRP sheets and plates. Structural Survey 19(4): 185-192.

11. Bedford Reinforced Plastics, Inc. Prodeck8. http://www.bedfordplastics.com/Prodeck8.pdf.

12. Berg, A.C., L.C. Bank, M.G. Oliva, J.S. Russell. 2004. "Construction of a FRP Reinforced Bridge Deck on US Highway 151 in Wisconsin”. Proceedings of Transportation Research Board Annual Meeting, January 11-15, Washington DC. 
13. Bijen, J. 2003. Durability of Engineering Structures: Design, Repair and Maintenance. CRC, Florida: Boca Rotan. Woodhead Publishing, London.

14. Bourke, K. and H.Davies. 1999. "Estimating Service Lives Using The Factor Method for Use in Whole Life Costing”, in Durability of Building Materials and Components 8, eds. M.A. Lacasse and D.J. Vanier, 1518 -1526. Canada: NRC Research Press, Vancouver, CA

15. Brockhoff, K. 1975. "The performance of forecasting groups in computer dialogue and face to face discussions". In The Delphi Method: Techniques and Applications, eds. H. Linstone and M. Turoff, 291-321. London: Addison-Wesley.

16. Bureau of Labor Statistics, United States Department of Labor. Consumer Price Index. http://stats.bls.gov/cpi/home.htm.

17. Cassity. 2000. Fiber_Reinforced Polymer Bridge Decks. http://www.nabro.unl.edu/articles/20000805/index.asp. Last viewed: September 1, 2006.

18. Chajes, M.J., H.W. Shenton III, and W.W. Finch. 2001. Performance of Glass Fiber Reinforced Polymer Deck on Steel Girder Bridge. Transportation Research Record 1770: 105-112.

19. Chandler, Richard F. 2004. LCC Model for Evaluating the Sustainability of Bridge Decks - A Comparison of Conventional Concrete Joints and Engineered Cementitious Composites Link Stabs. Ann Arbor: Center for Sustainable System, University of Michigan.

20. Chiewanichakorn, M., A.J. Aref and S. Alampalli. 2003. Failure Analysis of Fiber Reinforced Polymer Bridge Deck System. Journal of Composites, Technology, and Research 25(2): 121-129.

21. Creese, R.C. 1999. "Overcoming Composite Cost Differentials by Life-Cycle Costing". Proceedings of Conference on Polymer Composite, April 19-21, Parkersburg, West Virginia.

22. Creese, R.C. and T.B. Patrawala. 2000. A Cost Model for the Pultrusion Process. Cost Engineering 42(6): 38-43.

23. Creese, R.C., M.Adithan and B.S. Pabla. 1992. Estimating and Costing for the Metal Manufacturing Industries. New York: Marcel Dekker, Inc.

24. Dejke, V. 2001. Durability of FRP Reinforcement in Concrete. PhD diss., Chalmers University of Technology, Sweden.

25. Dept. of Building Materials, Chalmers Univ. of Technol, Sweden. 
http://www.bm.chalmers.se/research/Acrobat/alwien.pdf. Last viewed May 25, 2006.

26. Dokun, O. D., Jacobs, L. J., and Haj-Ali, R. M. 2000. Ultrasonic Monitoring of Material Degradation in FRP Composites. Engineering Mechanics 126(7): 704-710.

27. Ehlen, M. A. 1997. Life-Cycle Costs of New Construction Materials. Journal of Infrastructure Systems Dec.: 129-133.

28. Ehlen, M.A. 1999. Life-Cycle Costs of Fiber-Reinforced-Polymer Bridge Decks. Journal of Materials in Civil Engineering August 1999: 224-230.

29. Ehlen, M.A. and H.E. Marshall. 1996. The Economics of New Technology Material - A Case Study of FRP Bridge Decking. Washington DC: US Department of Commerce.

30. Ehlen, Mark A. 2003. Bridge LCC 2.0. Gaithersburg, MD: National Institute of Standards and Technology.

31. Emblemsvag, J. 2001. Activity-Based Life-Cycle Costing. Managerial Auditing Journal. 16(1): 17 -27.

32. Federal Highway Administration. FRP Composite Bridge Technology Presentation. http://www.fhwa.dot.gov/bridge/frp/frphstry.htm. Released Date: February 4, 2002.

33. Federal Highway Administration. 1997 Federal Highway Cost Allocation Study, USDOT. http://www.ota.fhwa.dot.gov/hcas/final.

34. Federal Highway Administration. US Department of Transportation. http://www.fhwa.dot.gov.

35. Feng P., and Ye L.P. 2004. Applications and research on fiber reinforced polymer bridge decks. Industrial Construction 34: 290-301 (English translation).

36. Florida District of Transportation. BDR Bridge Cost Estimating, July 2006. http://www.dot.state.fl.us/Structures/StructuresManual/CurrentRelease/DesignGuideli nes/SDG_9.2_Cost_Estimating_Process.htm.

37. Fowles . J. (ed.) 1978. Handbook of Future Research. Westport: Greenwood Press.

38. Frangopol et al., 2001. Reliability-based life-cycle management of highway bridges. Journal of Computing in Civil Engineering 15: 27-34.

39. Fuller, L. 2001. LCC Methodology. Energy Management Teleworkshops. http://www.energyworkshops.org/.PDF. Released March 2001

40. Gannon, E.J. 1998. A Life Cycle Cost Model for Use in Optimization of Concrete Bridge Deck Repair and Rehabilitation. PhD diss., Pennsylvania State University. 
41. GangaRao H.V.S., Vijay, P.V. 1997. “Aging of Structural Composites under Varying Environmental Conditions”. Proceedings of the $3^{\text {rd }}$ International Non metallic (FRP) Reinforced for Concrete Structures Symposium 2: 91-98.

42. Gurtler, Herbert W. 2004. Composite Action of FRP Bridge Decks Adhesively Bonded to Steel Main Girders. PhD diss., Ecole Polytechnique Federale de Lausanne.

43. Hastak, M. and A.Mirmiran. D. Richard. 2003. A Framework for Life-Cycle Cost Assessment of Composites in Construction. Journal of Reinforced Plastics and Composites 22(15): 1409-1430.

44. Hastak, M. and Halpin, D.W. 2000. A Model for Life-Cycle Cost-Benefit Assessment of Composite Materials in Construction. Journal of Composites for Construction 4(3): 103-111.

45. Hong, T. and M. Hastak. 2006. Construction, Inspection, and Maintenance of FRP Deck Panels. Journal of Composites for Construction: 561 - 572.

46. Hong, T., M. Hastak, and A. Mirmiran. 2005. “Composite Materials in Construction - A Life-Cycle Perspective”. Proceedings of the 4th International Workshop on LifeCycle Cost Analysis and Design of Civil Infrastructures Systems, May 8-11, Cocoa Beach, Florida.

47. Hovde, J. 2004. Factor Methods for Service Life Prediction - State of the Art. CIB W080/RILEM 175 SLM Service Life Methodologies - Prediction of Service Life for Buildings and Components. CIB Report: Publication 294, Part A.

48. Indiana Department of Transportation. 2004. Constructability, Maintainability and Operability of Fiber Reinforced Polymer (FRP) Bridge Deck Panels. Indiana: INDOT Research.

49. Indiana Department of Transportation. http://www.in.gov/indot/.

50. Iskander, M., and Hanna, S. 2003. "Engineering Performance of FRP Composite Piling." Proceedings of Transportation Research Board 2002 Annual Meeting, January 13-17, Washington DC.

51. Lindvall, A. 2006. Probabilistic, Performance based Service Life Design of Concrete Structures. http://www.bm.chalmers.se/research/Acrobat/alwien.pdf. Last viewed: May 2506.

52. Liu, Z. 2007. Testing and Analysis of a Fiber Reinforced Polymer (FRP) Bridge Deck. PhD diss., Virginia Tech. 
53. Lopez-Anido, R. 1998. Life Cycle Cost Evaluation of FRP Composite Bridge Decks. Technical Report. Morgantown: WV University Research Corporation.

54. Lopez-Anido, R. 2001. "Life-Cycle Cost Survey of Concrete Bridge Decks - A Benchmark for FRP Bridge Deck Replacement". Proceedings of Transportation Research Board 2001 Annual Meeting, January 7-11, Washington, DC.

55. Management and Accounting Web. The Learning Curve or Experience Curve Summary. http://maaw.info/learningCurveSummary.htm.

56. Martin Marietta Composites. http://www.martinmarietta.com.

57. Moser, K. 2004. Engineering Design Methods for Service Life Prediction: State of the Art. CIB W080/RILEM 175 SLM Service Life Methodologies - Prediction of Service Life for Buildings and Components. CIB Report: Publication 294, Part B.

58. Moser, K. 1999. “Towards the practical evaluation of service life - Illustrative application of the probabilistic approach". Proceedings of the $8^{\text {th }}$ International Conference on Durability of Building Materials and Components (8DBMC), Ottawa, Canada: 1319-1329.

59. Moser, K., Edvardsen, C. 2002. "Engineering design methods for service life prediction”. Proceedings of the $9^{\text {th }}$ International Conference on Durability of Building Materials and Components (9DBMC), March 17-21, Brisbane, Australia, paper 222.

60. NASA. Cost Estimating Resources. http://www.jsc.nasa.gov/bu2/resources.html.

61. Nathan, T.R. and O.U. Onyemelukwe. 2000. "Comparison of Bridge Deck Alternatives Using Life-Cycle Costs". Proceedings of the $8^{\text {th }}$ ASCE Specialty Conference on Probabilistic Mechanics and Structural Reliability, July 24-26, Notre Dame, Indiana.

62. NCHRP. 2006. Field Inspection of In-Service FRP Bridge Decks. Transportation Research Board: NCHRP Project 10-64.

63. Nishizaki, I., N.Takeda, Y.Ishizuka and T.Shimomura. 2006. “A Case Study of Life Cycle Cost Based on a Real FRP Bridge”. Proceedings of the Third International Conference on FRP Composites iN Civil Engineering, December 13-15, Miami, Florida, 99-102.

64. Norman, G. 1990. Life-Cycle Costing. Property Management 8(4): 344-356.

65. North Carolina Department of Transportation. http://www.ncdot.com.

66. Nystrom, H., Watkins, S. E., Nanni, A. and Murray, S. 2003. Financial Viability of Fiber-Reinforced Polymer (FRP) Bridges. ASCE Journal of Management in 
Engineering 19 (1): 2-8.

67. O ‘Connor, J.S. 2001. “New York’s Experience with FRP Bridge Decks”. In Polymer Composites II - Applications of Composites in Infrastructure Renewal and Economic Development., eds. R.C. Creese and H. GangaRao, CRC Press, 21:32.

68. O’Connor, J.S. 2005. "Experience in the United States with Fiber-Reinforced Polymer Composite Bridge Decks and Superstructures". Proceedings of the 6th International Bridge Engineering Conference, July 17-20, 2005, Boston, MA

69. O 'Connor, J.S. Current Practices in FRP Composite Technology FRP Bridge Decks and Superstructure. http://www.fhwa.dot.gov/bridge/frp/deckprac.cfm. Last updated March 30, 2007.

70. Reeve, S.R. 2002. "FRP Composite Bridge Decks: Barriers to Market Development. In Polymer Composites II, ed. R. C. Creese and H. GangaRao, Morgantown: CRC Press.

71. Reising, R.M.W., Shahrooz, B.M., Hunt, V.J. and Lenett, M.S., Christopher, S., Neumann, A.R., Helmicki, A.J. 2001. Performance of Five Span Steel Bridge with Fiber Reinforced Polymer Composite Deck Panels. Transportation Research Record 1770: 113-123.

72. Robert, J. 2005. Deck Replacement for the Skewed Truss Bridge on MD 24 Over Deer Creek in Harford County, Maryland Utilizing a Fiber Reinforced Polymer (FRP) Bridge Deck. http://best.umd.edu/publications/IBC-02-5.pdf

73. Robinson, Jon. 1996. Plant and equipment acquisition: a Life-Cycle Costing case study. Facilities 14(5): 21-25.

74. Robinson, R. 1993. "Life Cycle Costing of Highways". In Life Cycle Costing for Construction, ed. John W. Bull, London: Blackie, 53:85 Taylor and Francis.

75. Rostasy, F., Hankers, C, and E.H. Ranish. 1992. "Strengthening of RC and PC Structures with Bonded FRP Plates”. Proceedings of Advanced Composite Materials in Bridges and Structures, CSCE, Sherbrooke, Canada, 253-263.

76. Roychoudhury, P. and R.C. Creese. 2001. Cost Analysis of FRP Bridge Decks. AACE International Transactions EST 02:1-8.

77. Roychoudury , P. 2001. A Life Cycle Cost Estimation Model for FRP Bridge Decks. MS Thesis, West Virginia University.

78. Rudbeck, C. 1999. Methods for designing building envelope components prepared for repair and maintenance. PhD diss., Technical University of Denmark. 
79. Saadatmanesh, H and F.E. Tannous. 1997. "Durability of Fiber Reinforced Plastic (FRP) Rebars and Tendons in Aggressive Environments". Proceedings of International Seminar of Repair and Rehabilitation of Reinforced Concrete Structures: The State of the Art, ASCE, Maracaibo, Venezuela, April 28-May 1, 120133.

80. Sahirman, S., R.C. Creese, H.GangaRao, M.Jaraieidi, B. Gopalakhrisnan., C. Brown. 2003. "Economic Analysis of Fiber Reinforced Polymer (FRP) Bridge Decks". Proceedings of Industrial Engineering Research Conference, May, Portland, Oregon.

81. Sahirman, S., R.C. Creese, and H. GangaRao. 2005. "Preliminary Study of life-cycle Cost Model for Fiber Reinforced Polymer Bridge Deck". Proceedings of the 4th International Workshop on Life-Cycle Cost Analysis and Design of Civil Infrastructures Systems, May 8-11, Cocoa Beach, Florida.

82. Sahirman, S., R.C. Creese and H. GangaRao. 2008. "FRP Bridge Deck Life Cycle Cost Analyzer”. In Life Cycle Civil Engineering, ed. F. Biondini and D. Frangopol: 883-888. CRC Press.

83. Sahirman, S., R.C. Creese, H.GangaRao, M. Jaraieidi, B. Gopalakhrisnan, C. Brown. 2009. “A Life Cycle Cost Analyzer for FRP Economic Viability Analysis”. Paper Submitted for IIE Conference, Miami, FL.

84. Sanders, D.H. and Zhang, Y.J. 1994. Bridge Deterioration Models for States with Small Bridge Inventories. Transportation Research Record 1442: 101-109.

85. Shekar, V., S.H. Petro and H.V.S. GangaRao. 2002. Construction of FiberReinforced Plastic Modular Decks for Highway Bridges. Transportation Research Record 1813: 203-209.

86. Shekar, V., S.H. Petro and H.V.S. GangaRao. 2003. Fiber-Reinforced Polymer Composite Bridges in West Virginia. Transportation Research Record 1819: 378384.

87. Sobanjo, John O. and Paul D. Thompson. 2001. Development of Agency Maintenance, Repair \& Rehabilitation (MR\&R) Cost Data for Florida’s Bridge Management System. FDOT, Florida: State Maintenance Office.

88. Solid Waste Management Board West Virginia. http://www.state.wv.us/swmb.

89. Sridharan, S. 1997. Environmental durability of E-glass/vinyl ester composites in hotmoist conditions. PhD diss., Georgia Institute of Technology.

90. Tang, B. 1997. "Fiber Reinforced Polymer Composites Applications in USA". Proceedings of the First Korea/USA Road Workshop, January 28-29. 
91. Tang, B. and W. Podolny. 1998. “A Successful Beginning for Fiber Reinforced Polymer (FRP) Composite Materials in Bridge Applications”. FWHA Proceedings of International Conference of Corrosion and Rehabilitation of Reinforced Concrete Structure, December 7-11.

92. Teply, B., Novak, D., Kersner, Z., Lawanwisut, W. 1999. Deterioration of reinforced concrete: probabilistic and sensitivity analyses. Acta Polytecnica and 8DBMC: 1357-1366.

93. The International Organization for Standardization. ISO 2001. http://www.iso.org.

94. Vijay, V.P. and Hota V.S. GangaRao. 1999. Development of Fiber Reinforced Plastics for Highway Application (Task-A2) - Aging Behavior of Concrete Beams Reinforced with GFRP Bars. Final Report. WVDOH RP \#T-699-FRP-1. WVDOT, West Virginia.

95. Wang, Y., Zureick, A. H. 1994. Characterization of the Longitudinal Tensile Behavior of Pultruded I-Shape Structural Members Using Coupon Specimens. Composite Structures 29: 463-472.

96. West Virginia Department of Transportation. http://www.wvdot.com.

97. West Virginia Department of Transportation. 2003 Crash Data http://www.wvdot.com/engineering/Manuals/Traffic/2003CrashData.pdf.

98. Whipp, R.W. 2001. "Constructing the Market Street Bridge”. In Polymer Composites II, ed. R.C. Creese and H. GangaRao : 117 - 124 CRC Press.

99. WV State Climate Center. http:// www.wvclimate.org/climate_data_links.html.

100. Xi Y, Chang S, Asiz A, and Li Y. 2004. Long Term Durability of Fiber Reinforced Polymers (FRPs) and In-Situ Monitoring of FRP Bridge Decks at O'Fallon Park Bridge. Colorado: Colorado Department of Transportation Research Branch.

101. Zhou, A. and J.J. Lesko. 2003. “ Fiber-reinforced polymer decks for bridge systems: stiffness and strength". Proceedings of the European Bridge Engineering Conference, March 27-28, Rotterdam, Netherlands, Paper 9.

102. www.artba.org. 
APPENDICES 
Appendix 1. Questionnaire \#1

Dear ...........,

My name is Sidharta Sahirman, a Ph.D. student researcher for Center of Excellence, West Virginia University, Morgantown, WV. Currently, we are conducting a research project with one of the objectives to develop a service life prediction of FRP bridge decks.

In order to achieve the above objective, we would like to draw upon the expertise and experiences of bridge professionals / researchers. We would therefore like to request you to please take a few minutes with this survey. In this short questionnaire, we would like your opinion about the importance of each factor that may have effect on FRP bridge deck service life.

Attached, please find the short questionnaire. Kindly email your opinion to:

Sidharta Sahirman (ssahirma@mix.wvu.edu)

Your help is greatly appreciated.

Best regards,

Sidharta Sahirman

Center of Excellence

School of Engineering and Mineral Resources

West Virginia University

Morgantown, WV 26507 
On scale of 1 to 5 where 1 represents “not significant” and 5 represents “very significant”,

1. How would you rate the effects of the following factor on FRP deck's quality?

a. Fiber and Resin type
$\square 1$
$\square 2$
$\square$
$\square 4 \quad \square 5$

b. Manufacturing processes

$\square 1 \quad \square 2 \quad \square 3 \quad \square 4 \quad \square 5$

c. Bridge deck designs

$\square 1 \quad \square 2 \quad \square 3 \quad \square 4 \quad \square 5$

2. How would you rate the effect of the following factor on FRP deck's service life?

a. Wearing surface type and thickness

$\square 1 \quad \square 2 \quad \square 3 \quad \square 4 \quad \square 5$

b. Humidity of the surrounding area

$\square 1 \quad \square 2 \quad \square 3 \quad \square 4 \quad \square 5$

c. Light and UV exposure of the surrounding area

$\square 1 \quad \square 2 \quad \square 3 \quad \square 4 \quad \square 5$

d. Alkali content of the soil

$\square 1 \quad \square 2 \quad \square 3 \quad \square 4 \quad \square 5$

e. Number of freeze-thaw cycles

$\square 1 \quad \square 2 \quad \square 3 \quad \square 4 \quad \square 5$

3. Please list other factor(s) that may contribute significant effects on the FRP deck's service life: 
Appendix 2. Questionnaire \#2

Dear

My name is Sidharta Sahirman, a Ph.D. student researcher for Center of Excellence, West Virginia University, Morgantown, WV. As you may have known, we are conducting a research project with one of the objectives to develop a service life prediction of FRP bridge decks.

We would like to extend our thank you for taking the time to fill out the first questionnaire for this project. Your help to achieve the objective of this project is greatly appreciated. Based on the responses, the importance of each factor that may have effect on FRP bridge deck service life has been determined. For the second round of the questionnaire, we would like your opinion about your estimates of FRP bridge deck service life given a certain set of conditions. Please fill in the short survey presented on the attachment.

Kindly email your opinion to: Sidharta Sahirman (ssahirma@mix.wvu.edu). Thank you so much for your support to this project.

Best regards,

Sidharta Sahirman

Center of Excellence

School of Engineering and Mineral Resources

West Virginia University

Morgantown, WV 26507 


\section{Respondent:}

1. In general, what is your estimate of FRP bridge deck service life? $<30 \quad$ Years

2. Based on your opinion, please estimate the most likely age at which FRP bridge deck starts showing degradation or delamination of the top surface//skin

$<5 \quad$ Years

3. What is your estimates (minimum, most probably, maximum) of pultruded FRP bridge deck service life for each set of conditions below?

$\begin{array}{lcccc}\text { Freeze Thaw Cycles } & \text { Mild } & \text { Moderate } & \text { Mild } & \text { Mild } \\ \text { Average Daily Traffic } & \text { 5,000-10,000 } & \text { 5,000-10,000 } & \text { 5,000-10,000 } & 20,000-30,000 \\ \text { Wearing Surface } & \text { Polymer Concrete } & \text { Polymer Concrete } & \text { Conventional Asphalt } & \text { Conventional Asphalt } \\ \text { Service Life Expectation (yrs) } & <30 & <30 & <30 & <30 \\ \text { Minimum Service Life (yrs) } & <30 & <30 & <30 & <30 \\ \text { Maximum Service Life (yrs) } & <30 & <30 & <30 & <30\end{array}$

\section{Comments/Notes}

Thank you for your time. Your help is greatly appreciated. 
Appendix 3. Example Calculation for La Chein Bridge

1. Bridge Geometry

$\begin{array}{ll}\text { Span of bridge } & =32.5^{\prime} \text { (c/c bearings) } \\ \text { Out to out bridge width } & =24.3^{\prime} \\ \text { Number of span } & =1 \\ \text { Number of lanes } & =1 \\ \text { Skew } & =0^{\circ} \\ \text { Deck overhang } & =10^{\prime}\end{array}$

2. Detail of Stringer

Assuming:

Number of stringers $\quad=6$

Spacing of stringers = 4' 6”

3. Detail of FRP Deck

Thickness of deck = 8”

Self weight of deck $\quad=16$ psf

4. Detail of Wearing Surface

Wearing surface material = Polymer Concrete Overlay

Weight of wearing surface $=3 \mathrm{psf}$

5. Design of Stringer (Based on Service-Load Method)

5.1. Exterior Stringer

Assume:

The deck is simply supported on the exterior and on the adjacent interior stringer

Deck and wearing surface: 19 psf

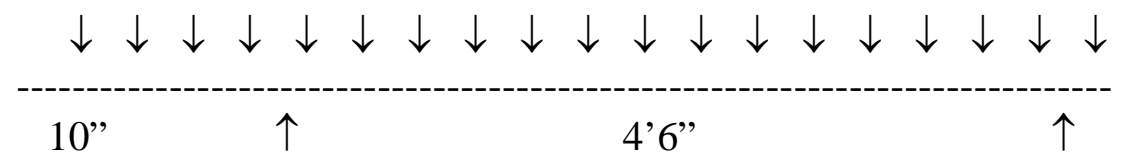

Dead Load $=\mathrm{DL}=0.019\left(10 ”+4{ }^{\prime} 6^{\prime \prime} / 2\right)=0.059 \mathrm{k} / \mathrm{ft}$

Dead Load of guard rails, posts, etc. $\approx 0.06 \mathrm{k} / \mathrm{ft}$

Self weight of stringer $=0.086 \mathrm{k} / \mathrm{ft}$ (proposed section W18x86)

Total dead load on exterior stringer $=\mathrm{W}_{\mathrm{DL}}=0.205 \mathrm{k} / \mathrm{ft}$

Maximum dead load moment $=\mathrm{M}_{\mathrm{DL}}=\left(\mathrm{W}_{\mathrm{DL}} \cdot \mathrm{L}^{2}\right) / 8$

$\mathrm{M}_{\mathrm{DL}}=27.01 \mathrm{k} \mathrm{ft}$ 
Distribution Factor

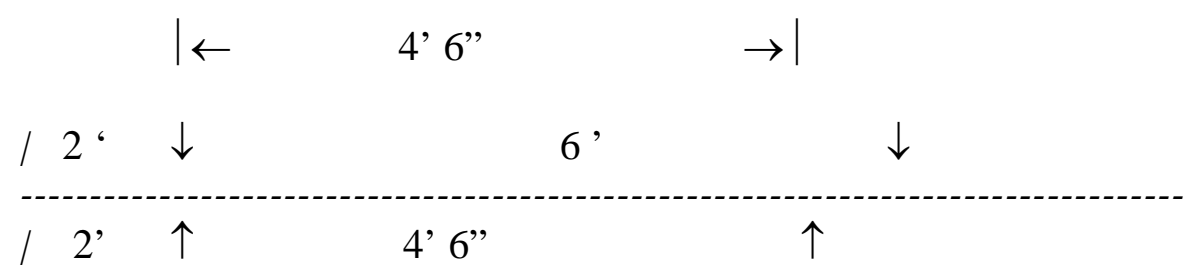

To compute the live load on the exterior stringer, the wheel load is positioned $2 \mathrm{ft}$ inside the edge (AASHTO)

Wheel load on exterior stringer $=0.741 \mathrm{P}($ Level Method, AASHTO)

Wheel load factor, $\mathrm{DF}_{\mathrm{ext}}=\mathrm{S} /(4+0.25 \mathrm{~S})=4^{\prime} 6^{\prime \prime} /\left(4+0.25 * 4{ }^{\prime} 6\right.$ ”) $)=0.818$

Use $\mathrm{DF}_{\text {ext }}=0.818$

Live Load Moment

Maximum live load moment in exterior stringer for HS-25 from AASHTO (for L = 32.5')

$=394.6 \mathrm{k} \mathrm{ft}$

Impact Factor $=50 /(\mathrm{L}+125)=0.30$

$\mathrm{M}_{\mathrm{LL}} *$ Impact $* \mathrm{DF}_{\mathrm{ext}}=210$

Total moment for exterior stringer, $\quad \mathrm{M}_{\mathrm{ext}}=\mathrm{M}_{\mathrm{DL}}+\left(\mathrm{M}_{\mathrm{LL}} *\right.$ Impact $\left.* \mathrm{DF} \mathrm{ext}\right)=237$

Shear Due to Dead Load (Exterior Stringer)

Dead load on exterior stringer $\mathrm{W}_{\mathrm{DL}}=0.205 \mathrm{k} / \mathrm{ft}$

Shear Load $=\mathrm{V}_{\mathrm{DL}}=\left(\mathrm{W}_{\mathrm{DL}} \cdot \mathrm{L}\right) / 2=3.32 \mathrm{kips}$

Shear Due to Live Load (Exterior Stringer)

Maximum shear due to live load is computed as a reaction in the exterior stringer when the wheel loads are positioned as per AASHTO 3.23.3. Fractions of wheel load are placed on the stringer with the rear load on the support.

\section{Distribution Factor}

For the wheel load near the support, the fraction of wheel load distributed to the exterior stringer is 0.818 (by the level method)

Shear Due to Live Load

End shear reaction for HS $25=68.5$ kips (AASHTO)

$\mathrm{V}_{\mathrm{LL}}=68.5 / 2 *(0.818)=28$

$\mathrm{V}_{\mathrm{LL}} *$ impact $=36$

Total shear for exterior stringer $=\mathrm{V}_{\mathrm{ext}}=\mathrm{V}_{\mathrm{DL}}+\mathrm{V}_{\mathrm{LL}} *$ impact $=40$ 


\subsection{Interior Stringer}

Bending Moment Due to Dead Load

Dead load due to FRP deck and wearing surface $=0.086 \mathrm{k} / \mathrm{ft}$

Dead load due to guard rails, posts, etc per stringer $=0.03 \mathrm{k} / \mathrm{ft}$

Self weight of stringer $=0.086 \mathrm{k} / \mathrm{ft}$

Total dead load on interior stringer $=\mathrm{W}_{\mathrm{DL}}=0.202$

Maximum dead load moment $=\mathrm{M}_{\mathrm{DL}}=\mathrm{W}_{\mathrm{DL}} \cdot \mathrm{L}^{2} / 8=26.604 \mathrm{k} / \mathrm{ft}$

Bending Moment Due to Live Load

Distribution Factor $=0.643$

The bending moment in the interior stringer is computed according to AASHTO 3.23.2.2

For a single lane bridge $D_{\text {INT }}=\mathrm{s} / 7=4$ '6”/7 = 0.643

Impact Factor $=0.317$

Maximum live load moment $=\mathrm{M}_{\mathrm{LL}}=394.55 \mathrm{k} \mathrm{ft}$

$\mathrm{M}_{\mathrm{LL}} * \mathrm{I} * \mathrm{DF}=0.643 / 2 * 394.55 * 1.317=167$

Total Moment for Interior $=\mathrm{M}_{\mathrm{INT}}=\mathrm{M}_{\mathrm{DL}}+\mathrm{M}_{\mathrm{LL}} * \mathrm{I} * \mathrm{DF}=193.68$

$\mathrm{M}_{\mathrm{INT}}<\mathrm{M}_{\mathrm{EXT}}($ Exterior stringer moment control )

Shear Due to Dead Load

$\mathrm{V}_{\mathrm{DL}}=0.5 . \mathrm{W}_{\mathrm{DL}} \mathrm{L}=3.27$

Shear Due to Live Load

End shear reaction for HS-25 = 68.5 kips (AASHTO)

$\mathrm{V}_{\mathrm{LL}}=0.5 * 68.5 * \mathrm{DF}_{\mathrm{INT}}=22.02$

Total shear for interior stringer $=\mathrm{V}_{\mathrm{INT}}=\mathrm{V}_{\mathrm{DL}}+\mathrm{V}_{\mathrm{LL}}=25.29$

$\mathrm{V}_{\text {INT }}<\mathrm{V}_{\text {EXT }}$

Design Moment (Exterior Stringer Moment Control) $=237$

Design Shear (Exterior Stringer Shear Control $)=40$

6. Required Stringer Section

$\mathrm{S}=\mathrm{M} / \mathrm{F}_{\mathrm{b}}$

$\mathrm{F}_{\mathrm{b}}=0.55 \mathrm{~F}_{\mathrm{Y}} \quad$ (AASHTO table 10.32.1.17)

Minimum depth to span ration L/25

7. Proposed Stringer Properties (W18 x 86)

Stringer depth should be greater than Minimum depth to span ratio

Section modulus should be greater than $\mathrm{S}$ (required stringer section)

Young's modulus of elasticity $29 \times 10^{6} \mathrm{psi}$ 
8. Check for Deflection Due to Static Load

Assuming all stringers deflect the same amount, deflection factor for each stringer $=\mathrm{DF}$ $=$ MLL x I x DF

Moment Due to Live Load $x$ Impact $x$ DF

$\mathrm{M}_{\mathrm{MAX}}=\left(\mathrm{P}_{\mathrm{EQ}} \cdot \mathrm{L}\right) / \quad ; \mathrm{P}_{\mathrm{EQ}}=$ Equivalent Single Point Load

$\mathrm{P}_{\mathrm{EFF}}=4 \times \mathrm{M}_{\mathrm{MAX}} / \mathrm{L}$

Deflection due to Live Load $x$ Impact $x$ DF

$\mathrm{A}=\left(\mathrm{P}_{\mathrm{EFF}} \mathrm{L}^{3}\right) /(48 \mathrm{E} \mathrm{I})$

Maximum Allowable Deflection $=\mathrm{L} / 800$ should be greater than $\mathrm{A}$

$\mathrm{OK}$

9. Check for Stresses

Induced bending stress should be less than allowable bending stress (27 ksi)

OK

10. Check for Shear in the Stringer

Maximum shear stress $=\mathrm{v} /(\mathrm{dtw})$ should be less than allowable shear stress $=0.33 \mathrm{x}$ Fy $\mathrm{OK}$ 
Appendix 4. Summary of Inspection Reports

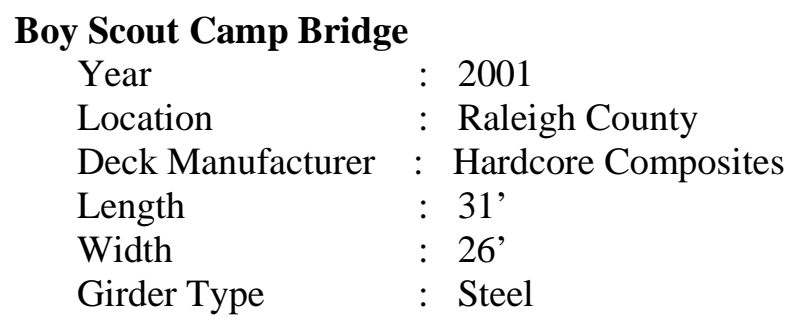

\section{No inspection information obtained.}

\section{Goat Farm Bridge}

\begin{tabular}{lcl} 
Year & $:$ & 2003 (Finish built in 2004) \\
ADT & $:$ & $20(2001), 10(2004)$ \\
Design Load & $:$ & HS-25 \\
Deflection Limit & $:$ & L/800 \\
Bridge Span(s) & $:$ & Single span \\
Location & $:$ & Jackson County, County Route 21 \\
Deck Manufacturer & $:$ & Kansas Structural Composites \\
Thickness of Deck & $:$ & $\mathbf{4}$ inches \\
Length & $:$ & $12.2 \mathrm{~m}$ \\
Width & $:$ & $4.6 \mathrm{~m}$ \\
Girder Type & $:$ & Steel \\
Type of Fastener & $:$ Mechanical fasteners (Z clips) \\
\multicolumn{2}{l}{ Type of Wearing Surface : Polymer concrete }
\end{tabular}

Periodic Inspection is every 2 years, starting 2006 (2006 report is on file)

In Depth Periodic Inspection is every 6 Yrs

Problem Reported So Far?

Year Problem

06 Deck and Wearing surface is in good condition.

No deficiencies found.
Repair Suggested?

No

\section{Hanover Bridge}

$\begin{array}{ll}\text { Year } & : 2001 \\ \text { ADT } & : \text { 700, 670(2006), 800(2003), 500(2000), } 500 \text { (1988) } \\ \text { Design Load } & : \text { HS-25 } \\ \text { Deflection Limit } & : \text { L/800 } \\ \text { Bridge Span(s) } & : \text { Two Spans } \\ \text { Location } & : \text { Pendelton County } \\ \text { Deck Manufacturer } & : \text { Kansas Structural Composites (Hand Lay up) } \\ \text { Thickness } & : 8 \text { “ } \\ \text { Length } & : 36.6 \mathrm{~m} \\ \text { Width } & : 8.5 \mathrm{~m} \\ \text { Girder Type } & : \text { Steel Wide Flange Beam } \\ \text { Type of Wearing Surface : Polymer Concrete with Asphalt Overlay }\end{array}$

Periodic Inspection is every 2 years, starting at 2005 (2005 and 2007 reports are on file) 
In Depth Periodic Inspection is every 6 Yrs starting at 2003 (2003 report is on file)

Interim Inspection (when necessary) (2006 report is on file)

Problem Reported So Far?

Year Problem

03 Deck and Wearing surface is in fair condition.

Repair Suggested?

05 Deck: Poor condition.

06 Deck: Poor condition.

07 Deck: Poor condition Yes

\section{Howell's Mill Bridge}

Year $\quad$ : 2003 (Finish construction Fall 2002)

ADT : :3,100 (2001), 3,400 (2004)

Design Load : : HS-25

Deflection Limit $\quad:$ L/800

Bridge Span(s) : : Two spans

Location : Cabel County

Deck Manufacturer : Martin Marietta Composites (Duraspan)

Length $\quad: 74.7 \mathrm{~m}$

Width $\quad: 10.1 \mathrm{~m}$

Girder Type : : Steel

Type of Wearing Surface : Asphalt Overlay

Periodic Inspection is every 2 yrs starting at 2005 (2005 and 2007 reports are on file)

In Depth Periodic Inspection is every 6 yrs starting at Year 2003 (2003 report is on file)

Problem Reported So Far?

\section{Year Problem}

$05 \quad$ FRP deck is in good condition.

Repair Suggested?

$07 \quad$ FRP deck is in good condition.

The 1" asphalt is cracking and breaking up over the deck joints No

Note:

Repair cost for replacing the 1" specialized asphalt deck with a regular 1.5” asphalt wearing mix would be around \$7,500 and it would take 1 long day (Jeff Ball)

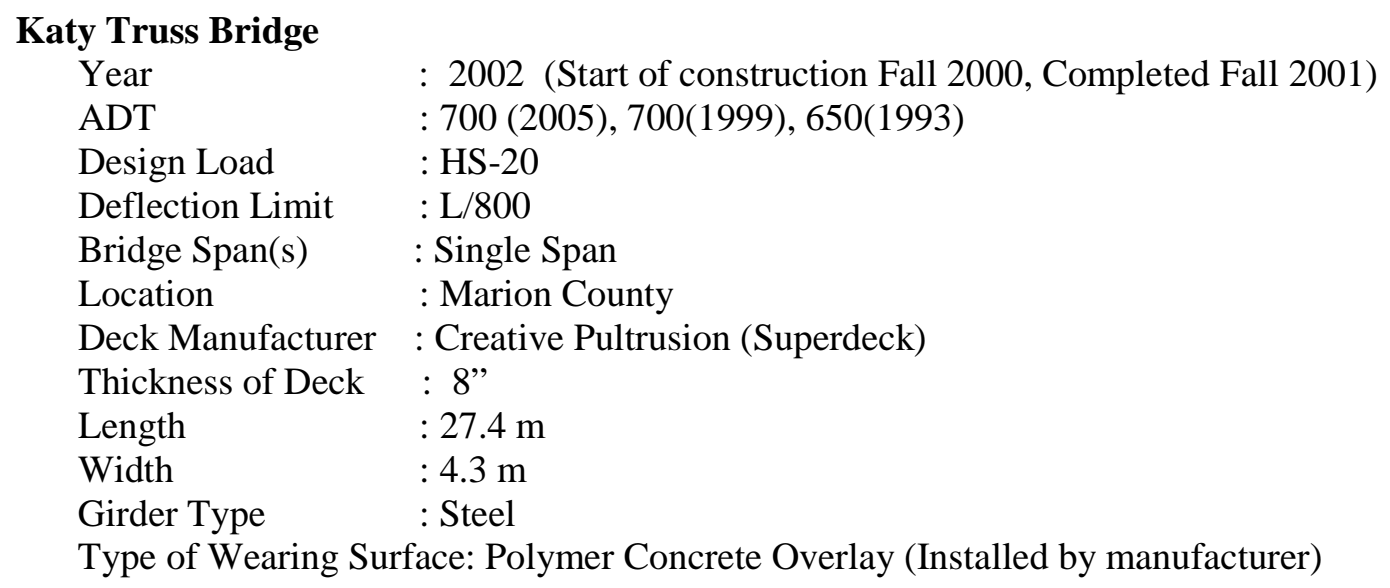


Periodic Inspection is every 2 yrs, starting at 2003 (2003 and 2005 reports are on file)

In Depth Periodic Inspection is every 6 yrs starting at 2001(2001 and 2007 reports are on file)

Problem Reported So Far?

Year Problem

07 Deck: Good condition

Wearing Surface: The polymer is loose and missing

throughout the bridge. It is recommended that the wearing Yes surface is replaced in its entirety.

\title{
Repair Suggested?
}

\section{Kite Creek Bridge}

$\begin{array}{ll}\text { Year } & \text { : Spring 2002 } \\ \text { ADT } & : \text { 500 (Yr 2000, 2003) } \\ \text { Design Load } & : \text { HS - 25 } \\ \text { Deflection Limit } & : \text { L/800 } \\ \text { Bridge Span(s) } & \text { : Single Span } \\ \text { Location } & : \text { Monroe County } \\ \text { Thickness of Deck } & : \text {, } \\ \text { Length } & : \text { 35' } \\ \text { Width } & : \text { 24’ } \\ \text { Girder Type } & : \text { Steel } \\ \text { Type of Wearing Surface : HLBC }\end{array}$

Periodic Inspection is every 2 yrs starting at 2003 (2005 report is on file)

In Depth Periodic Inspection is every 6 yrs

Problem Reported So Far?

\section{Year Problem}

05 The HLBC wearing surface has open transverse cracks

Repair Suggested? approx. 18” apart across the entire deck.

\author{
Yes
}

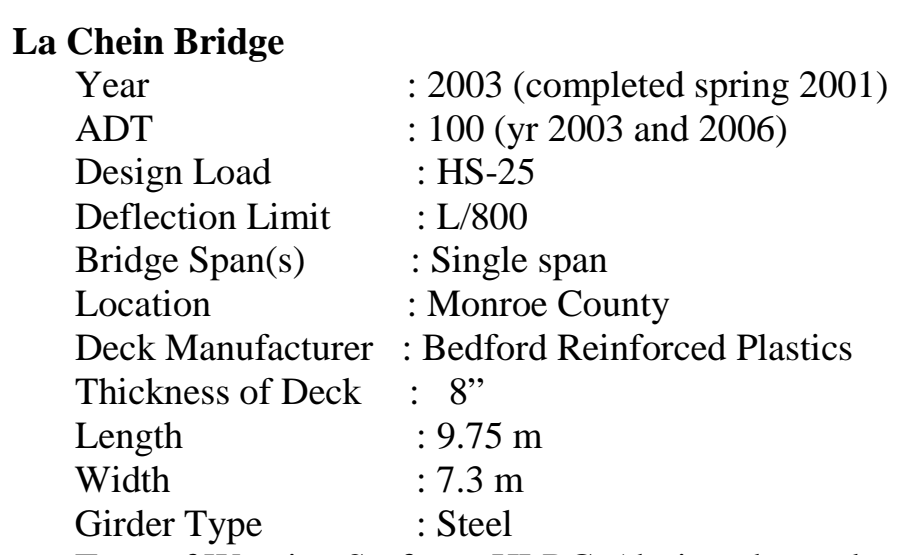

Type of Wearing Surface : HLBC (designed as polymer concrete overlay 3/8 “)

Note: Average cost of inspection: \$ 500

Average time of inspection: 10 hours (including travel time)

(Note: Cost includes inspector hours and equipments; may want to note \# inspectors) 
Problem Reported So Far?

\section{Year Problem}

06 has numerous transverse open cracks and unevenness in each crack location

07 some transverse open cracks and unevenness

\section{Repair Suggested?}

Yes

Yes

Any Repair Performed So far?

Not sure repair is possible. The only thing could be done is sealing the existing wearing surface and adding more asphalt to it (WS was roto milled off by the deck manufacturer! They were not able to take it all off without damaging the deck modules)

\author{
Laurel Lick Bridge \\ Year : May, 1997 \\ Bridge Span(s) : : Single Span \\ Location : Lewis County (County Road 26/6) \\ Deck Manufacturer : Creative Pultrusion (Superdeck) \\ Length $\quad: 6.1 \mathrm{~m} / 20 \mathrm{ft}$ \\ Width $\quad: 4.88 \mathrm{~m} / 16 \mathrm{ft}$ \\ Girder Type : : GFRP-I-Beam \\ Type of Wearing Surface : Polyester Polymer Concrete \\ ADT : 300(2003), 50(2006) \\ Thickness of Deck : 8” \\ Type of Fastener : Mechanical (1/2 “ diameter HUCK BOM-R16-20 blind \\ fasteners mechanically locked).
}

For less than $20 \mathrm{ft}$ bridges, inspection frequency is 5 years with average time of inspection 1-2 hours (based on interview with Doug Gould, bridge engineers for less than $20 \mathrm{ft}$ bridges in this DOT district). Inspection report 2004 was read. Deck and wearing surface are in good condition.

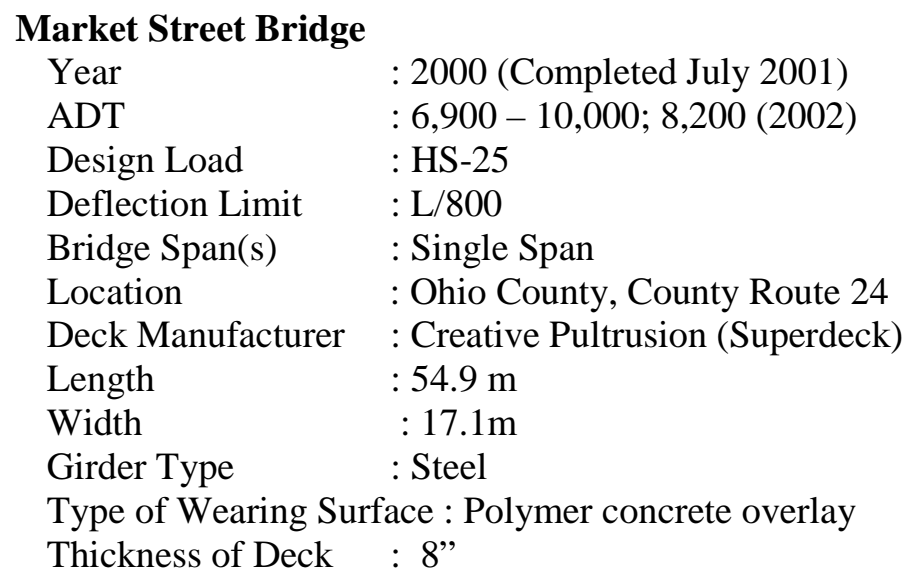

Periodic Inspection is every 2yrs starting at Year 2003 (2003 and 2005 reports are on file) In Depth Periodic Inspection is every 6 yrs starting at 2001 (2001 report is on file) 
Problem Reported So Far?

Year Problem

05 Deck: good condition.

Repair Suggested?

Wearing surface: the $1 \frac{1}{2}$ " wearing surface which

consists of polyurethane concrete and granite chips

is in good condition. A few minor cracks were observed

in the overlay. Sealing is recommended.

Yes

\section{Montrose Bridge}

$\begin{array}{ll}\text { Year } & \text { : October 29, 2001 } \\ \text { ADT } & : 600(2000,2003,2006) \\ \text { Design Load } & : \text { HS }-25 \\ \text { Deflection Limit } & : \text { L/800 } \\ \text { Bridge Span(s) } & \text { : Single Span Steel Wide Flange Beam } \\ \text { Location } & \text { : Randolph County } \\ \text { Deck Manufacturer } & : \text { Hardcore Composites (VARTM) } \\ \text { Thickness of Deck } & : \text { " } \\ \text { Length } & : 11.9 \mathrm{~m} \\ \text { Width } & : 8.5 \mathrm{~m} \\ \text { Girder Type } & : \text { Steel }\end{array}$

Type of Wearing Surface :

Originally Transpo Epoxy Overlay 3/8”, soon begin to separate and disintegrate. In 2002 $2 \frac{1}{4}$ ”HLBC was applied

Periodic Inspection is every 2 yrs, starting at 2005 (2005 and 2007 reports are on file) In Depth Periodic Inspection is every 6 yrs, starting at 2003 (2003 report is on file)

Problem Reported So Far?

Year Problem

07 Deck: Generally in good condition

Repair Suggested?

Wearing surface: Fair condition

05 Deck: Good condition

Wearing surface: Good condition

03 Deck: Good condition

Wearing surface: Good condition

\section{West Buckeye Bridge}

Year : 2001

Deck Manufacturer: Kansas Structural Composites (Hand Layup)

Length

Width : : $11 \mathrm{~m}$

Girder Type : : Steel

\section{No inspection information obtained.}


Wickwire Run Bridge

$\begin{array}{ll}\text { Year } & : 1997 \\ \text { ADT } & : 100(1996), 100(1999), 300(2002), 300 \text { (2005) } \\ \text { Design Load } & : \text { HS-25 } \\ \text { Deflection Limit } & : \text { L/800 } \\ \text { Bridge Span(s) } & \text { : Single Span } \\ \text { Deck Manufacturer } & \text { : Creative Pultrusion (Superdeck) } \\ \text { Length } & : 9.14 \mathrm{~m} \\ \text { Width } & : 6.6 \mathrm{~m} \\ \text { Girder Type } & : \text { Steel } \\ \text { Type of Wearing Surface : Polyester Polymer Concrete } \\ \text { Thickness of W. Surface : } 1.27 \text { cm (0.5 inch) } \\ \text { Thickness of Deck } & : \text { " } \\ \text { Type of Fastener } & : 1 / 2 \text { “ diameter blind fasteners and epoxy. }\end{array}$

Periodic Inspection is every 2 yrs starting at 1999 (1999, 2001, 2005, 2007 reports are on file)

In Depth Periodic Inspection is every 6 Yrs starting at 1997(1997 and 2003 reports are on file)

Problem Reported So Far?

Year Problem

01 Deck is in good condition.

Repair Suggested?

Concrete Polymer wearing surface is in fair condition.

Transverse cracks have developed in the wearing surface above the deck panel joints.

03 Transverse cracks have developed in the wearing surface above the deck panel joints.

05 Transverse cracks have developed in the wearing surface above the deck panel joints.

07 Transverse cracks have developed in the wearing surface above the deck panel joints.

Yes 
Appendix 5. Mid Point Approach for FRP Bridge Deck Learning Curve

An investigation of a unit cost model using lot midpoint as an alternate model to predict the economic feasibility of bridge decks was developed. The Crawford Model was applied using the lot midpoint of the given data to obtain the unit cost directly from the model built. This approach was also applied to data collected for WV Bridges. The results were then compared to the previous results to study the appropriateness of the new approach. The examined performance is the average absolute percentage error of the estimated unit values compared to the actual unit values. It was expected that the performance of the lot midpoint approach with the Crawford Model would be better than the Wright Model explained above.

The lot mid-point (LMP) is the unit number that corresponds with the average unit cost for the lot. It represents the entire lot, which is the deck area for the particular bridge. The y-coordinate of this point, which represents cost, should be the average unit cost (AUC) for that lot. In order to provide the true LMP, a good estimate is necessary to reduce cycles to determine the midpoint. There are numerous lot midpoint estimation formulas, and the best lot midpoint heuristic found was:

$x=\frac{F+L+2 \sqrt{F L}}{4}$

Where

$\mathrm{F}=$ First Lot Unit and

L = Last Lot Unit.

Using the LMP heuristics, the regression analysis was conducted and the value of b (the slope of the equation) was determined. The "true" LMP is determined using the equation 
$\mathrm{LMP}=\left[\frac{(L+.5)^{b+1}-(F-.5)^{b+1}}{N(b+1)}\right]^{(1 / b)}$

Where

$\mathrm{N}=$ Total Units

$\mathrm{b}=$ Slope of the Equation

Based on the new values of LMP, the regression analysis was reexamined. If the value of b obtained is similar to the one previously obtained, the above LMP is the "true" LMP. The same steps as in the unit cost learning curve estimate are followed. If the values of the two b's are very different, additional iteration should be investigated. Based on preliminary research, the lot mid-point approach was slightly better than the Wright Model [80]. Also, the result emphasized the previous conclusion: FRP bridge decks should be competitive with Steel Reinforced SRC by 2013, if the rates of improvement remain constant during future production and the yearly installation of FRP decks area continues at the same annual amount.

Considering the insignificant difference in the accuracy between the two models and simplicity of the first model, the final formula used is based on Wright Model. 